\title{
Urocortin-2 improves right ventricular function and attenuates pulmonary arterial hypertension
}

\author{
Rui Adão ${ }^{1 \dagger}$, Pedro Mendes-Ferreira ${ }^{1 \dagger}$, Diana Santos-Ribeiro', Carolina Maia-Rocha ${ }^{1}$, \\ Luís D. Pimentel ${ }^{1}$, Cláudia Monteiro-Pinto ${ }^{1}$, Eamon P. Mulvaney ${ }^{2}$, Helen M. Reid ${ }^{2}$, \\ B. Therese Kinsella ${ }^{2}$, François Potus ${ }^{3}$, Sandra Breuils-Bonnet ${ }^{3}$, Miriam T. Rademaker ${ }^{4}$, \\ Steeve Provencher ${ }^{3}$, Sébastien Bonnet ${ }^{3}$, Adelino F. Leite-Moreira ${ }^{1}$, and \\ Carmen Brás-Silva ${ }^{1,5}$ *
}

\begin{abstract}
${ }^{1}$ Department of Surgery and Physiology, Cardiovascular Research and Development Center - UnlC, Faculty of Medicine, University of Porto, Al. Prof. Hernâni Monteiro, $4200-319$ Porto, Portugal; ${ }^{2}$ UCD Conway Institute for Biomolecular and Biomedical Research, University College Dublin, Belfield, Dublin,Ireland; ${ }^{3}$ Pulmonary Hypertension Research Group, Institut Universitaire de Cardiologie et de Pneumologie de Québec, Laval University, Quebec City, Canada; ${ }^{4}$ Department of Medicine, Christchurch Heart Institute, University of OtagoChristchurch, Christchurch, New Zealand; and ${ }^{5}$ Faculty of Nutrition and Food Sciences, University of Porto, 4200-319 Porto, Portugal
\end{abstract}

Received 28 June 2017; revised 26 December 2017; editorial decision 20 March 2018; accepted 22 March 2018; online publish-ahead-of-print 23 March 2018

Time for primary review: 55 days

\begin{abstract}
Aims
Pulmonary arterial hypertension (PAH) is a devastating disease and treatment options are limited. Urocortin-2 (Ucn-2) has shown promising therapeutic effects in experimental and clinical left ventricular heart failure (HF). Our aim was to analyse the expression of Ucn-2 in human and experimental PAH, and to investigate the effects of human Ucn-2 (hUcn-2) administration in rats with monocrotaline (MCT)-induced pulmonary hypertension (PH).

Methods $\quad$ Tissue samples were collected from patients with and without PAH and from rats with MCT-induced PH. hUcn-2 (5 and results $\quad \mu g / \mathrm{kg}$, bi-daily, i.p., for 10 days) or vehicle was administered to male wistar rats subjected to MCT injection or to pulmonary artery banding (PAB) to induce right ventricular (RV) overload without PAH. Expression of Ucn-2 and its receptor was increased in the RV of patients and rats with $\mathrm{PAH}$. hUcn-2 treatment reduced $\mathrm{PAH}$ in MCT rats, resulting in decreased morbidity, improved exercise capacity and attenuated pulmonary arterial and RV remodelling and dysfunction. Additionally, RV gene expression of hypertrophy and failure signalling pathways were attenuated. hUcn-2 treatment also attenuated PAB-induced RV hypertrophy.

Conclusions $\quad$ Ucn-2 levels are altered in human and experimental PAH. hUcn-2 treatment attenuates PAH and RV dysfunction in MCT-induced $\mathrm{PH}$, has direct anti-remodelling effects on the pressure-overloaded RV, and improves pulmonary vascular function.
\end{abstract}

Keywords

Urocortin-2 • Pulmonary hypertension - Vascular remodelling • Cardiac hypertrophy • Right ventricular failure

\section{Introduction}

Pulmonary arterial hypertension (PAH) is a rare and severe condition characterized by intense pulmonary vascular remodelling, vasoconstriction, endothelial dysfunction, inflammation and in situ thrombosis, leading to elevated pulmonary vascular resistance (PVR) and right ventricular (RV) failure. ${ }^{1,2}$ Available therapies decrease patients' risk of short-term mortality and clinical worsening ${ }^{3}$; however, long-term prognosis remains poor. ${ }^{4} \mathrm{RV}$ function is the main predictor of the outcome in $\mathrm{PAH}^{5}$ and thus new therapies should also protect against RV maladaptation and failure. $^{6}$

Urocortin-2 (Ucn-2) is an endogenous vasoactive peptide of the corticotropin-releasing hormone $(\mathrm{CRH})$ family that binds with high affinity to the Type $2 \mathrm{CRH}$ receptor (CRHR2), which is expressed abundantly in the cardiovascular system. ${ }^{7}$ Ucn-2 promotes important cardiac haemodynamic effects, including vasodilation and positive cardiac inotropic, chronotropic, and lusitropic actions. ${ }^{8}$ Additionally, the Ucn-2/CRHR2 system exhibits cardioprotective actions, preventing cell

\footnotetext{
* Corresponding author. Tel: +351 220426 822; fax: +351 225513 646, E-mail: carmensb@med.up.pt

† The first two authors contributed equally to the study.

Published on behalf of the European Society of Cardiology. All rights reserved. (c) The Author(s) 2018. For permissions, please email: journals.permissions@oup.com.
} 
necrosis and apoptosis ${ }^{9,10}$ and decreasing infarct size in the rat heart after ischaemia-reperfusion injury. ${ }^{10-12}$

Acute Ucn-2 administration in experimental heart failure (HF) has beneficial haemodynamic effects, while suppressing adverse neurohormonal responses, ${ }^{13,14}$ whereas chronic treatment after experimental myocardial infarction improves cardiac function and structure. ${ }^{15}$ In patients with stable congestive ${ }^{16}$ and acute decompensated $\mathrm{HF}^{17}{ }^{17}$ intravenous $U_{c n}-2$ produces an increase in cardiac output $(C O)$ and left ventricular (LV) ejection fraction (EF) in association with a reduction in systemic vascular resistance, blood pressure and cardiac work. Plasma levels of Ucn-2 are elevated in patients with abdominal aortic aneurysm, ${ }^{18}$ LV systolic dysfunction with coronary artery disease ${ }^{19}$ and nonischaemic dilated cardiomyopathy, ${ }^{20}$ suggesting a potential role of Ucn-2 as a biomarker in heart disease. Additionally, plasma concentrations of $\mathrm{N}$-terminal-proUcn-2 are independently and inversely related to 2-year survival in $\mathrm{HF}^{21}$

Ucn-2 is reported to induce vasorelaxation of human coronary arteries independently of the endothelium, ${ }^{22}$ while in healthy volunteers, arterial vasodilatation appears to be at least partly mediated by endothelial nitric oxide. ${ }^{23}$ Ucn-2 is also associated with abdominal aortic aneurysm and mediates anti-proliferative effects on vascular smooth muscle cells. ${ }^{18}$ Moreover, Ucn-2 has sustained blood pressurelowering effects in hypertensive rats and attenuates hypertensioninduced LV hypertrophy and dysfunction, ${ }^{24}$ suggesting a novel therapeutic approach for systemic arterial hypertension.

Considering the need for new cardiac-directed drugs in $\mathrm{PAH}$, and the cardioprotective effects of Ucn-2 in HF, we hypothesized that Ucn-2 might have a potential role in the treatment of established $\mathrm{PAH}$. In this study, we evaluated the expression of Ucn-2/CRHR2 signalling in human and experimental $\mathrm{PAH}$, and investigated the functional and structural effects of chronic human Ucn-2 (hUcn-2) treatment on the heart and pulmonary vessels of rats with monocrotaline (MCT)-induced pulmonary hypertension (PH). To distinguish cardiac-specific actions from effects on the pulmonary vasculature, $h U_{c n}-2$ treatment was also studied in an experimental model of pressure overload by pulmonary artery banding $(\mathrm{PAB})$, which results in $\mathrm{RV}$ loading without $\mathrm{PAH}$.

\section{Methods}

All patients or their legal representatives (in the case of autopsy) gave informed consent before the beginning of the study in accordance to the declaration of Helsinki, and institutional guidelines were approved by Institut Universitaire de Cardiologie et de Pneumologie de Québec (CER-20773). The usage of human tissues follow recommendations published, ${ }^{25}$ in collaboration with the Institut Universitaire de Cardiologie et de Pneumologie de Québec site of the Respiratory Health Network tissue bank of the Fonds de recherche du Québec - Santé (FRQS) (www.tissuebank.ca). All animal experiments were performed in accordance with the recommendations of the Guide for the Care and Use of Laboratory Animals, published by the US National Institutes of Health (NIH Publication No. 85-23, Revised 2011), and were approved by the ethical committee of the Faculty of Medicine of the University of Porto and the Portuguese Foundation for Science and Technology, and certified by the Portuguese National Authority for Animal Health (PTDC/ DTP-FTO/0130/2012; 0421/000/000/2013). A detailed method section is available in Supplementary material online.

\subsection{Human samples}

Human RV samples were collected from patients with and without PAH (see Supplementary material online, Table S1) at the time of cardiac surgery, heart transplantation or autopsy (within $3 \mathrm{~h}$ of death). Samples were categorized according to clinical history and designated as compensated RV (CRV) or RV failure (RVF). ${ }^{26}$ Blood samples were also collected from $\mathrm{PAH}$ patients and age-matched controls. ${ }^{27}$

\subsection{Animal study}

$\mathrm{PAH}$ was induced as previously described. ${ }^{28}$ Seven-week-old male Wistar rats (Charles River Laboratories, 180-200 g) randomly received an injection of MCT (60 mg/kg, s.c., Sigma-Aldrich) or an equal amount of vehicle. Two weeks after MCT/vehicle administration, animals were further randomly divided to receive $\mathrm{h} U \mathrm{cn}-2$ (Bachem) at a dose of $5 \mu \mathrm{g} / \mathrm{kg}$ (bi-daily, i.p.) or an equal amount of vehicle $(0.9 \% \mathrm{NaCl})$ for 10 days, resulting in four groups: Ctrl + vehicle (C); Ctrl + hUcn-2 (CU); MCT + vehicle (M); MCT + hUcn-2 (MU). After the treatment period, animals were submitted to exercise testing and echocardiographic and invasive haemodynamic analysis, with subsequent sample collection for in vitro functional studies, morphological, histological, and molecular analysis, as detailed in Supplementary material online. To determine whether MCT-induced $\mathrm{PH}$ was already present prior to therapy, a subgroup of animals underwent the same experimental protocol and was evaluated at an earlier time point (14 days) (see Supplementary material online, Figures S7 and S8).

An additional subgroup of rats was subjected to PAB (16-gauge) or sham procedure, ${ }^{29}$ where applying a pulmonary artery constriction resulted in a degree of hypertrophy and RV overload identical to the MCT-induced PH model (see Supplementary material online, Figure S6). Two weeks after $\mathrm{PAB}$, animals randomly received $\mathrm{hU} \mathrm{cn}-2$ or vehicle for 10 days, resulting in three groups: Sham + vehicle $(S) ; P A B+$ vehicle $(B)$, and $P A B+h U c n-2(B U)$. Sampling was performed as in the MCT protocol.

\subsection{Survival analysis}

The defined end-point for the survival analysis was a $20 \%$ loss of body weight plus oedema/ascites and decreased movement. When this endpoint was reached, animals were euthanized with an anaesthetic overdose (sodium pentobarbital $100 \mathrm{mg} / \mathrm{kg}$, Eutasil, CEVA). Only those animals reaching the end-point before evaluation at study-end were considered valid and used in the survival analysis.

\subsection{Exercise capacity test}

Animal exercise capacity was tested on a close-chamber treadmill set with electric stimulation (LE8710R, Columbus Instruments) coupled to a gas analyser. Peak effort to assess maximal oxygen consumption $\left(\mathrm{VO}_{2 \max }\right)^{30}$ and endurance tests ${ }^{31}$ were evaluated in different sets of animals, and were performed 13 and 23 days after PAH induction.

\subsection{Echocardiography}

Echocardiographic analysis, ${ }^{28}$ was performed 13 days (baseline) and 24 days after PAH induction. Animals were lightly anaesthetized (inhalation of $8 \%$ sevofluorane for induction, and 2-3.5\% for maintenance). Echocardiographic evaluation was performed using a $15 \mathrm{MHz}$ probe (GE Healthcare) and a Acuson Sequoia C512 echocardiography system (Siemens), for determination of pulmonary flow and RV structure. 


\subsection{Invasive haemodynamic evaluation}

Following echocardiographic evaluation, the animals were intubated and ventilated. Using an open chest approach, as previously described in, ${ }^{28}$ pressure - volume catheters were introduced in the RV and LV (SPR-869 and SPR-847, respectively, Millar Instruments). A flow probe was implanted around the ascending aorta (MA2.5PSB, Transonic Systems). Baseline and inferior vena cava occlusion recordings were obtained, and a bolus injection of hypertonic saline was administered to account for parallel conductance. Pressure and volume signals were continuously acquired (MPVS Ultra, Millar Instruments), digitally recorded (PowerLab 16/30, ADlnstruments), and analysed off-line (LabChart 7 Pro, ADInstruments). Following anaesthetic overdose, blood samples were taken, the animals exsanguinated and heart and lungs collected en bloc.

\subsection{Morphometric and histological analysis}

Following removal, the lungs, $R V$ and $L V+$ septum $(L V+S)$ were carefully separated and weighed. Tibia length was measured for weight normalization. RV and lung samples were collected, snap frozen in liquid nitrogen, and stored at $-80^{\circ} \mathrm{C}$. For mRNA quantification, samples were submerged in RNA stabilization reagent (RNAlater, Qiagen), and for histological analysis, samples were stored in buffered $10 \%$ formaldehyde.

\subsection{Assessment of isolated pulmonary artery endothelial function and vascular acute analysis}

As previously described in, ${ }^{28}$ second-generation pulmonary arteries (200-400 $\mu \mathrm{m}$ diameter) were dissected from the left upper lobe of rats. Arterial rings were isolated and mounted in a bath myograph system (720 MO, DMT). Maximum tension development was assessed with 80 $\mathrm{mM} \mathrm{KCl}$ solution. For the determination of the acute vasodilatory effects of $h \cup c n-2$, arterial rings were contracted with phenylephrine $\left(10^{-5} \mathrm{M}\right)$, and a dose response to hUcn-2 $\left(10^{-9}\right.$ to $\left.5 \times 10^{-7} \mathrm{M}\right)$ or vehicle $\left(\mathrm{ddH}_{2} \mathrm{O}\right)$ was performed. Maximal relaxation to $\mathrm{hUcn}-2\left(\mathrm{E}_{\max }\right)$ and the concentration of $h U_{c n}-2$ required for $50 \%$ of the maximal response $\left(E_{50}\right)$ were calculated. Pulmonary artery endothelial function was assessed by attaining a dose-response curve to acetylcholine $\left(10^{-9}\right.$ to $\left.10^{-5} \mathrm{M}\right)$ after pre-contraction with phenylephrine $\left(10^{-5} \mathrm{M}\right)$. Maximal relaxation to acetylcholine and $\mathrm{EC}_{50}$ were calculated. Analysis was performed offline (LabChart 7 Pro, ADlnstruments).

\subsection{In vitro studies in isolated skinned cardiomyocytes}

$\mathrm{RV}$ samples (stored at $-80^{\circ} \mathrm{C}$ ) were defrosted in relax solution, and a biopsy taken, subjected to mechanical disruption, and permeabilized with $0.1 \%$ Triton X-100. Under microscopic view (model 1X51, Olympus) and through imaging software (VSL 900B, Aurora Scientific), a single cardiomyocyte was attached to a force transducer (model 403 A, Aurora Scientific) and a length controller (model 315 C-I, Aurora Scientific). Cell length was digitally adjusted through custom-designed software (series 600 A digital controller, Aurora Scientific), and steady-state passive force measured at increasing sarcomere lengths $(1.8-2.3 \mu \mathrm{m})$. Force measurements were normalized to each cardiomyocyte cross-sectional area (CSA) and a minimum of three cells per animal measured. ${ }^{29}$

\subsection{Quantitative RT-PCR, immunoblot- ting, and enzyme-linked immunosorbent assay}

For human samples, total RNA was isolated from tissue using the RNeasy micro kit according to the manufacturer's instruction, and mRNA reverse transcribed and amplified using one-step kit TaqMan probes. qRT-PCR was performed with the ABI Prism 7900 Sequence Detector (Applied Byosystems), and $18 \mathrm{~s}$ used as a housekeeping gene. The relative expression level of Ucn-2 and CRHR2 was determined by the $2^{-\Delta C t} * 100$.

For rat samples, total RNA was extracted using the RNeasy Mini Kit according to manufacturer's instructions, and relative mRNA expression quantified by two-step Real-Time PCR (Step-One Applied Biosystems). Glyceraldehyde 3-phosphate dehydrogenase (GAPDH) was used as a reference gene, and results presented in arbitrary units and normalized for the control group. Primers used were designed in-house (see Supplementary material online, Table S2).

For immunoblotting experiments, human and rat RV total protein was extracted and separated in a 10\% SDS-PAGE gel, electroblotted into nitrocellulose membrane, and probed for primary antibodies (see Supplementary material online, Table S3). After washing, the membrane was probed with secondary antibodies (Li-COR Biosciences) and visualized using an Odyssey scanner (Li-COR Biosciences). Human RV CRHR2 expression was quantified using a horse-radish peroxidase conjugate secondary antibody (Bio-Rad) and ChemiDoc system, and normalized for total protein content (Amido Black, Sigma Aldrich).

Blood collected from rats and humans was centrifuged and dispensed plasma assayed for Ucn-2 concentrations using solid-phase sandwich enzyme-linked immunosorbent assay according to manufacturer's instructions (SEC585Ra and SEC585Hu, Cloud-Clone Corp.).

\subsection{Statistical analysis}

The results are presented as the mean \pm S.E.M. Survival analysis was performed in R (version 3.4.1) using PwrGSD package (version 2.0), whereas GraphPad Software v7 (GraphPad Software Inc., San Diego, CA, USA) was used in all other parameters. Two-way analysis of variance (ANOVA), with repeated-measures when suitable, was used to analyse most parameters with Tukey's method for post hoc comparisons between groups. Where appropriate, Student $t$-test or one-way ANOVA with Tukey's method for post hoc comparisons were used. Survival analysis was estimated according to the Kaplan-Meier method and comparisons were performed using a generalized FlemingHarrington test ( $p=1, q=1$ ) for non-proportional hazards, which gives more weight to later events. A $P$-value of $<0.05$ was considered to be statistically significant.

\section{Results}

\subsection{Levels of Ucn-2 and CRHR2 are altered in PAH-induced RVF and are modulated by chronic hUcn-2 treatment}

Plasma concentrations of Ucn-2 were unchanged in human PAH compared with controls (Figure 1A). Measurement of Ucn-2 mRNA levels in the RV of PAH patients with RVF showed increased expression compared with non-failure patients (Figure 1B), whereas CRHR2 protein levels were found to be elevated in human PAH (Figure 1 and D). There were no differences between male and female patients on both 

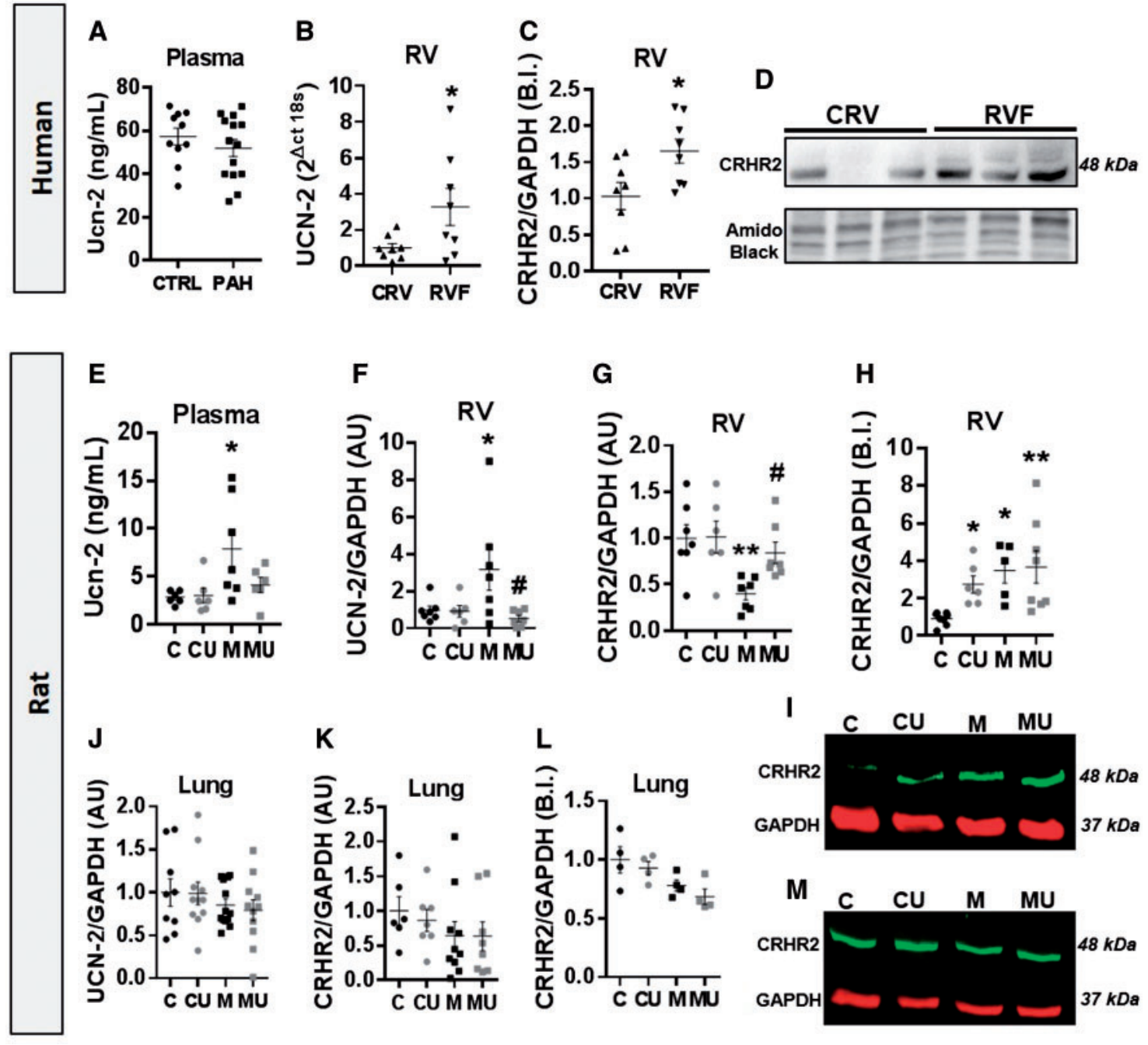

Figure I Levels of Ucn-2 and CRHR2 are altered in PAH-induced RVF and are modulated by chronic hUcn- 2 treatment. (A) Plasma Ucn-2 concentrations in patients with PAH ( $n=10-14$ /group). ( $B$ and $C$ ) mRNA expression of Ucn-2 and CRHR2 protein levels in the RV of patients with CRV and RVF. (D) Representative blots of CRHR2 immunoreactivity in human RV samples ( $n=8 /$ group). ( $E$ ) Plasma Ucn-2 concentrations in control and MCT-injected rats with (CU/MU) and without (C/M) hUcn-2 treatment ( $n=6$-7/group). ( $F$ and $G$ ) mRNA expression of Ucn- 2 and CRHR2 in the RV of MCT-induced PH protocol ( $n=6-7 /$ group). ( $H$ and I) CRHR2 protein levels in the RV of MCT-induced PH protocol and corresponding representative blots of CRHR2 immunoreactivity ( $n=5-9 / g r o u p)$. ( and $K)$ mRNA expression of $U c n-2$ and CRHR2 in the lungs of MCT-induced PH protocol ( $n=9-13 / g r o u p)$. ( $L$ and M) CRHR2 protein levels in the lungs of MCT-induced $\mathrm{PH}$ protocol and corresponding representative blots of CRHR2 immunoreactivity ( $n=4 /$ group). Results are presented as the mean \pm S.E.M. $* P<0.05$ vs. $C R V$ in (panels $B$ and $C$ ). ${ }^{*} P<0.05$, $* * P<0.01$ vs. $C ;{ }^{*} P<0.05$ vs. M in $(E-H$ ). Student $t$-test was performed to compare groups in panels $(A-C)$, while two-way ANOVA was used for all the other parameters presented.

plasma and RV mRNA Ucn-2 (see Supplementary material online, Figure S1). Plasma concentrations of Ucn-2 were increased in MCTinduced $\mathrm{PH}$ compared with controls, and hUcn-2 therapy in control and MCT rats did not chronically increase the Ucn-2 plasma concentrations (Figure 1E). MCT animals treated with hUcn-2 showed a reversal of RV Ucn-2 and CRHR2 mRNA expression to control levels compared with the MCT group without treatment, which were elevated (Figure $1 F$ and $G$ ). Although there were no significant differences in MCT group, administration of $\mathrm{hUcn}-2$ in control animals resulted in an increased CRHR2 protein expression (Figure $1 \mathrm{H}$ and I). Indeed, the CRHR2 receptor is present in cardiomyocytes from control and MCT RV (see Supplementary material online, Figure S2).
However, as seen for Ucn-2 in the lungs from PAH patients (see Supplementary material online, Figure S1), we did not find any differences between the groups in the expression of Ucn-2 and CRHR2 in experimental PAH (Figure $1 \mathrm{~J}-\mathrm{M})$.

\subsection{Treatment with hUcn-2 decreases mor- bidity and improved exercise capacity in experimental PAH}

In our experimental protocol (Figure 2A) we observed that the mean bodyweight and gain of MCT-induced $\mathrm{PH}$ animals were significantly reduced compared with control animals after 24 days. Treatment with $\mathrm{h} U \mathrm{cn}-2$, while reducing bodyweight gain in 
A

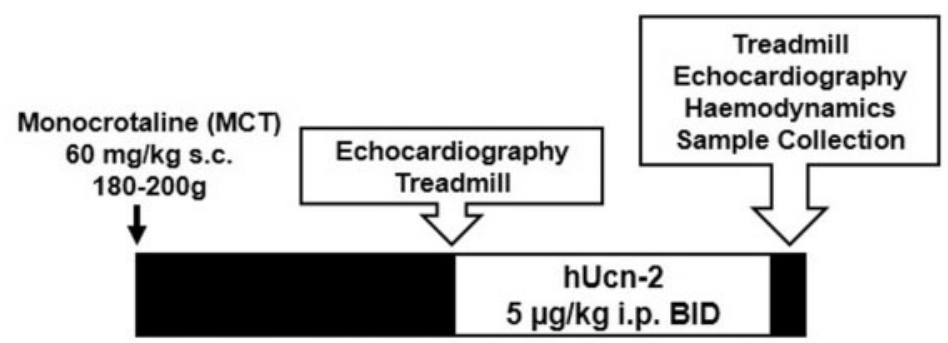

Day 0
1314

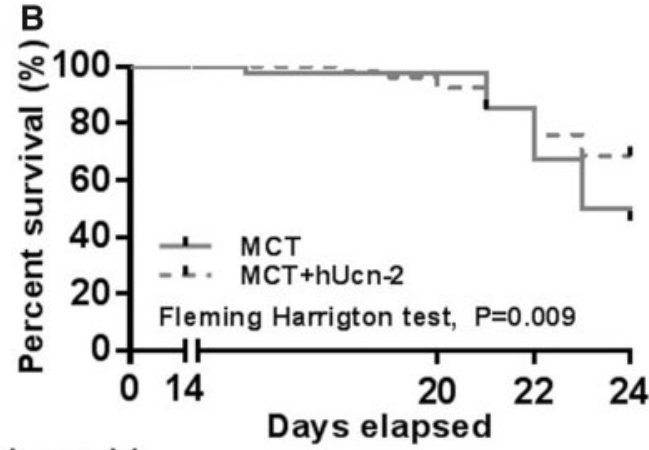

Number at risk MCT 47

MCT+hUcn-2 54

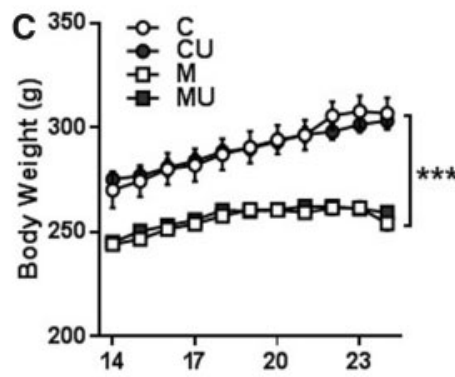

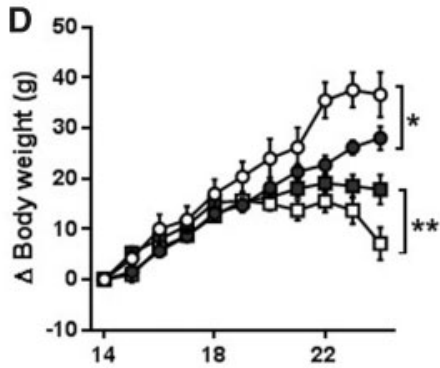

E

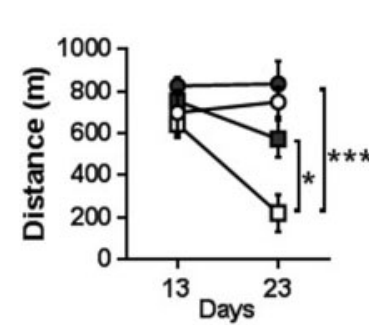

$\begin{array}{lll}46 & 38 & 22\end{array}$

Figure 2 Effect of hUcn-2 on morbidity and exercise capacity. (A) Diagram of rat experimental MCT protocol. (B) Survival analysis in MCT-injected rats ( $n=47-54 /$ group). ( $C$ and $D)$ Mean body weight and bodyweight gain in Control and MCT-injected rats with (CU/MU) and without (C/M) hUcn-2 treatment $(n=17-54 / g r o u p)$. ( $E$ and $F$ ) Distance run and maximal oxygen consumption during endurance testing in all experimental groups ( $n=4-7 / g r o u p)$. Results are presented as the mean \pm S.E.M. $* P<0.05$, ${ }^{*} P<<0.01$, $* * * P<0.001$. For panel $(B)$, Kaplan-Meier survival analysis was performed. Two-way ANOVA repeated measures test were used for all the other parameters presented.

control animals, increased bodyweight gain in $\mathrm{MCT}$ animals (Figure 2C and D).

MU group showed a lower percentage of animals reaching the defined end-point, which serves as a surrogate for clinical worsening, and could potentially represent an improvement in late mortality (Figure 2B). Treatment with hUcn-2 for 10 days also significantly improved the exercise capacity, with increases seen in distance run and maximum rate of oxygen consumption $\left(\mathrm{VO}_{2 \max }\right)$ (Figure $2 E$ and $F$ ).

\section{$3.3 \mathrm{hUcn}-2$ treatment reduces cardiac and pulmonary arterial remodelling in MCT-induced PH}

In MCT animals, administration of hUcn-2 resulted in decreased $\mathrm{RV}$ and pulmonary vascular remodelling (Figure $3 \mathrm{~A}$ ). hUcn-2 treatment attenuated MCT-induced increases in both RV and right atrial dilation (Figure $3 B$ and $C$ ) as well as the RV weight normalized to left ventricle plus septum weight (RV/LV $+\mathrm{S}$ ) (Figure 3D). Lung weight normalized to tibia length (Lung/TL), was reduced by hUcn-2 treatment compared with the MCT group (Figure $3 E$ ). This shows a decrease of fluid build-up in the lungs, potentially as a result of improved LV diastolic function (see Supplementary material online, Figure S5) in treated animals. Animals with $\mathrm{PAH}$ and without pharmacological intervention also presented increased cardiomyocyte CSA, as well as fibrosis deposition (Figure $3 F$ and $G$ ). hUcn-2 treatment normalized both cardiomyocyte size and fibrotic tissue deposition. Pulmonary small artery $(15-50 \mu \mathrm{m})$ remodelling was also decreased in MU group, as measured by a decline in mean lumen/total ratio and mean medial thickness (Figure $3 \mathrm{H}$ and I). A detailed morphometric analysis to evaluate vascular remodelling in all, small $(15-50 \mu \mathrm{m})$ and medium $(50-100 \mu \mathrm{m})$ pulmonary arterioles can be found in Supplementary material online, Figure S3.

\section{4 hUcn-2 attenuates pulmonary endothe- lial dysfunction and induces vasodilatory effects in MCT-induced PH}

Isolated pulmonary arterial rings pre-contracted with phenylephrine $\left(10^{-5} \mathrm{M}\right)$, exhibited a vasodilation response when incubated with hUcn-2 $\left(10^{-9}\right.$ to $\left.5 \times 10^{-7} \mathrm{M}\right)$ (Figure $4 A$ and $B$ ). In rings isolated from MCT animals, although present, vasodilation was significantly decreased, when compared with controls (Figure 4C). The vasodilation response to $\mathrm{h} U \mathrm{cn}-2$ in both groups was independent of the endothelium (see Supplementary material online, Figure S4). Furthermore, pre-treatment with hUcn-2 (50 nM) attenuated phenylephrine-induced vasoconstriction in pulmonary arterial 
A
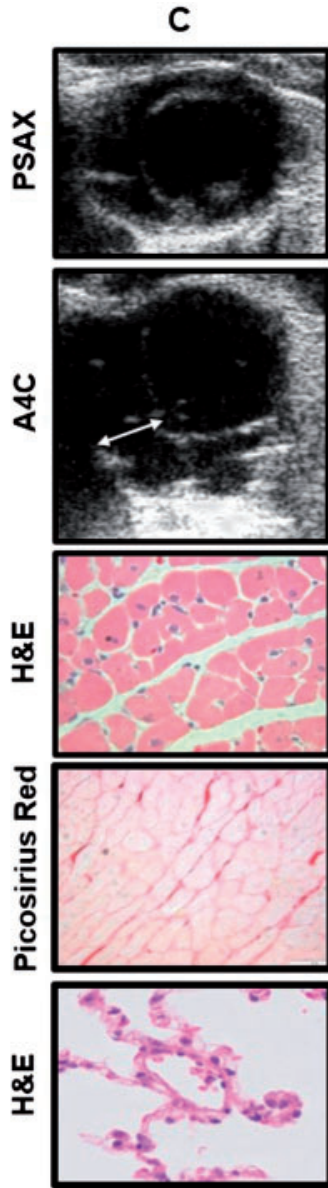

B
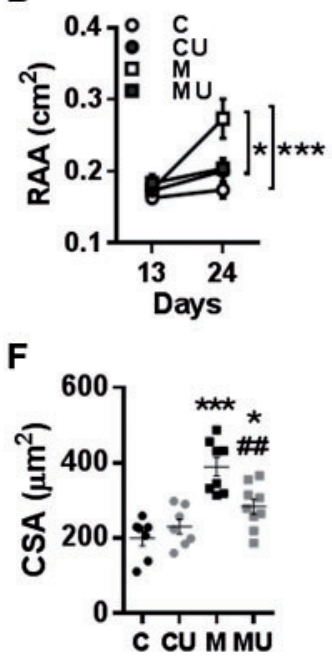

CU
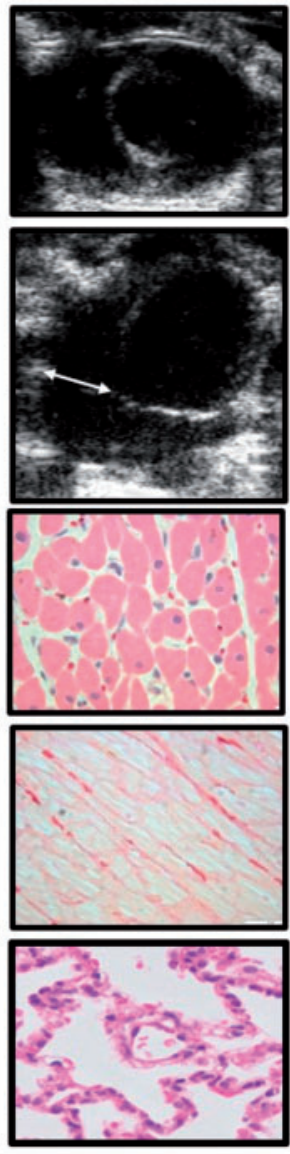

C

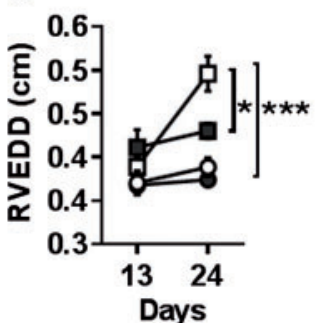

G

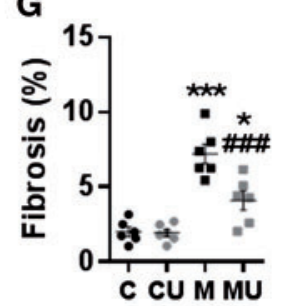

M
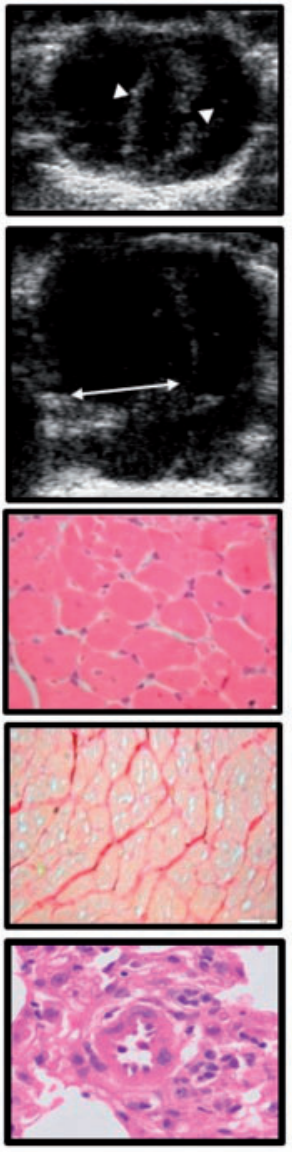

D

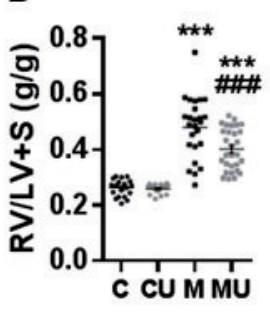

H

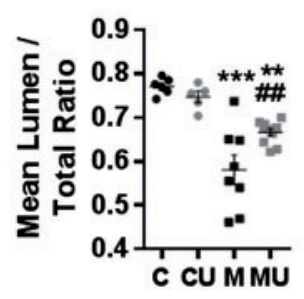

MU
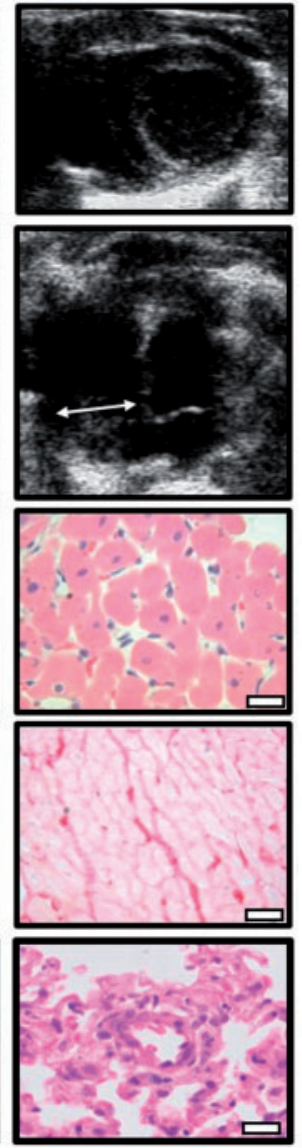

E

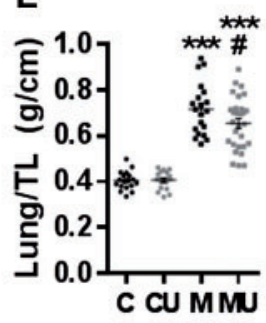

I

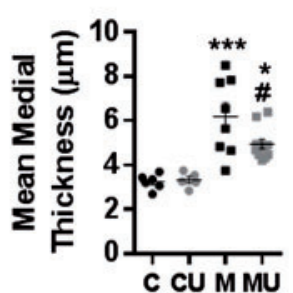

Figure 3 Treatment with hUcn-2 attenuates RV and pulmonary vascular remodelling. (A) Representative echocardiographs (first line PSAX = parasternal short axis view; second line $\mathrm{A} 4 \mathrm{C}=$ apical four chamber view) of Control and MCT-injected rats with (CU/MU) and without (C/M) hUcn-2 treatment; interventricular septum hypertrophy and bowing shown by white arrow heads, and RV dilation by white double arrow. Representative haematoxylin and eosin $(\mathrm{H} \& \mathrm{E})$ and picosirius red staining of RV samples (third and fourth lines) and representative H\&E staining of lung samples (fifth line) of all experimental groups. Scale bars represent $50 \mu \mathrm{m}$ (400× magnification) in H\&E stainings, and $25 \mu \mathrm{m}$ (200× magnification) in picosirius red staining. (B and C) RAA (right atrial area) and RVEDD analysis ( $n=8-17 / g r o u p)$. ( $D$ and $E)$ RV/LV $+S$ and Lung/TL ratio analysis ( $n=17-29 / g r o u p)$. (F and $G$ ) Cardiomyocyte CSA and RV fibrosis ( $n=7-9 / g r o u p)$. ( $H$ and $l)$ Mean Lumen/Total ratio and mean medial thickness in small vessels $(<50 \mu m)$ analysis $(n=5-11 / g r o u p)$. Results are presented as the mean \pm S.E.M. ${ }^{*} P<0.05,{ }^{* *} P<0.01$, ${ }^{* * *} P<0.001$ vs. $C ;{ }^{\#} P<0.05,{ }^{\# \#} P<0.01$, ${ }^{\# \#} P<0.001$ vs. M. Two-way ANOVA repeated measures test was used for comparisons in panels ( $B$ and $C$ ), and two-way ANOVA was used for all the other parameters presented. 

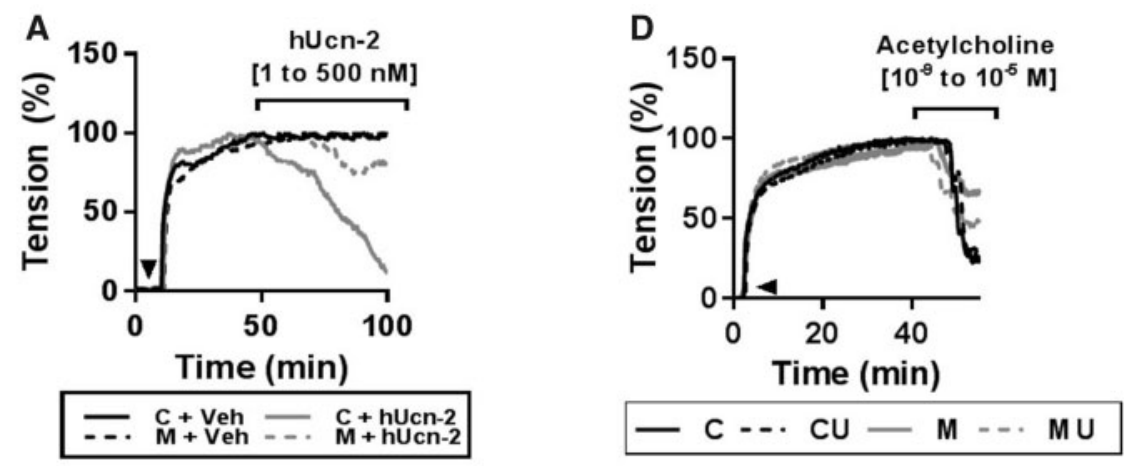

B

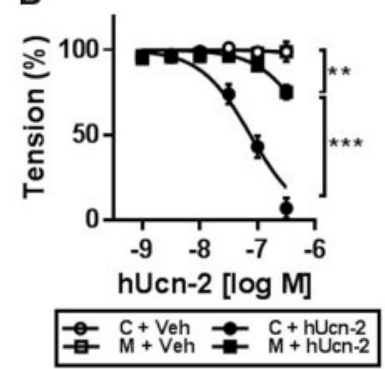

C

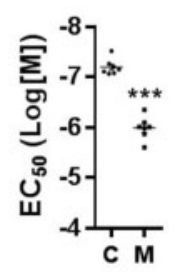

E

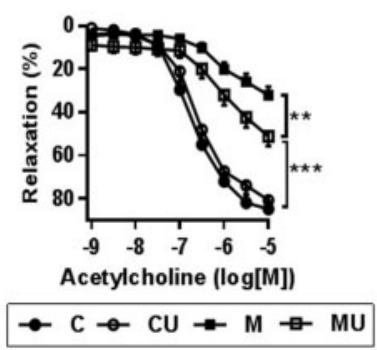

$\mathbf{F}$

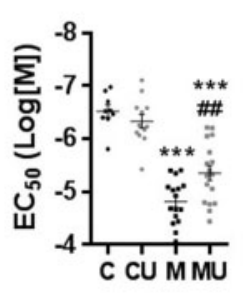

Figure 4 Acute and chronic treatment with hUcn-2 results in improved pulmonary arterial function in MCT-induced PH. (A and B) Relaxation in isolated pulmonary arterial rings from Control $(C)$ and $M C T$-injected rats $(M)$ pre-contracted with phenylephrine $\left(10^{-5} \mathrm{M}\right)$ in response to vehicle $(V e h)$ and hUcn-2 $\left(10^{-9}\right.$ to $5 \times 10^{-7} \mathrm{M}$; left panel). Black arrowhead on panel $(A)$ represents incubation with $10^{-5} \mathrm{M}$ of phenylephrine. (C) EC 50 for $\mathrm{hUcn}-2$ in $C$ and $M$ groups ( $n=7$ /group). ( $D$ and $E$ ) Relaxation in isolated pulmonary arterial rings from $C, C U, M$, and $M U$ rats pre-contracted with phenylephrine $\left(10^{-5} \mathrm{M}\right)$ in response to an acetylcholine dose-response $\left(10^{-9}\right.$ to $10^{-5} \mathrm{M}$; left panel). Black arrowhead on the panel $(D)$ represents incubation with $10^{-5} \mathrm{M}$ of phenylephrine. (F) $\mathrm{EC}_{50}$ for acetylcholine in $\mathrm{C}, \mathrm{CU}, \mathrm{M}$, and $\mathrm{MU}$ groups ( $n=9-17 /$ group). Results are presented as the mean $\pm \mathrm{S}$.E.M. $* * P<0.01$, ***P<0.001 vs. line tar-

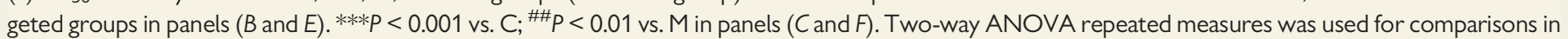
panels $(B$ and $E$ ), while two-way ANOVA was used for panel $(F)$. Student $t$-test was used for panel $(C)$.

rings isolated from control animals, while there was no inhibitory effect in the MCT group with hUcn-2 pre-treatment (50 and $500 \mathrm{nM}$ ) (see Supplementary material online, Figure S4). We found compromised relaxation in a dose-response test to acetylcholine in pulmonary arteries isolated from MCT animals and treating animals with $\mathrm{hUcn}-2$, while not changing phenylephrine-induced maximal tension (data not shown), significantly enhanced endothelial function, by increasing the maximal response to acetylcholine (Figure $4 D$ and E). Furthermore, hUcn-2 decreased the EC50 (Figure 4F), increasing receptor sensitivity to acetylcholine.

\subsection{MCT-induced RV dysfunction is attenu- ated with hUcn-2 treatment}

Pulmonary flow compromise with subsequent RV overload results in RV dysfunction. Likewise, echocardiographic analysis revealed a deteriorated pulmonary flow with the presence of mid-systolic notching (Figure 5A, first panel) in the $M$ group, where pulmonary artery acceleration time normalized to ejection time ratio (PAAT/PAET) and pulmonary artery velocity-time integral (PAVTI) were decreased (Figure 5B and C). TAPSE was also decreased (Figure 5D). hUcn-2 therapy improved pulmonary flow and increased TAPSE. RV catheterization showed that MCTinduced $\mathrm{PH}$ resulted in $\mathrm{RV}$ dysfunction 3 weeks after $\mathrm{MCT}$ administration (Figure 5E). hUcn-2 treatment reduced PVR (Figure 5F), and this resulted in decreased RV end-systolic pressure (RVSP, Figure 5G), consistent with lessened RV hypertrophy, RV dilation (end-diastolic volume, EDV, Figure $5 \mathrm{~L}$ ) and RV dysfunction as shown by the increase of EF (Figure $5 \mathrm{H}$ ) and $\mathrm{CO}$ (Figure 5l). Additionally, hUcn-2 therapy attenuated diastolic dysfunction, with reduced filling pressures, improved relaxation, and decreased diastolic stiffness, quantified by lower end-diastolic pressure (RVDP, Figure 5J), reduced isovolumic relaxation time constant (tau, Figure 5K), and decreased end-diastolic elastance (Eed, Figure 5M), respectively. Additionally, treated animals demonstrated improved systolic function, with decreased arterial elastance (Ea) while preserving contractility (Ees) resulting in improved RV-PA coupling (Ees/Ea) (Figure $5 \mathrm{~N}$ ). Intrinsic diastolic RV function, as measured in isolated skinned cardiomyocytes (Figure 50), was also improved with hUcn-2 treatment, once the increase in passive tension at several sarcomeric lenghts (Figure 5P) was attenuated in MU animals. Similar to the RV, hUcn-2 treatment improved global LV function, recovering both systolic and diastolic function (see Supplementary material online, Figure S5).

\subsection{Molecular alterations in MCT-induced $\mathrm{PH}$ are reduced with hUcn-2 treatment}

Rats with MCT-induced $\mathrm{PH}$ displayed increased brain natriuretic peptide (BNP) (Figure 6A) and endothelin-1 (ET-1) (Figure 6B) RV expression - peptides that are associated with cardiac overload and hypertrophy. Moreover, increased expression of apoptotic markers, 

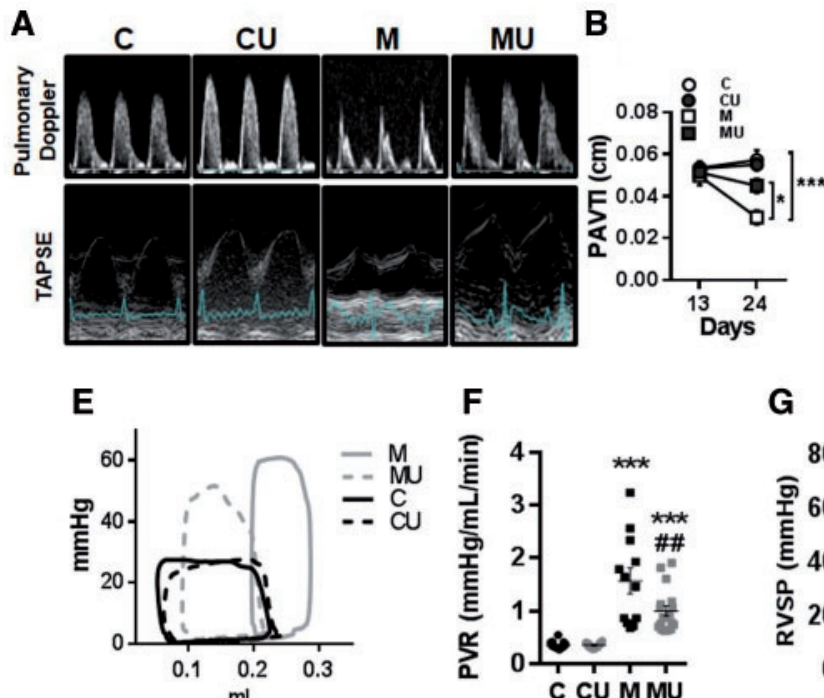

I

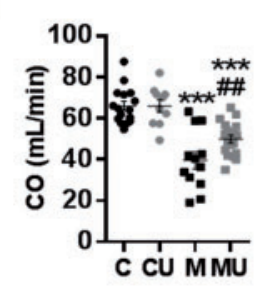

$\mathbf{F}$

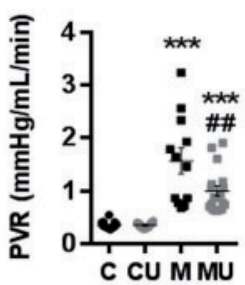

G

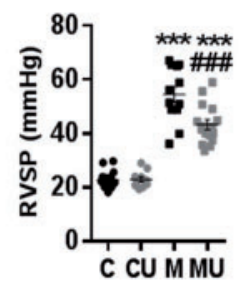

K

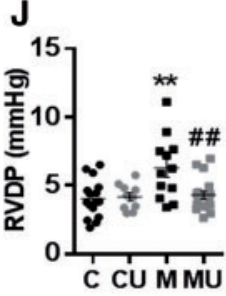

C

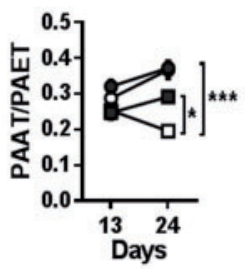

D

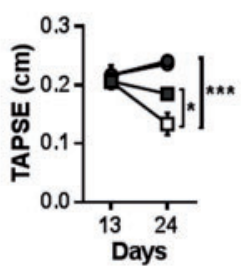

H

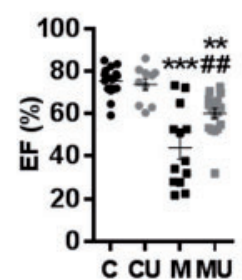

L

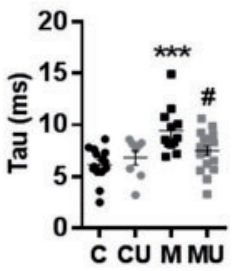

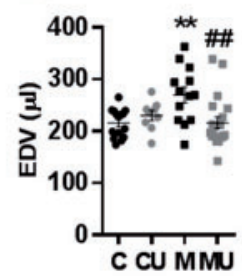

M

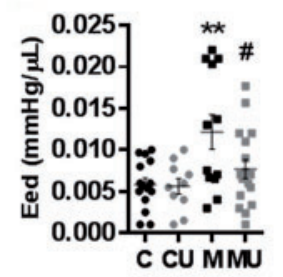

O

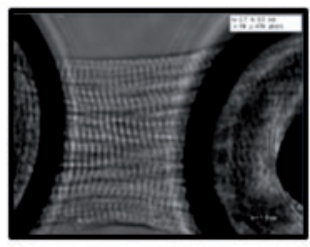

$\mathbf{N}$

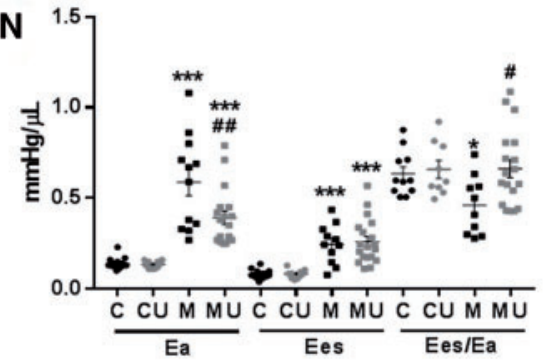

P

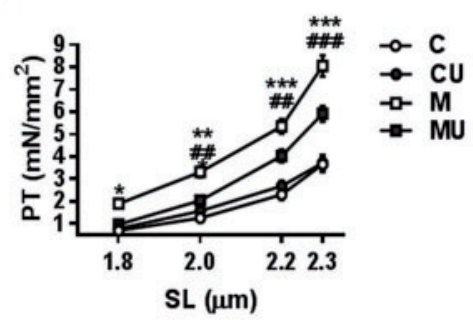

Figure 5 Treatment with hUcn-2 attenuates RV dysfunction in MCT-induced PH. (A) Representative figures of the echocardiographic analysis. (B-D) PAVTI, PAAT/PAET, and TAPSE analysis. (E) Representative pressure-volume loops of the different experimental groups. (F-N) PVR, RVSP, EF, CO, RVDP, Tau, end-diastolic volume, end-diastolic stiffness (Eed), and end-systolic elastance normalized to pulmonary artery elastance (Ees/Ea) ratio analysis in all experimental groups ( $n=10-18$ /group). ( $O$ and $P$ ) Representative single isolated skinned cardiomyocyte and passive tension (PT) in cardiomyocytes isolated from the $\mathrm{RV}$ of all groups ( $n=10-18 /$ group, $n \approx 30$ cardiomyocytes/group). Results are presented as the mean \pm S.E.M. $* P<0.05$, $* * P<0.01, * * * P<0.001$ vs. line targeted groups (panels B-D) and vs. $C$ in panels ( $F-N$ and $P$ ); ${ }^{*} P<0.05 ;{ }^{\# \#} P<0.01 ;{ }^{\# \#} P<0.001$ vs. M in panels $(F-N)$ and vs. MU in panel $(P)$. Two-way ANOVA repeated measures test was used for comparisons in panels ( $B-D$ and $P$ ), while two-way ANOVA was used for all the other parameters presented.

namely caspase- 3 and caspase-8, was also observed in MCT animals (Figure 6C). Treatment with hUcn-2 reduced the expression of these markers of cardiac damage. The increase in RV fibrosis seen in MCT rats was paralleled by augmented levels of RV collagen type III alpha 1
(Col3A1) mRNA (Figure 6D), which were reversed by hUcn-2 treatment. In MCT-induced PH we also observed a shift towards $\beta$-myosin heavy chain (MHC) mRNA amplification and corresponding decline in $\alpha M H C$, resulting in marked increase in the $\beta / \alpha M H C$ ratio in $M C T$ 
A

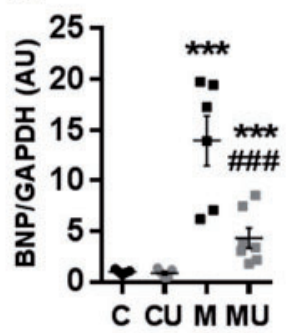

B

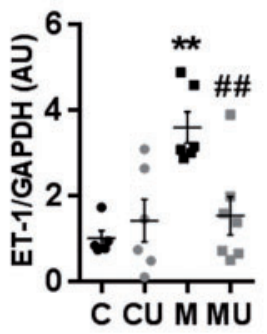

C

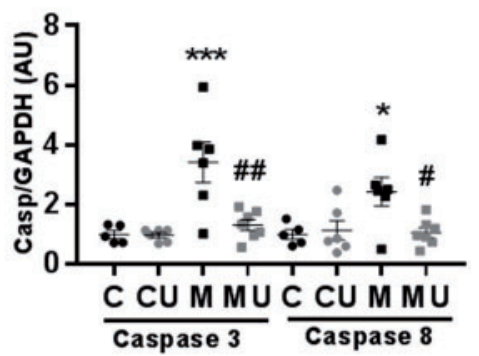

D

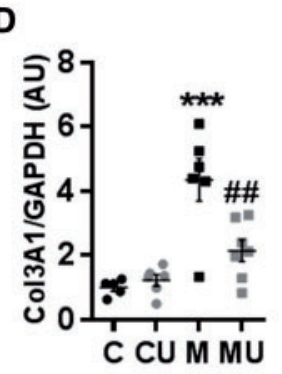

\section{E}

G
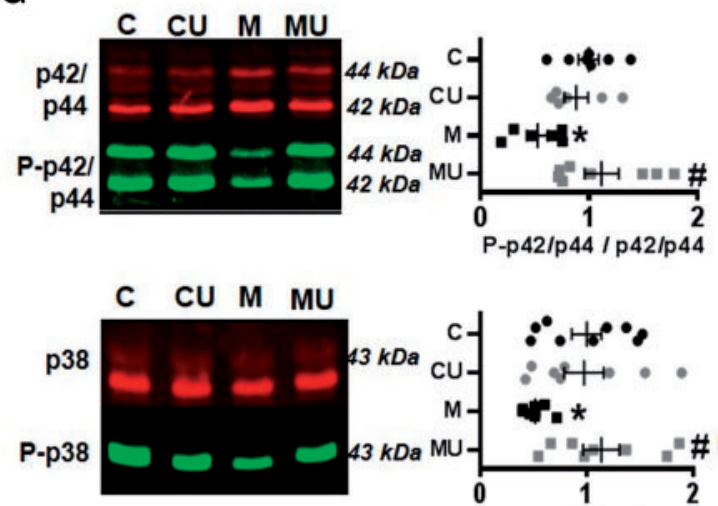

H

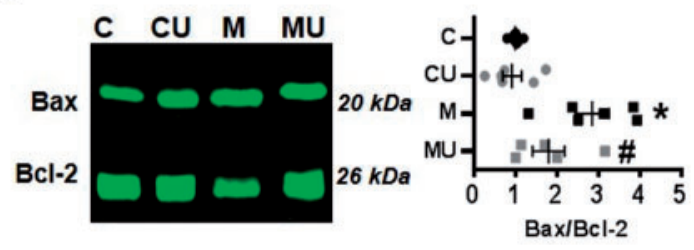

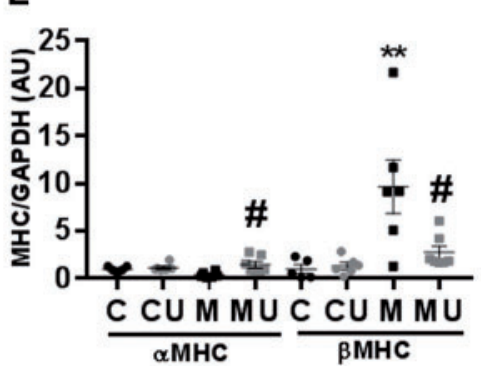

$F$

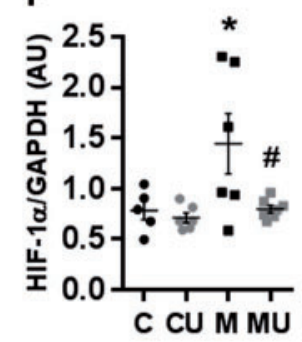

I
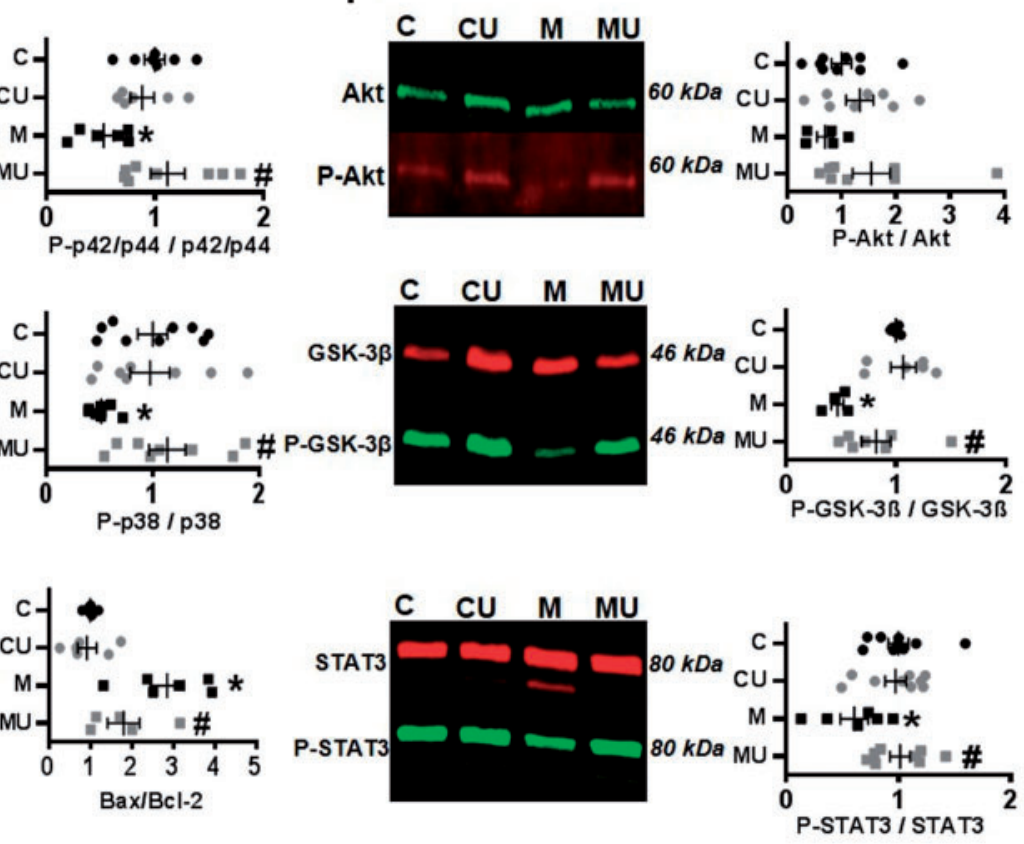

Figure 6 Chronic hUcn-2 treatment attenuates molecular alterations in experimental PAH-induced RVF. (A-F) BNP, ET-1, caspase-3 and -8, Col3A1, $\mathrm{MHC}$, and HIF-1 $\alpha$ mRNA expression in the RV of Control and MCT-injected rats with (CU/MU) and without (C/M) hUcn-2 treatment ( $n=5-7 / g r o u p)$. ( $G$ ) Protein phosphorylation of p42/44 (Thr202/Tyr204) and p38 (Thr180/Tyr182) in the RV of all groups. (H and I) Analysis of pro-survival pathways in the RV of all experimental groups, with Bax/Bcl-2 ratio and phosphorylation of Akt (Ser473), GSK-3 $\beta$ (Ser9), and STAT3 (Tyr705) ( $n=6-8 / g r o u p)$. Results are presented as the mean \pm S.E.M. ${ }^{*} P<0.05,{ }^{* * P}<0.01$, ${ }^{* * * P}<0.001$ vs. $C ;{ }^{\#} P<0.05 ;{ }^{\# \#} P<0.01 ;{ }^{\# \#} P<0.001$ vs. M. Two-way ANOVA was used for all comparisons.

animals (Figure 6E). hUcn-2 therapy completely reversed the shift in MHC isoform expression. Furthermore, impaired RV function in MCT animals, underlined by decreased $\mathrm{CO}$ and RV perfusion, resulted in the up-regulation of hypoxia-inducible factor 1-alpha (HIF-1 $\alpha$ ) mRNA (Figure 6F), and again, hUcn-2 administration abolished this increase. Western blot analysis showed reduced activation of downstream mitogen-activated protein kinase (MAPK) pathways in the MCT group, with decreased phosphorylation of $\mathrm{p}-42 / 44$ and p38 proteins. Chronic treatment with hUcn-2 restored the levels of these proteins (Figure 6G). The apoptotic bcl-2 like protein-4 normalized to B-cell lymphoma 2 (Bax/Bcl-2) ratio was increased in the MCT group, and treatment with hUcn-2 also abolished this rise (Figure $6 \mathrm{H}$ ). Moreover, pro-survival signalling in the RV was diminished in MCT-induced $\mathrm{PH}$, with decreased protein phosphorylation of 
C

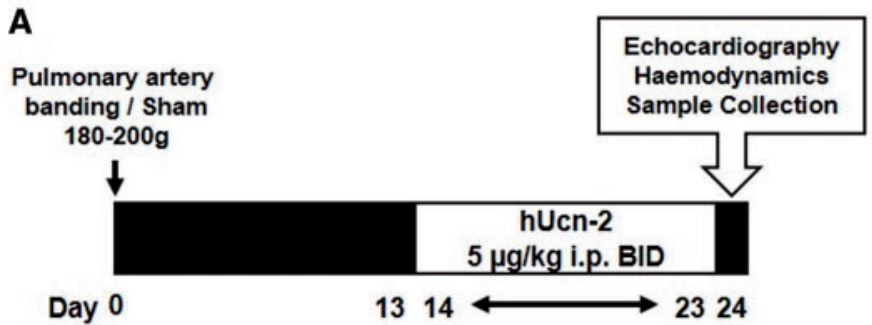

B
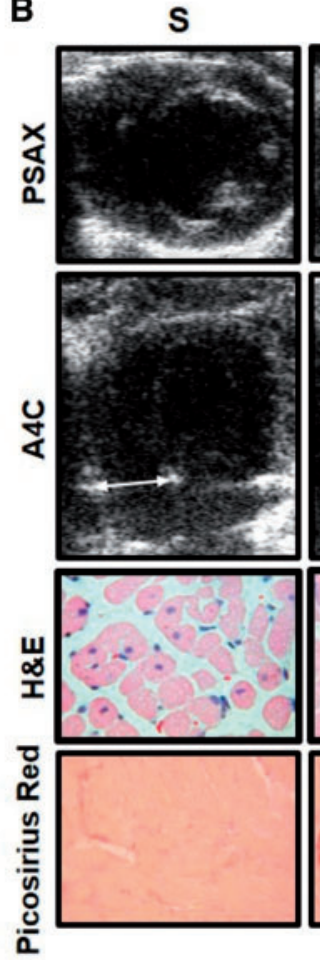

B
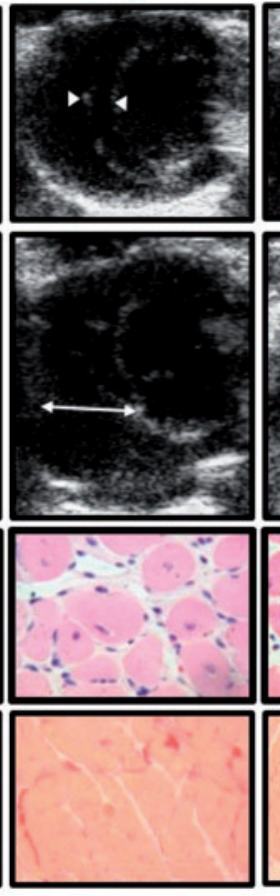

BU
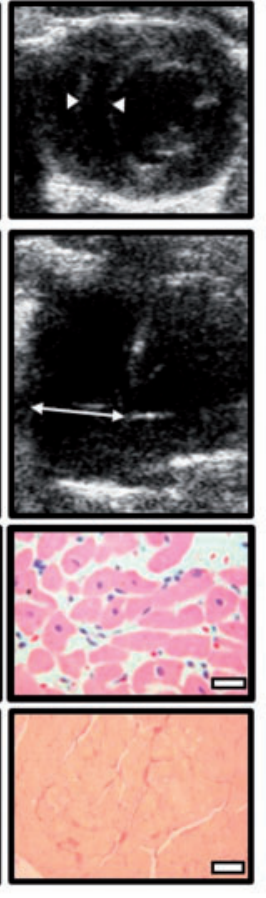

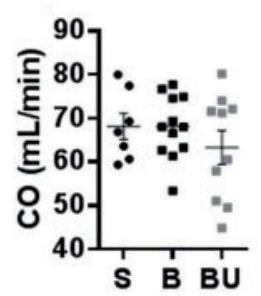

E

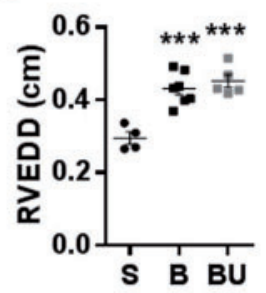

G

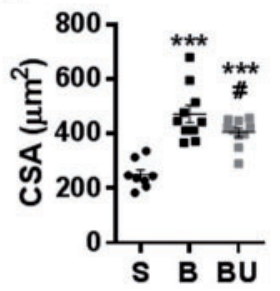

D

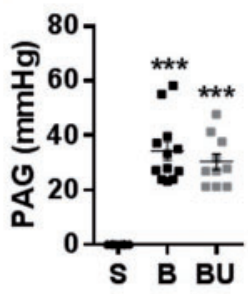

$\mathbf{F}$

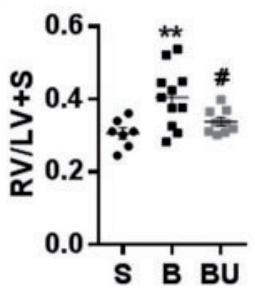

H

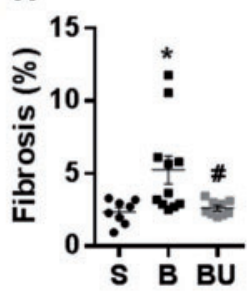

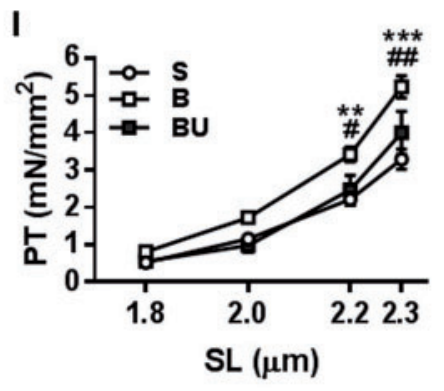

Figure 7 Chronic treatment with hUcn-2 decreases RV hypertrophy and fibrosis secondary to RV pressure overload. (A) Diagram depicting the PAB experimental protocol. (B) Representative echocardiographs (first line PSAX, parasternal short axis view; second line A4C, apical four chamber view), showing interventricular septum (white arrow heads) and RV diameter (white double arrow) in Sham and PAB rats with (BU) and without (S/B) hUcn-2 treatment. Representative H\&E and picosirius red staining of RV samples (third and fourth lines) of all groups. Scale bars represent $50 \mu \mathrm{m}(400 \times$ magnification) in $\mathrm{H} \& E$ staining, and $25 \mu \mathrm{m}$ (200× magnification) in picosirius red staining. (C) CO analysis in all groups. (D) Pulmonary artery gradient (PAG) across the PAB in both banding groups. ( $E$ and $F)$ RVEDD and RV/LV $+\mathrm{S}$ ratio analysis. $(G$ and $H)$ RV cardiomyocyte CSA and RV fibrosis analysis in all groups $(n=7-12 /$ group). (I) Passive tension (PT) in cardiomyocytes isolated from the RV of all groups ( $n=7-12$ rats/group, $n \approx 30$ cardiomyocytes/group). Results are presented as the mean \pm S.E.M. ${ }^{*} P<0.05$, ${ }^{* * P}<0.01$, ${ }^{* * *} P<0.001$ vs. S; ${ }^{\#} P<0.05 ;{ }^{\# \#} P<0.01$ vs. B in panels $(F-H)$ and vs. BU in panel $(I)$. One-way ANOVA repeated measures test was used for comparisons in panels (I), while one-way ANOVA was used for all the other parameters presented.

glycogen synthase kinase 3 beta (GSK3 $\beta$ ) and signal transducer and activator of transcription 3 (STAT3), which was reversed by hUcn-2. No differences were observed in protein kinase B (AKT) phosphorylation (Figure 6l).

\section{7 hUcn-2 treatment attenuated PAB-induced RV hypertrophy}

Using the PAB model (Figure 7A), the therapeutic effects of hUcn2 on the $R V$, independent from its action on the pulmonary vasculature, were investigated. $\mathrm{PAB}$ resulted in RV dilation, as judged by an increase in right ventricle end-diastolic dimension (RVEDD) (Figure 7E), hypertrophy, as evidenced by a higher RV/LV + S ratio (Figure 7F), and increased cardiomyocyte CSA (Figure 7G) and fibrosis (Figure 7H). hUcn-2 decreased RV hypertrophy and fibrosis relatively to untreated animals with the same degree of constriction (similar pulmonary artery gradient, Figure 7D), without compromising cardiac function (Figure 7C and see Supplementary material online, Figure S6). Finally, treatment with hUcn-2 attenuated the increase in passive stiffness observed in animals with PAB (Figure 7l). 


\section{Discussion}

This study evaluated the expression of the Ucn-2/CRHR2 system in $\mathrm{PAH}$ and investigated the effect of $\mathrm{hUcn}-2$ treatment in experimental $\mathrm{PAH}$ and RV hypertrophy. We found that Ucn-2 expression was increased in the RV of MCT-injected rats and patients with RVF, and that chronic hUcn-2 therapy attenuated experimental MCT-induced PH, as evidenced by beneficial effects on morbidity, exercise capacity and pulmonary and RV remodelling and dysfunction. Additionally, hUcn-2 treatment had direct effects on RV structure and function in a model of pressure loading of the $\mathrm{RV}$ without $\mathrm{PAH}$.

Recent studies in experimental HF have shown favourable effects of Ucn-2 treatment in pacing-induced $\mathrm{HF}^{13,14,32,33}$ myocardial infarction ${ }^{15}$ and systemic hypertension. ${ }^{24}$ Beneficial effects in healthy volunteers and patients with acute ${ }^{17}$ and chronic $\mathrm{HF}^{16,34}$ have further excited interest in the therapeutic potential of the urocortins, although whether or not the increased Ucn-2 circulating levels is a cardioprotective response is yet to be understood.

Our results show elevated RV expression and plasma concentrations of Ucn-2 in MCT-induced $\mathrm{PH}$, possibly in response to myocardial stress. Inversely, there was a decrease in CRHR2 mRNA levels in the RV, as observed in $\mathrm{HF}^{35}$ Interestingly, CRHR2 protein expression in MCT was increased in the RV. This mRNA/protein mismatch suggests a downregulation of CRHR2 mRNA that precedes any decline in CRHR2 protein expression, possibly due to a decrease in receptor endocytosis. ${ }^{36} \mathrm{In}$ adipose tissue from animals subjected to hypoxia, both CRHR2 mRNA and protein levels are increased acutely, and while receptor protein expression remains elevated over 10 days post-hypoxia, CRHR2 mRNA expression gradually decreases to pre-hypoxia levels by day $10 .^{37}$ In human RVF, we found an increase of Ucn-2 mRNA and CRHR2 protein expression compared with the non-failing RV, similarly to our animal model. We were unable to find significant differences in the plasma levels of Ucn-2 in human PAH. Only three studies have measured plasmatic Ucn-2 levels in human patients with cardiovascular disorders, reporting significantly different (up to 1000-fold) concentrations in their cohorts. ${ }^{18-20}$ However, Ucn-2 seems to be activated on circulating and inflammatory cells (buffy coat), which mediate vascular and myocardial remodelling mechanisms. ${ }^{38}$ Also, we did not find any differences in the lung expression of $U \mathrm{cn}-2$ and $C R H R 2$ in experimental PAH, suggesting a more profound dysregulation of Ucn-2/CRHR2 signalling in the RV as compared with the lung.

Despite the gender differences observed in other peptides from the Ucn family and CRHR2, ${ }^{39-41}$ there were no gender-related differences in plasma Ucn-2 levels in patients with heart disease, ${ }^{19,21}$ nor in the role of $\mathrm{CRHR} 2$ in $\mathrm{HF}^{20}$ This was also true in our small cohort of patients.

We next analysed the effects of chronic hUcn-2 therapy in MCTinduced $\mathrm{PH}$, and observed improvements in weight gain in the $\mathrm{MU}$ group, paralleled by an increase in exercise capacity, suggesting an integrated protective effect of hUcn-2 in the cardiovascular system and skeletal muscle. Exercise capacity, evaluated clinically by the 6-min walk test, and emulated here by exercise capacity testing, integrates the function of the whole cardiopulmonary system and has strong prognostic significance. ${ }^{1}$ Also, disease progression is associated with increased mortality in $\mathrm{PAH}$, and contains major prognostic relevance, ${ }^{42}$ therefore our findings that a lower percentage of MU rats achieved the defined end-points suggests a positive effect on future mortality.

Some of the beneficial Ucn-2 effects in HF result from direct actions on cardiomyocytes, however, they may be more pleiotropic. ${ }^{8}$ Indeed, $\mathrm{hU} \mathrm{cn}-2$ treatment resulted in the attenuation of both RV and pulmonary vascular remodelling. RV dilation and hypertrophy were significantly reduced with hUcn-2 treatment, in association with decreased cardiomyocyte size and RV fibrosis. These results are consistent with recent observations in which Ucn-2 reduced post-infarct remodelling, ${ }^{15}$ and retarded the development of hypertension-induced LV hypertrophy. ${ }^{24}$ Similarly, decreased pulmonary arterial small artery remodelling after hUcn-2 treatment led to a reduction in PVR and RV afterload, which explains, in part, the reduction in $\mathrm{RV}$ remodelling.

The observed RV dysfunction in MCT rats is consistent with decompensated RV hypertrophy, where compromised systolic flow is associated with elevated RVSP and correlates with decreased survival in $\mathrm{PAH}^{43}$ In MCT-induced $\mathrm{PH}, \mathrm{hUcn}-2$ improved pulmonary arterial flow and decreased RV afterload. TAPSE, an indicator of RV contractile function, was also improved. MCT-injected animals exhibited severe cardiac dysfunction, with compromised CO, EF and increased RVSP, which were both ameliorated by $\mathrm{hUcn}-2$. We also observed that MCT-induced $\mathrm{PH}$ was associated with RV-PA uncoupling, due to an insufficient increase in contractility to match the increase in afterload. ${ }^{44}$ Abnormal RV-PA coupling is a major determinant of RV HF and one of the leading causes of death in $\mathrm{PH}^{45}$ and its evaluation may help identify at-risk-patients or guide the timing of therapeutic interventions in $\mathrm{PAH} .{ }^{46}$ Remarkably, $\mathrm{hUcn}-2$ decreased pulmonary elastance (Ea) without compromising RV contractility (Ees), resulting in an improved RV-PA coupling. Diastolic dysfunction was also attenuated by hUcn-2, as shown by decreased stiffness and RV diastolic elastance. At the cellular level, $\mathrm{hUcn}-2$ reduced passive tension measured in isolated RV cardiomyocytes, contributing to the decreased stiffness and improved diastolic function observed.

Additionally, we observed an acute effect of $\mathrm{h} U \mathrm{cn}-2$ in modulating pulmonary artery vasomotor status, which probably contributed to a change in PVR. Several endothelium-independent and -dependent mechanisms have been proposed to describe Ucn-2-mediated vasodilation. ${ }^{22,23,47}$ Our analysis of acute $\mathrm{hUcn}-2$ effects in pulmonary arterial rings from MCT-injected animals demonstrated a significant endothelium-independent vasodilatory effect, although attenuated when compared with control vessels. This can be an advantage in $\mathrm{PAH}$ which is associated with impaired endothelial homeostatic mechanisms. Furthermore, Ucn-2 induces a potent prolonged arterial vasodilatation without causing significant tachyphylaxis, ${ }^{23}$ which is important especially when considering its potential application as a chronic PAH therapy.

Myocardial remodelling, increased wall stress, hypoxic damage and apoptosis in MCT-induced $\mathrm{PH}$ are correlated with increased RV mRNA expression of damage markers, ${ }^{28,48}$ which was reduced by $\mathrm{hUcn}-2$ therapy, either by directly acting on these signalling pathways, or indirectly by attenuating RV dysfunction. Moreover, the decreased phosphorylation of both ERK $1 / 2$ and p38 MAPK likely relates to the advanced stage of $\mathrm{HF}^{49}$ in our model, and its activation by $\mathrm{hUcn}-2,{ }^{50}$ may be a preventive mechanism. Akt was not affected by any drug administered (MCT/hUcn2), as previously reported in. ${ }^{51}$ Increased STAT3 and GSK3 $\beta$ phosphorylation and reduced $\mathrm{Bax} / \mathrm{BCl}-2$ ratio in $\mathrm{MU}$ rats match what has been previously described in vitro, ${ }^{52,53}$ demonstrating the cardioprotective Ucn-2 proprieties.

Recently, it was demonstrated that plasma Ucn-2 levels significantly increase in human and experimental LVHF. Additionally, continuous CRHR2 agonist infusion ( $100 \mu \mathrm{g} / \mathrm{kg} /$ day during 4 weeks) in control mice increased plasma Ucn-2 in a similar degree to that observed in mice with pressure overload-induced HF, resulting in cardiac dysfunction without having a significant effect on systolic blood pressure. ${ }^{20}$ These findings suggest that higher doses of chronic Ucn-2 administrations without vasorelaxation may have cardiotoxic effects, activating chronically the PKA, 
CaMKII, and AKT signalling pathways. In our experimental study, although $U_{c n}-2$ therapy modulated Ucn-2/CRHR2 expression in the RV, there was no significant increases in plasmatic $U_{c n}-2$, which could impair cardiac function.

The Ucn- 2 effects can be explained by pulmonary vascular mechanisms; however, it was unclear whether hUcn-2 has any myocardial-specific effects. Indeed, there is some concern over data suggesting that the Ucn-2 may induce hypertrophic responses in cardiac myocytes. ${ }^{20}$ Thus, similarly to a previous work by our group, ${ }^{28}$ we decided here to use a mild PAB model, as it better replicated the degree of overload observed in MCTinduced $\mathrm{PH}$, without pulmonary vascular involvement. ${ }^{29}$ Other works showed that adapted RVs with increased afterload but with compensated function have significant RV structural changes ${ }^{54-57}$; however, specific comparisons with this model can be difficult to make, as significant variances can be obtained in different conditions. Interestingly, hUcn-2 attenuated RV hypertrophy and fibrosis, without compromising function, indicating that hUcn-2 has a direct effect on the RV contributing to the improved RV function observed in $\mathrm{MU}$ animals, at least in $\mathrm{hUcn}-2$ dose used in MCT protocol. As in the MCT model, constriction of the pulmonary artery promotes not only structural changes, but also intrinsic alterations. ${ }^{29,58}$ Interestingly, hUcn-2 decreased passive tension development, contributing directly to attenuation of diastolic dysfunction in these animals, which could be the tipping point for RVF in $\mathrm{PAH}^{58}$

One limitation of our work is the lack of categorization of PAH patients accordingly to their RV phenotype with an individualized clinical follow-up. Indeed, the low levels of plasma Ucn-2 may relate to a CRV state in these patients. However, there is an association between Ucn-2/ CRHR2 expression and RV dysfunction. In the experimental setting, the limitations include the lack of investigation of subcellular mechanisms underlying the actions of $U \mathrm{cn}-2$ in the pulmonary vasculature, and this should be the subject of further research. Although not all characteristics of $\mathrm{PAH}$ are simulated by the MCT model, it shares many characteristics with primary and secondary human $\mathrm{PH}$, including pulmonary vascular remodelling, and RV and endothelial dysfunction ${ }^{38}$ and hUcn-2 ameliorated most of these parameters. Additionally, at 14 days after MCT administration animals exhibit RV hypertrophy, vascular remodelling, and pulmonary flow compromise, suggesting that $h \cup c n-2$ reverses already established PAH, which is clinically important. ${ }^{1}$ Also, LV dysfunction which is present in advanced stages of $\mathrm{PAH}^{59}$ was attenuated by $\mathrm{h} U \mathrm{cn}-2$, underscoring the putative translational implication. In PAB protocol, the underlying mechanisms of the myocardial-specific effects in RV should as well be a subject of further study.

In conclusion, this study demonstrated that Ucn-2/CRHR2 signalling has an important role in $\mathrm{PAH}$ and $\mathrm{RV}$ dysfunction, given that levels of Ucn-2 and its receptor are altered in human and experimental PAH. Additionally, hUcn-2 treatment improves cardiopulmonary structure and function, once it attenuates PAH and RV dysfunction in MCTinduced $\mathrm{PH}$, has direct anti-remodelling effects on the pressureoverloaded RV, and improves pulmonary vascular function.

\section{Supplementary material}

Supplementary material is available at Cardiovascular Research online.

\section{Acknowledgements}

The authors would like to acknowledge the support from the Histology and Electron Microscopy Service (HEMS) core facility at i3S - Instituto de Investigação e Inovação em Saúde, University of Porto for the help with histological immunohistochemistry for CRHR2 receptor protein.

Conflict of interest: none declared.

\section{Funding}

This work was supported by Portuguese Foundation for Science and Technology (FCT) through Grant UID/IC/00051/2013 (COMPETE_2020, POCl) and projects FCOMP-01-0124-FEDER-028695, FEDER, COMPETE, Ref: FCT-PTDC/DTP-FTO/0130/2012; NETDIAMOND (POCl-010145-FEDER-016385) and DOCnet (NORTE-01-0145-FEDER-000003, NORTE_2020, under PORTUGAL_2020 Partnership). PMF and RA are supported by FCT (SFRH/BD/87714/2012 and SFRH/BD/96403/2013, respectively).

\section{References}

1. Galie N, Humbert M, Vachiery JL, Gibbs S, Lang I, Torbicki A, Simonneau G, Peacock A, Vonk Noordegraaf A, Beghetti M, Ghofrani A, Gomez Sanchez MA, Hansmann G, Klepetko W, Lancellotti P, Matucci M, McDonagh T, Pierard LA, Trindade PT, Zompatori M, Hoeper M, Aboyans V, Vaz CA, Achenbach S, Agewall S, Allanore Y, Asteggiano R, Paolo Badano L, Albert Barbera J, Bouvaist H, Bueno H, Byrne RA, Carerj S, Castro G, Erol C, Falk V, Funck-Brentano C, Gorenflo M, Granton J, lung B, Kiely DG, Kirchhof P, Kjellstrom B, Landmesser U, Lekakis J, Lionis C, Lip GY, Orfanos SE, Park MH, Piepoli MF, Ponikowski P, Revel MP, Rigau D, Rosenkranz S, Voller H, Luis Zamorano J. 2015 ESC/ERS Guidelines for the diagnosis and treatment of pulmonary hypertension: the Joint Task Force for the Diagnosis and Treatment of Pulmonary Hypertension of the European Society of Cardiology (ESC) and the European Respiratory Society (ERS): Endorsed by: association for European Paediatric and Congenital Cardiology (AEPC), International Society for Heart and Lung Transplantation (ISHLT). Eur Heart J 2016;37:67-119.

2. Rabinovitch M. Molecular pathogenesis of pulmonary arterial hypertension. J Clin Invest 2012;122:4306-4313.

3. Humbert M, Lau EM, Montani D, Jais X, Sitbon O, Simonneau G. Advances in therapeutic interventions for patients with pulmonary arterial hypertension. Circulation 2014;130:2189-2208.

4. Humbert M, Sitbon O, Yaici A, Montani D, O'Callaghan DS, Jais X, Parent F, Savale L, Natali D, Gunther S, Chaouat A, Chabot F, Cordier JF, Habib G, Gressin V, Jing ZC, Souza R, Simonneau G. Survival in incident and prevalent cohorts of patients with pulmonary arterial hypertension. Eur Respir J 2010;36:549-555.

5. Vonk-Noordegraaf A, Haddad F, Chin KM, Forfia PR, Kawut SM, Lumens J, Naeije R, Newman J, Oudiz RJ, Provencher S, Torbicki A, Voelkel NF, Hassoun PM. Right heart adaptation to pulmonary arterial hypertension: physiology and pathobiology. J Am Coll Cardiol 2013;62:D22-D33.

6. Voelkel NF, Bogaard HJ, Gomez-Arroyo J. The need to recognize the pulmonary circulation and the right ventricle as an integrated functional unit: facts and hypotheses (2013 Grover Conference series). Pulm Circ 2015;5:81-89.

7. Wiley KE, Davenport AP. CRF2 receptors are highly expressed in the human cardiovascular system and their cognate ligands urocortins 2 and 3 are potent vasodilators. BrJ Pharmacol 2004;143:508-514.

8. Adão R, Santos-Ribeiro D, Rademaker MT, Leite-Moreira AF, Brás-Silva C. Urocortin 2 in cardiovascular health and disease. Drug Discov Today 2015;20:906-914.

9. Brar BK, Stephanou A, Knight R, Latchman DS. Activation of protein kinase B/Akt by urocortin is essential for its ability to protect cardiac cells against hypoxia/ reoxygenation-induced cell death. J Mol Cell Cardiol 2002;34:483-492.

10. Brar BK, Jonassen AK, Stephanou A, Santilli G, Railson J, Knight RA, Yellon DM, Latchman DS. Urocortin protects against ischemic and reperfusion injury via a MAPK-dependent pathway. J Biol Chem 2000;275:8508-8514.

11. Scarabelli TM, Pasini E, Stephanou A, Comini L, Curello S, Raddino R, Ferrari R, Knight R, Latchman DS. Urocortin promotes hemodynamic and bioenergetic recovery and improves cell survival in the isolated rat heart exposed to ischemia/reperfusion. J Am Coll Cardiol 2002;40:155-161.

12. Townsend PA, Davidson SM, Clarke SJ, Khaliulin I, Carroll CJ, Scarabelli TM, Knight RA, Stephanou A, Latchman DS, Halestrap AP. Urocortin prevents mitochondrial permeability transition in response to reperfusion injury indirectly by reducing oxidative stress. Am J Physiol Heart Circ Physiol 2007;293:H928-H938.

13. Rademaker MT, Ellmers LJ, Charles CJ, Mark Richards A. Urocortin 2 protects heart and kidney structure and function in an ovine model of acute decompensated heart failure: comparison with dobutamine. Int J Cardiol 2015;197:56-65.

14. Rademaker MT, Cameron VA, Charles CJ, Richards AM. Integrated hemodynamic, hormonal, and renal actions of urocortin 2 in normal and paced sheep: beneficial effects in heart failure. Circulation 2005;112:3624-3632. 
15. Ellmers LJ, Scott NJ, Cameron VA, Richards AM, Rademaker MT. Chronic urocortin 2 administration improves cardiac function and ameliorates cardiac remodeling after experimental myocardial infarction. J Cardiovasc Pharmacol 2015;65:269-275.

16. Davis ME, Pemberton CJ, Yandle TG, Fisher SF, Lainchbury JG, Frampton CM, Rademaker MT, Richards M. Urocortin 2 infusion in human heart failure. Eur Heart J 2007; 28:2589-2597.

17. Chan WY, Frampton CM, Crozier IG, Troughton RW, Richards AM. Urocortin-2 infusion in acute decompensated heart failure: findings from the UNICORN study (urocortin-2 in the treatment of acute heart failure as an adjunct over conventional therapy). JACC Heart Failure 2013; 1:433-441.

18. Emeto TI, Moxon JV, Biros E, Rush CM, Clancy P, Woodward L, Moran CS, Jose RJ Nguyen T, Walker PJ, Golledge J. Urocortin 2 is associated with abdominal aortic aneurysm and mediates anti-proliferative effects on vascular smooth muscle cells via corticotrophin releasing factor receptor 2. Clin Sci 2014; 126:517-527.

19. Topal E, Yagmur J, Otlu B, Atas H, Cansel M, Acikgoz N, Ermis N. Relationship of urocortin-2 with systolic and diastolic functions and coronary artery disease: an observational study. Anatolian J Cardiol 2012;12:115-120.

20. Tsuda T, Takefuji M, Wettschureck N, Kotani K, Morimoto R, Okumura T, Kaur H, Eguchi S, Sakaguchi T, Ishihama S, Kikuchi R, Unno K, Matsushita K, Ishikawa S, Offermanns S, Murohara T. Corticotropin releasing hormone receptor 2 exacerbates chronic cardiac dysfunction. J Exp Med 2017;214:1877-1888.

21. Liew OW, Yandle TG, Chong JP, Ng YX, Frampton CM, Ng TP, Lam CS, Richards AM. High-sensitivity sandwich ELISA for plasma NT-proUcn2: plasma concentrations and relationship to mortality in heart failure. Clin Chem 2016;62:856-865.

22. Smani T, Calderon E, Rodriguez-Moyano M, Dominguez-Rodriguez A, Diaz I, Ordóñez A. Urocortin-2 induces vasorelaxation of coronary arteries isolated from patients with heart failure. Clin Exp Pharmacol Physiol 2011;38:71-76.

23. Venkatasubramanian S, Griffiths ME, McLean SG, Miller MR, Luo R, Lang NN, Newby DE. Vascular effects of urocortins 2 and 3 in healthy volunteers. J Am Heart Assoc 2013;2:e004267.

24. Dieterle T, Meili-Butz S, Buhler K, Morandi C, John D, Buser PT, Rivier J, Vale WW, Peterson KL, Brink M. Immediate and sustained blood pressure lowering by urocortin 2: a novel approach to antihypertensive therapy? Hypertension 2009;53:739-744.

25. Bonnet S, Provencher S, Guignabert C, Perros F, Boucherat O, Schermuly RT, Hassoun PM, Rabinovitch M, Nicolls MR, Humbert M. Translating research into improved patient care in pulmonary arterial hypertension. Am J Respir Crit Care Med 2017; 195:583-595.

26. Potus F, Ruffenach G, Dahou A, Thebault C, Breuils-Bonnet S, Tremblay E, Nadeau V, Paradis R, Graydon C, Wong R, Johnson I, Paulin R, Lajoie AC, Perron J. Charbonneau E, Joubert P, Pibarot P, Michelakis ED, Provencher S, Bonnet S Downregulation of MicroRNA-126 contributes to the failing right ventricle in pulmonary arterial hypertension. Circulation 2015;132:932-943.

27. Renard S, Paulin R, Breuils-Bonnet S, Simard S, Pibarot P, Bonnet S, Provencher S. Pim-1: a new biomarker in pulmonary arterial hypertension. Pulm Circ 2013;3:74-81.

28. Mendes-Ferreira P, Maia-Rocha C, Adão R, Mendes MJ, Santos-Ribeiro D, Alves BS, Cerqueira RJ, Castro-Chaves P, Lourenço AP, De Keulenaer GW, Leite-Moreira AF, Brás-Silva $C$. Neuregulin-1 improves right ventricular function and attenuates experimental pulmonary arterial hypertension. Cardiovasc Res 2016;109:44-54.

29. Mendes-Ferreira P, Santos-Ribeiro D, Adão R, Maia-Rocha C, Mendes-Ferreira M, Sousa-Mendes C, Leite-Moreira AF, Brás-Silva C. Distinct right ventricle remodeling in response to pressure overload in the rat. Am J Physiol Heart Circ Physiol 2016;311 $\mathrm{H} 85-\mathrm{H} 95$.

30. Leite S, Oliveira-Pinto J, Tavares-Silva M, Abdellatif M, Fontoura D, Falcão-Pires I, Leite-Moreira AF, Lourenço AP. Echocardiography and invasive hemodynamics during stress testing for diagnosis of heart failure with preserved ejection fraction: an experimental study. Am J Physiol Heart Circ Physiol 2015;308:H1556-H1563.

31. Piao L, Fang YH, Parikh KS, Ryan J], D'Souza KM, Theccanat T, Toth PT, Pogoriler J, Paul J, Blaxall BC, Akhter SA, Archer SL. GRK2-mediated inhibition of adrenergic and dopaminergic signaling in right ventricular hypertrophy: therapeutic implications in pulmonary hypertension. Circulation 2012;126:2859-2869.

32. Rademaker MT, Charles C], Espiner EA, Fisher S, Frampton CM, Kirkpatrick CM, Lainchbury JG, Nicholls MG, Richards AM, Vale WW. Beneficial hemodynamic, endocrine, and renal effects of urocortin in experimental heart failure: comparison with normal sheep. J Am Coll Cardiol 2002;40:1495-1505.

33. Rademaker MT, Charles C], Ellmers LJ, Lewis LK, Nicholls MG, Richards AM. Prolonged urocortin 2 administration in experimental heart failure: sustained hemodynamic, endocrine, and renal effects. Hypertension 2011;57:1136-1144.

34. Davis ME, Pemberton CJ, Yandle TG, Fisher SF, Lainchbury JG, Frampton CM, Rademaker MT, Richards AM. Urocortin 2 infusion in healthy humans: hemodynamic neurohormonal, and renal responses. J Am Coll Cardiol 2007;49:461-471.

35. Nishikimi T, Miyata A, Horio T, Yoshihara F, Nagaya N, Takishita S, Yutani C, Matsuo $\mathrm{H}$, Matsuoka $\mathrm{H}$, Kangawa K. Urocortin, a member of the corticotropin-releasing factor family, in normal and diseased heart. Am J Physiol Heart Circ Physiol 2000;279. $\mathrm{H} 3031-\mathrm{H} 3039$.

36. Markovic D, Punn A, Lehnert H, Grammatopoulos DK. Molecular determinants and feedback circuits regulating type $2 \mathrm{CRH}$ receptor signal integration. Biochim Biophys Acta 2011;1813:896-907.

37. Xiong $Y$, Qu Z, Chen N, Gong H, Song M, Chen X, Du J, Xu C. The local corticotropin-releasing hormone receptor 2 signalling pathway partly mediates hypoxia-induced increases in lipolysis via the cAMP-protein kinase A signalling pathway in white adipose tissue. Mol Cell Endocrinol 2014;392:106-114.

38. Santos-Ribeiro D, Mendes-Ferreira P, Maia-Rocha C, Adao R, Leite-Moreira AF, Bras-Silva C. Pulmonary arterial hypertension: basic knowledge for clinicians. Arch Cardiovasc Dis 2016;109:550-561.

39. Hasdemir B, Mhaske P, Paruthiyil S, Garnett EA, Heyman MB, Matloubian M, Bhargava A. Sex- and corticotropin-releasing factor receptor 2- dependent actions of urocortin 1 during inflammation. Am J Physiol Regul Integr Comp Physiol 2016;310: R1244-R1257.

40. Ng LL, Loke IW, O'Brien RJ, Squire IB, Davies JE. Plasma urocortin in human systolic heart failure. Clin Sci 2004;106:383-388.

41. Wang S, Zhu X, Cong B, You X, Wang Y, Wang W, Ni X. Estrogenic action on arterial smooth muscle: permissive for maintenance of CRHR2 expression. Endocrinology 2012;153:1915-1924.

42. McLaughlin VV, Hoeper MM, Channick RN, Chin KM, Delcroix M, Gaine S, Ghofrani HA, Jansa P, Lang IM, Mehta S, Pulido T, Sastry BKS, Simonneau G, Sitbon O, Souza R, Torbicki A, Tapson VF, Perchenet L, Preiss R, Verweij P, Rubin LJ, Galie N. Pulmonary arterial hypertension-related morbidity is prognostic for mortality. J Am Coll Cardiol 2018;71:752-763.

43. Bossone E, D'andrea A, D'alto M, Citro R, Argiento P, Ferrara F, Cittadini A Rubenfire M, Naeije R. Echocardiography in pulmonary arterial hypertension: from diagnosis to prognosis. J Am Soc Echocardiogr 2013;26:1-14.

44. de Man FS, Handoko ML, van Ballegoij JJ, Schalij I, Bogaards SJ, Postmus PE, van der Velden J, Westerhof N, Paulus WJ, Vonk-Noordegraaf A. Bisoprolol delays progression towards right heart failure in experimental pulmonary hypertension. Circ Heart Fail 2012;5:97-105.

45. Courand PY, Pina Jomir G, Khouatra C, Scheiber C, Turquier S, Glerant JC, Mastroianni B, Gentil B, Blanchet-Legens AS, Dib A, Derumeaux G, Humbert M, Mornex JF, Cordier JF, Cottin V. Prognostic value of right ventricular ejection fraction in pulmonary arterial hypertension. Eur Respir J 2015;45:139-149.

46. Sanz J, Garcia-Alvarez A, Fernandez-Friera L, Nair A, Mirelis JG, Sawit ST, Pinney S, Fuster $\mathrm{V}$. Right ventriculo-arterial coupling in pulmonary hypertension: a magnetic resonance study. Heart 2012;98:238-243.

47. Chan YC, Yao XQ, Lau CW, Chan FL, He GW, Bourreau JP, Huang Y. The relaxant effect of urocortin in rat pulmonary arteries. Regul Pept 2004;121:11-18.

48. Lamberts RR, Caldenhoven E, Lansink M, Witte G, Vaessen RJ, St Cyr JA, Stienen G] Preservation of diastolic function in monocrotaline-induced right ventricular hypertrophy in rats. Am J Physiol Heart Circ Physiol 2007;293:H1869-H1876.

49. Li H, Yu Z, Zu X, Liu F, Jin Y, Jiang Y, Liu H. [Classification of the cell lines in the extraction of intracellular metabolites based on ultra performance liquid chromatography-time of flight mass spectrometry]. Se Pu 2009;27:387-390.

50. Huang M, Kempuraj D, Papadopoulou N, Kourelis T, Donelan J, Manola A Theoharides TC. Urocortin induces interleukin-6 release from rat cardiomyocytes through p38 MAP kinase, ERK and NF-kappaB activation. J Mol Endocrinol 2009;42: 397-405.

51. Kiss T, Kovacs K, Komocsi A, Tornyos A, Zalan P, Sumegi B, Gallyas F, Kovacs K Jr. Novel mechanisms of sildenafil in pulmonary hypertension involving cytokines/chemokines, MAP kinases and Akt. PLoS One 2014:9:e104890.

52. Walther S, Awad S, Lonchyna VA, Blatter LA. NFAT transcription factor regulation by urocortin II in cardiac myocytes and heart failure. Am J Physiol Heart Circ Physio 2014;306:H856-H866.

53. Gao XF, Zhou Y, Wang DY, Lew KS, Richards AM, Wang P. Urocortin-2 suppression of p38-MAPK signaling as an additional mechanism for ischemic cardioprotection. Mol Cell Biochem 2015;398:135-146.

54. Borgdorff MA, Koop AM, Bloks VW, Dickinson MG, Steendijk P, Sillje HH, van Wiechen MP, Berger RM, Bartelds B. Clinical symptoms of right ventricular failure in experimental chronic pressure load are associated with progressive diastolic dysfunction. J Mol Cell Cardiol 2015;79:244-253.

55. Aguero J, Ishikawa K, Hadri L, Santos-Gallego C, Fish K, Hammoudi N, Chaanine A, Torquato S, Naim C, Ibanez B, Pereda D, Garcia-Alvarez A, Fuster V, Sengupta PP, Leopold JA, Hajiar RJ. Characterization of right ventricular remodeling and failure in a chronic pulmonary hypertension model. Am J Physiol Heart Circ Physiol 2014;307: H1204-H1215

56. Egemnazarov B, Schmidt A, Crnkovic S, Sydykov A, Nagy BM, Kovacs G, Weissmann $\mathrm{N}$, Olschewski H, Olschewski A, Kwapiszewska G, Marsh LM. Pressure overload creates right ventricular diastolic dysfunction in a mouse model: assessment by echocardiography. J Am Soc Echocardiogr 2015;28:828-843.

57. Hirata M, Ousaka D, Arai S, Okuyama M, Tarui S, Kobayashi J, Kasahara S, Sano S. Novel model of pulmonary artery banding leading to right heart failure in rats. Biomed Res Int 2015;2015:753210.

58. Rain S, Andersen S, Najafi A, Gammelgaard Schultz J, da Silva Goncalves Bos D, Handoko ML, Bogaard HJ, Vonk-Noordegraaf A, Andersen A, van der Velden J, Ottenheijm CA, de Man FS. Right ventricular myocardial stiffness in experimental pulmonary arterial hypertension: relative contribution of fibrosis and myofibril stiffness. Circ Heart Fail 2016;9:e002636.

59. Hardegree EL, Sachdev A, Fenstad ER, Villarraga HR, Frantz RP, McGoon MD, Oh JK Ammash NM, Connolly HM, Eidem BW, Pellikka PA, Kane GC. Impaired left ventricular mechanics in pulmonary arterial hypertension: identification of a cohort at high risk. Circ Heart Fail 2013:6:748-755. 


\section{Online supplements to:}

\section{Urocortin-2 improves right ventricular function and attenuates pulmonary arterial hypertension}

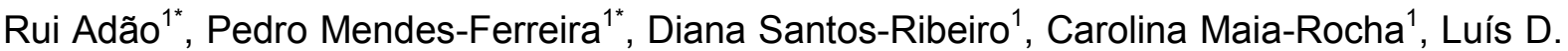
Pimentel $^{1}$, Cláudia Monteiro-Pinto ${ }^{1}$, Eamon P. Mulvaney ${ }^{2}$, Helen M. Reid ${ }^{2}$, B. Therese Kinsella ${ }^{2}$, François Potus $^{3}$, Sandra Breuils-Bonnet ${ }^{3}$, Miriam T. Rademaker ${ }^{4}$, Steeve Provencher $^{3}$, Sébastien Bonnet ${ }^{3}$, Adelino F. Leite-Moreira ${ }^{1}$, Carmen Brás-Silva ${ }^{1,5}$

${ }^{1}$ Department of Surgery and Physiology, Cardiovascular Research and Development Center - UnIC, Faculty of Medicine, University of Porto, 4200-319 Porto, Portugal;

${ }^{2}$ UCD Conway Institute for Biomolecular \& Biomedical Research, University College Dublin, Belfield, Dublin, Ireland;

${ }^{3}$ Pulmonary Hypertension Research Group, Institut Universitaire de Cardiologie et de Pneumologie de Québec, Laval University, Quebec City, Canada;

${ }^{4}$ Christchuch Heart Institute, Department of Medicine, University of Otago-Christchurch, Christchurch, New Zealand;

${ }^{5}$ Faculty of Nutrition and Food Sciences, University of Porto, Portugal.

\section{Address correspondence to:}

Carmen Brás Silva

Department of Surgery and Physiology

Cardiovascular Research and Development Center - UnIC

Faculty of Medicine, University of Porto

Al. Prof. Hernâni Monteiro,4200-319 Porto, Portugal

Telephone:(+351)220426822

Fax:(+351)225513646

e-mail:carmensb@med.up.pt 


\section{Supplementary methods}

All patients or their legal representatives (in the case of autopsy) gave informed consent before the beginning of the study in accordance to the declaration of Helsinki, and institutional guidelines were approved by Institut Universitaire de Cardiologie et de Pneumologie de Québec (CER-20773). The usage of human tissues follow recommendations published, ${ }^{1}$ in collaboration with the Institut Universitaire de Cardiologie et de Pneumologie de Québec site of the Respiratory Health Network tissue bank of the Fonds de recherche du Québec - Santé (FRQS)(www.tissuebank.ca).

All animal experiments were performed in accordance with the recommendations of the Guide for the Care and Use of Laboratory Animals, published by the US National Institutes of Health (NIH Publication No. 85-23, Revised 2011), and were approved by the ethical committee of the Faculty of Medicine of the University of Porto and the Portuguese Foundation for Science and Technology, and certified by the Portuguese National Authority for Animal Health (PTDC/DTP-FTO/0130/2012; 0421/000/000/2013). All animal manipulations were executed by trained researchers, certified with a Laboratory Animal Sciences course according to the Federation of European Laboratory Animal Science Association. Animals were kept in groups of 2-per cage under controlled environment with a 12-h-light-dark cycle at $22^{\circ} \mathrm{C}$ room temperature, with water and food ad libitum.

\section{Human samples}

Human RV samples were collected from patients with and without PAH at the time of cardiac surgery (see Table S1), heart transplantation or autopsy (performed within $3 \mathrm{~h}$ of death). Samples were categorized according to clinical history and the tricuspid annular plane systolic excursion (TAPSE), and designated as normal RV (NRV) or RV failure (RVF) as previously reported. ${ }^{2}$ Human lung samples were obtained from PAH patients at the time of lung transplantation and from non-PAH controls during tumour resection from non-cancerous segments. ${ }^{3}$ Blood samples were also collected from PAH patients and age-matched controls as previously described. ${ }^{4}$

\section{Animal models and experimental design}

PAH was induced as previously described. ${ }^{5}$ Seven-week-old male Wistar rats (Charles River Laboratories, $180-200 \mathrm{~g}$ ) randomly received an injection of monocrotaline (MCT, $60 \mathrm{mg} / \mathrm{kg}$, s.c., Sigma-Aldrich) or an equal amount of vehicle. Two weeks after MCT/vehicle administration, animals were further randomly received hUcn-2 (Bachem) at a dose of 5 $\mathrm{ug} / \mathrm{kg}$ (bi-daily, i.p.) or an equal amount of vehicle $(0.9 \% \mathrm{NaCl})$ for 10 days, resulting in four groups: Ctrl+vehicle (C); Ctrl+hUcn-2 (CU); MCT+vehicle (M); MCT+hUcn-2 (MU). After the treatment period, animals were submitted to exercise testing and echocardiographic and invasive haemodynamic analysis, with subsequent sample collection for in vitro functional studies, morphological, histological, and molecular analysis, as detailed in supplemental material. To determine whether MCT-induced $\mathrm{PH}$ was already present prior to therapy, an additional group underwent the same experimental protocol and was evaluated at an earlier time point (14 days) (see Figure S7 and S8).

Another group of animals was subjected to pulmonary artery banding (PAB), as previously described, ${ }^{6}$ applying a pulmonary artery constriction resulted in a degree of hypertrophy and RV overload identical to the MCT-induced PH model (see Figure S6), and submitted to the same randomization, time points, and chronic treatment protocol. Seven-week old male Wistar rats (Charles River Laboratories, 180-200 g) were sedated, anaesthetized and monitored as above mentioned (for the haemodynamic evaluation). The animal was placed in right lateral decubitus, the left thorax was shaved, depilated and wiped clean with iodine solution. Under a surgical microscope (Wilde M651, Leica microsystems), a small incision was created at the axillary level, the pectoral muscles were carefully dissected and retracted, and the thorax was opened at the second intercostal space. The thymus was moved and the pulmonary artery visualized. Using blunt forceps, the pulmonary artery was dissected free 
from both sides and a perforated spinal cord hook (Fine Science Tools) was used to pass a 6-0 prolene suture around the pulmonary artery. A 16-gauge needle with a blunt tip was placed parallel to the pulmonary artery, and the suture was quickly tied leaving a $1.65 \mathrm{~mm}$ constriction. The thorax was closed with 5-0 prolene, taking care not to cause pneumothorax, the pectoral muscles were put back in place and the skin was closed using 7-0 prolene. The suture site was infiltrated with lidocaine $(1 \%)$ and a subcutaneous injection of saline was administered to compensate for fluid losses, as well as analgesia (morphine, 4 $\mathrm{mg} / \mathrm{kg}$ every 4 hours for the first 48 hours). Anaesthesia was interrupted and the animals were allowed to recover until full motion was achieved, and placed in a clean cage on top of a heating pad with easy access to food and water. Suture integrity was checked for the next 3-4 days to ensure proper wound closure. Sham animals underwent the exact same protocol, except that the suture around the PA was loosely tied, and were not failed PAB attempts. No mortality was observed 3 weeks after PAB. Two weeks after PAB, animals randomly received hUcn-2 or vehicle for 10 days, resulting in three groups: Sham + vehicle $(\mathrm{S})$; $\mathrm{PAB}+$ vehicle $(\mathrm{B})$ and $\mathrm{PAB}+\mathrm{hUcn}-2(\mathrm{BU})$. Sampling was performed as in the MCT protocol.

\section{Drugs preparation}

A solution of MCT was prepared wherein $300 \mathrm{mg}$ was dissolved in $2.36 \mathrm{~mL}$ of $1 \mathrm{M} \mathrm{HCl}$, diluted with distilled water to $\sim 1.60 \mathrm{~mL}$, neutralized with $1.52 \mathrm{~mL}$ of $1 \mathrm{M} \mathrm{NaOH}$, and $\mathrm{pH}$ adjusted to 7.00 .

The hUcn-2 dosages, administration routes and treatment duration were selected based on previous studies ${ }^{7}$ and preliminary dose-finding experiments (unpublished data). A stock solution of hUcn-2 was initially prepared by dissolving $1 \mathrm{mg}$ in $1 \mathrm{~mL}$ of $\mathrm{NaCl}$, which was further diluted with $\mathrm{NaCl}$ to achieve a final working concentration of $0.002 \mathrm{mg} / \mathrm{mL}$.

\section{Survival analysis}

The defined end-point for the survival analysis was a $20 \%$ loss of body weight plus oedema/ascites and decreased movement. When this end-point was reached, animals were euthanized with an anaesthetic overdose (sodium pentobarbital 100mg/kg, Eutasil, CEVA). Only those animals reaching the end-point before evaluation at study-end were considered valid and used in the survival analysis.

\section{Exercise capacity test}

Animal exercise capacity was tested on a close-chamber treadmill set with electric stimulation (LE8710R, Columbus Instruments) coupled to a gas analyser. Peak effort and endurance tests were evaluated in different sets of animals. To assess maximal oxygen consumption $\left(\mathrm{VO}_{2} \mathrm{max}\right)$, treadmill velocity was increased after an initial adaption period at $9 \mathrm{~m} / \mathrm{min}$ to $18 \mathrm{~m} / \mathrm{min}$ and then stepped up by $3 \mathrm{~m} / \mathrm{min}$ every minute, at a treadmill inclination of $15^{\circ}{ }^{8}$ whereas in endurance testing, initial speed was set at $10 \mathrm{~m} / \mathrm{min}$, with increases of $5 \mathrm{~m} / \mathrm{min}$ every 5 minutes, for 30 minutes or until the animal fatigued. ${ }^{9}$ Both tests were performed 13 (prior to treatment group allocation; baseline) and 23 days after PAH induction.

\section{Echocardiography}

Echocardiographic analysis was performed 13 days (baseline) and 24 days after PAH induction as previously described. ${ }^{5}$ Briefly, animals were lightly anaesthetized (inhalation of $8 \%$ sevofluorane in a closed chamber for induction, and $2-3.5 \%$ for maintenance through a nose cone) and placed in a left lateral decubitus position on a heating pad with homeothermic control through a rectal probe. The thorax was shaved, cleaned and scanned with a $15 \mathrm{MHz}$ linear probe (15L8 probe coupled to an Acuson Sequoia C512 echocardiography system, Siemens) for determination of pulmonary flow and RV structure. Acquisitions were averaged over three consecutive heartbeats by a researcher blinded to the experimental group. Pulmonary artery acceleration time (PAAT), pulmonary artery 
ejection time (PAET) and the pulmonary artery velocity-time integral (PAVTI) were evaluated through conventional Doppler in parasternal short-axis view, and the PAAT/PAET ratio calculated. RV end-diastolic dimension (RVEDD), right atrial area (RAA), and TAPSE were obtained in an apical 4-chamber projection.

\section{Invasive haemodynamic evaluation}

Following echocardiographic evaluation, the animals were intubated using a 14-gauge catheter and ventilated (MouseVent G500, Kent Scientific) with $100 \% \mathrm{O}_{2}$, with tidal volume and respiratory rate adjusted to animal weight, and monitored for peripheral oximetry, heart rate (HR), capnography, and respiratory rate (PhysioSuite, Kent Scientific). Anaesthesia was titrated according to toe-pich reflex. The animals were placed on their right side, the internal femoral vein catheterized for fluid administration, and a left thoracotomy performed. High fidelity pressure-volume catheters were inserted through the apex of the RV and LV and positioned along the long axis (SPR-869 and SPR-847, for the RV and LV, respectively, Millar Instruments, Texas, USA), and a flow probe (MA2.5PSB, Transonic Systems) implanted around the ascending aorta for $\mathrm{CO}$ acquisition and field inhomogeneity normalization. Baseline and inferior vena cava occlusion recordings were obtained, and a bolus injection of $50 \mu \mathrm{L}$ hypertonic saline was administered to account for parallel conductance. Pressure and volume signals were continuously acquired (MPVS Ultra, Millar Instruments), digitally recorded (PowerLab 16/30, ADInstruments), and analysed off-line (LabChart 7 Pro, ADInstruments). Following anaesthetic overdose (sodium pentobarbital $100 \mathrm{mg} / \mathrm{kg}$, Eutasil, CEVA), blood samples were taken into EDTA tubes, the animals exsanguinated and heart and lungs collected en bloc for subsequent histological and molecular analysis. ${ }^{5}$

\section{Morphometric and histological analysis}

Following removal, the lungs, RV and LV + septum $(L V+S)$ were carefully separated and weighed before being flushed with cold physiological salt solution (PSS, $130 \mathrm{mM} \mathrm{NaCl}$, $4.7 \mathrm{mM} \mathrm{KCl}, 1.18 \mathrm{mM} \mathrm{KH} 2 \mathrm{PO} 4,1.17 \mathrm{mM} \mathrm{MgSO} 4,14.9 \mathrm{mM} \mathrm{NaHCO}, 5.5 \mathrm{mM}$ glucose, $0.026 \mathrm{mM}$ EDTA and $1.6 \mathrm{mM} \mathrm{CaCl} 2$ ) to remove excess blood. RV and lung samples were collected, snap frozen in liquid nitrogen, and stored at $-80^{\circ} \mathrm{C}$. For mRNA quantification, samples were submerged in RNA stabilization reagent (RNAlater, Qiagen). Tibia length was measured for weight normalization.

For histological analysis, samples of RV and lung tissue were submerged in fixative solution (10\% formaldehyde) and dehydrated before undergoing diaphanization and impregnation in liquid paraffin. Four $\mu \mathrm{m}$ sections of RV were cut and stained with haematoxylin and eosin (HE) to evaluate cardiomyocyte morphology, and with Picro Sirius Red to quantify fibrosis. Sections were digitally photographed (Olympus XC30, Olympus) and analysed using imaging software (Cell^ $\mathrm{B}$, Olympus). ${ }^{5}$

For the lung tissue, HE-stained tissue sections were scanned at 40X magnification using the Philips IntelliSite UltraFast Scanner system and supported by QuPath (Version 0.1.2) software analysis package. ${ }^{10}$ Morphometric analysis was carried out on each of the lung sections, where all vessels/arterioles present in 10 fields/section $\left(10 \mathrm{~mm}^{2}\right)$ were categorized into small $(15-50 \mu \mathrm{m})$, medium $(50-100 \mu \mathrm{m})$ and large $(>100 \mu \mathrm{m})$ and measurements for the total and lumen vessel diameter recorded, essentially as previously described. ${ }^{11}$ Based on these measurements, values for the Lumen/Total Vessel Diameter Ratio, Medial Thickness $(\mu \mathrm{m})$ and Degree of Vessel Occlusion (\%) were calculated. Additionally, Vessel Occlusion was categorized as: no evidence of neointimal formation (open); partial $(<50 \%)$ luminal occlusion; and full-luminal occlusion (closed). ${ }^{12}$

Assessment of isolated pulmonary artery endothelial function and vascular acute analysis 
After heparinization, euthanasia was achieved with anaesthetic overdose (sodium pentobarbital $100 \mathrm{mg} / \mathrm{kg}$, Eutasil, CEVA), the heart and lung removed en bloc, and submerged in cold physiological salt solution (PSS, $130 \mathrm{mM} \mathrm{NaCl}, 4.7 \mathrm{KCl}, 1.18 \mathrm{mM}$ $\mathrm{KH} 2 \mathrm{PO} 4,1.17 \mathrm{mM}$ MgSO4, $14.9 \mathrm{mM} \mathrm{NaHCO}$, $5.5 \mathrm{mM}$ glucose, $0.026 \mathrm{mM}$ EDTA and 1.6 $\mathrm{mM} \mathrm{CaCl} 2$ ). The left upper lung was used to isolate second-generation pulmonary arteries $(200-400 \mu \mathrm{m}$ diameter). Arterial rings $(2 \pm 0.2 \mathrm{~mm})$ were cut and mounted between two metallic pins in a horizontal bath myograph system (DMT Myograph $720 \mathrm{MO}$, ADInstruments) at $95 \% \mathrm{O}_{2} / 5 \% \mathrm{CO}_{2}$, a constant temperature of $37^{\circ} \mathrm{C}$ and $\mathrm{pH}$ of 7.4 . Following a stabilization period, normalization of each arterial ring to its optimal length (length-tension curve to transmural target pressure) and maximum tension development was assessed with $80 \mathrm{mM} \mathrm{KCl}$ (KPSS) solution. ${ }^{5}$

For the determination of the acute vasodilatory effects of hUcn-2, arterial rings were contracted with phenylephrine $\left(10^{-5} \mathrm{M}\right)$ and allowed to stabilize, after which a dose response to hUcn-2 $\left(10^{-9}\right.$ to $\left.5 \times 10^{-7} \mathrm{M}\right)$ or vehicle $\left(\mathrm{ddH}_{2} \mathrm{O}\right.$, equal volume) was performed. The dose response to hUcn-2 was also carried out in endothelium-denuded vessels, affected by passing a 7-0 silk suture over the intimal surface of the lumen to remove the endothelial layer. Maximal relaxation to $\mathrm{hUcn}-2$ (Emax) and the concentration of $\mathrm{hUcn}-2$ required for $50 \%$ of the maximal response $\left(\mathrm{EC}_{50}\right)$ were calculated.

For the determination of the acute vasoconstriction-inhibiting effects of Ucn-2, the arterial rings were firstly contracted with phenylephrine $\left(10^{-5} \mathrm{M}\right)$, followed by relaxation via 15minutes incubation with $50 \mathrm{nM}$ hUnc-2 $\left(5 \times 10^{-8} \mathrm{M}\right)$, - the closest concentration to the $\mathrm{EC}_{50}$ $\left(63 \mathrm{mM}\right.$, or $\left.10^{-7.2} \mathrm{M}\right)$ of control arterial rings - and then contracted again with phenylephrine $\left(10^{-5} \mathrm{M}\right)$. Contraction inhibition was calculated as the ratio of maximum developed tension between the second and the first phenylephrine contraction. An alternative set of arterial rings isolated from MCT animals was pre-incubated with the higher dose of hUcn-2 $(500 \mathrm{nM}$, $\left.5 \times 10^{-7} \mathrm{M}\right)$.

Pulmonary artery endothelial function was assessed by attaining a dose-response curve to acetylcholine $\left(10^{-9}\right.$ to $\left.10^{-5} \mathrm{M}\right)$ after pre-contraction with phenylephrine $\left(10^{-5} \mathrm{M}\right)$. Maximal relaxation to acetylcholine and $\mathrm{EC}_{50}$ were calculated. Analysis was performed offline (LabChart 7 Pro, ADInstruments).

\section{In vitro studies in isolated skinned cardiomyocytes}

RV samples (stored at $-80^{\circ} \mathrm{C}$ ) were defrosted in relax solution, and a biopsy taken, subjected to mechanical disruption, and permeabilized with $0.1 \%$ Triton X-100. Under microscopic view (model 1X51, Olympus) and through imaging software (VSL 900B, Aurora Scientific), a single cardiomyocyte was attached to a force transducer (model $403 \mathrm{~A}$, Aurora Scientific) and a length controller (model $315 \mathrm{C}-\mathrm{I}$, Aurora Scientific). Cell length was digitally adjusted through custom-designed software (series 600A digital controller, Aurora Scientific), and steady-state passive force measured at increasing sarcomere lengths $(1.8-2.3 \mu \mathrm{m})$. Force measurements were normalized to each cardiomyocyte cross-sectional area (CSA) and a minimum of three cells per animal measured. ${ }^{6}$

\section{Quantitative RT-PCR, immunoblotting, immunochemistry and enzyme-linked immunosorbent assay}

For human samples, total RNA was isolated from tissue using the RNeasy micro kit according to the manufacturer's instruction, and mRNA reverse transcribed and amplified using one-step kit TaqMan probes. qRT-PCR was performed with the ABI Prism 7900 Sequence Detector (Applied Byosystems), and $18 \mathrm{~s}$ used as a housekeeping gene. The relative expression level of Ucn-2 and CRHR2 was determined by the $2^{-\Delta \mathrm{Ct} *} 100$.

For rat samples, total RNA was extracted using the RNeasy Mini Kit according to manufacturer's instructions, and relative mRNA expression of Ucn-2, CRHR2, B-type brain natriuretic peptide (BNP), Endothelin-1 (ET-1), Hypoxia-inducible factor 1-alpha (HIF-1 $\alpha$ ), Collagen type III alpha 1 (Col3A1), Caspase-3 and -8, myosin heavy chain $\beta$ (BMHC) and myosin heavy chain $\alpha(\alpha \mathrm{MHC})$ quantified by two-step Real-Time PCR (Step-One Applied 
Biosystems). Glyceraldehyde 3-phosphate dehydrogenase (GAPDH) was used as a reference gene, and final results presented in arbitrary units and normalized for the control group. All assays were performed in duplicate. Primers used were designed in-house (see Table S2).

For immunoblotting experiments, RV samples were homogenized in ice-cold RIPA lysis buffer (Cell Signaling Technology) containing protease and phosphatase inhibitors. Extracts were centrifuged at $12000 \mathrm{rpm}$ for $20 \mathrm{~min}$ at $4^{\circ} \mathrm{C}$, supernatants collected, total protein concentration determined, and $30 \mu \mathrm{g}$ separated in a $10 \%$ SDS-PAGE gel. Proteins were electroblotted onto a $0.2 \mu \mathrm{m}$ nitrocellulose membrane, blocked with $5 \%$ skinned milk and incubated overnight at $4^{\circ} \mathrm{C}$ with primary antibodies (see Table S3). After washing, the membrane was probed with secondary antibodies (IRDye 680LT, Goat-anti-Mouse Ab and IRDye $800 \mathrm{CW}$, Goat-anti-Rabbit Ab, Li-COR Biosciences) and visualized using an Odyssey scanner (infrared imaging system, Li-COR Biosciences). Human RV CRHR2 expression was quantified using a horse-radish peroxidase conjugate secondary antibody (Bio-Rad) and ChemiDoc system, and normalized for total protein content (Amido Black, Sigma Aldrich).

For immunohistochemistry, RV sections were deparaffinized and rehydrated. Antigen Retrieval was performed according to the manufacturer in a steamer. Sections were incubated overnight at $4^{\circ}$ with the primary antibody anti- CRHR2 (Abcam, ab203585) at 1:250, diluted in antibody diluent (Thermofisher scientific, USA). Slides were then washed in TBS-T20 and incubated with POLYVIEW® PLUS HRP-DAB (Anti-Rabbit) Kit and counterstained with haematoxylin, provided in the kit. Positive and negative controls were included.

Blood collected from rats and humans was centrifuged and dispensed plasma assayed for Ucn-2 concentrations using solid-phase sandwich enzyme-linked immunosorbent assay according to manufacturer's instructions (SEC585Ra and SEC585Hu, Enzyme-linked immunosorbent assay kits for Ucn-2, Cloud-Clone Corp.). In addition, buffy coat was analysed for Ucn-2 expression in human samples.

\section{Statistical analysis}

The results are presented as the mean \pm SEM. Survival analysis was performed in $R$ (version 3.4.1) using PwrGSD package (version 2.0), whereas GraphPad Software v7 (GraphPad Software Inc., San Diego, CA, USA) was used in all other parameters. Two-way analysis of variance (ANOVA), with repeated-measures when suitable, was used to analyze most parameters with Tukey's method for post hoc comparisons between groups. Where appropriate, Student t-test or one-way ANOVA with Tukey's method for post hoc comparisons were used. Survival analysis was estimated according to the Kaplan-Meier method and comparisons were performed using a generalized Fleming-Harrington test $(p=$ $1, q=1$ ) for nonproportional hazards, which gives more weight to later events. A $P$-value of $<0.05$ was considered to be statistically significant. 
Table S1 Patient characteristics

\begin{tabular}{|c|c|c|c|}
\hline & CRV $(n=8)$ & $\operatorname{RVF}(n=8)$ & P-value \\
\hline Female sex, \% & 75 & 60 & N/A \\
\hline Age, y & $35 \pm 7$ & $56 \pm 9$ & NS \\
\hline \multicolumn{4}{|c|}{$\underline{\text { Subclass of PAH }}$} \\
\hline IPAH & - & $1(12.5)$ & - \\
\hline SSc-PAH & - & $3(37.5)$ & - \\
\hline Other & - & $4(50)$ & - \\
\hline \multicolumn{4}{|l|}{ NYHA, \% } \\
\hline I & 50 & - & - \\
\hline II & 50 & - & - \\
\hline III & - & 25 & - \\
\hline IV & - & 25 & - \\
\hline \multicolumn{4}{|l|}{ 3D Echo } \\
\hline LVEF, \% & $58 \pm 2$ & $56 \pm 3$ & NS \\
\hline TAPSE, mm & $22 \pm 2$ & $13 \pm 2$ & $P<0.01$ \\
\hline RVFS, \% & $54.5 \pm 2.9$ & $27.8 \pm 4.1$ & $P<0.01$ \\
\hline \multicolumn{4}{|l|}{$\underline{\mathrm{RHC}}$} \\
\hline $\mathrm{mPAP}, \mathrm{mmHg}$ & $19.5 \pm 0.5$ & $44.0 \pm 3.0$ & $P<0.01$ \\
\hline $\mathrm{RAP}, \mathrm{mmHg}$ & $7.5 \pm 1.5$ & $10.8 \pm 3.9$ & NS \\
\hline PCWP, mmHg & $8.0 \pm 3.0$ & $10.3 \pm 1.7$ & NS \\
\hline $\mathrm{Cl}, \mathrm{L} / \mathrm{min} / \mathrm{m} 2$ & $2.35 \pm 0.17$ & $2.41 \pm 0.22$ & NS \\
\hline PVR, dyne.s/cm & $236 \pm 63$ & $646 \pm 72$ & $P<0.01$ \\
\hline
\end{tabular}

$\mathrm{CI}$, cardiac index; $\mathrm{CRV}$, compensated right ventricle; IPAH, idiopathic pulmonary arterial hypertension; SSc-PAH, systemic sclerosis associated pulmonary arterial hypertension; LVEF, left ventricle ejection fraction; mPAP, mean pulmonary artery pressure; NYHA, new York Heart Association classification functional classification; PCWP, pre-capillary wedge pressure; PVR, pulmonary vascular resistance; RAP, right atria pressure; RHC, right heart catheterization; RVF, right ventricle failure; RVFS, right ventricle fractional shortening; TAPSE, tricuspid annular plane systolic excursion. Values are presented as mean \pm SEM. 
Table S2 Primer Sequence

\begin{tabular}{|c|c|}
\hline Gene & Primer Sequence \\
\hline GAPDH & $\begin{array}{l}\text { P1 - }{ }^{5} \text { TGGCCTTCCGTGTTCCTACCC }{ }^{3}{ }^{\prime} \\
\text { P2 - }{ }^{5} \text { CCGCCTGCTTCACCACCTTCT }\end{array}$ \\
\hline UCN-2 & $\begin{array}{l}\text { P1- }{ }^{5} \text { CGTTGGCATAACGCCTCAC }{ }^{3} \\
\text { P2- }{ }^{5} \text { GGACACAGAGCTGGGAGTG }{ }^{3}\end{array}$ \\
\hline CRHR2 & $\begin{array}{l}\text { P1 - }{ }^{5} \text { TGCAACTCATCGACCACGAA }{ }^{3}{ }^{3} \\
\text { P2- }{ }^{5} \text { CAGGTAGCAGCCTTCCACAA }{ }^{3}\end{array}$ \\
\hline ET-1 & 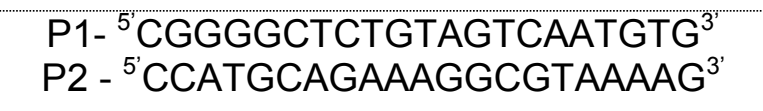 \\
\hline BNP & $\begin{array}{l}\text { P1- }{ }^{5} \text { CAG AGC TGG GGA AAG AAG AG }{ }^{3} \\
\text { P2- }{ }^{\prime} \text { GGACCAAGGCCCTACAAAAGA }{ }^{\prime}\end{array}$ \\
\hline HIF-1a & 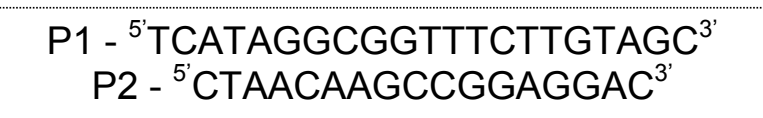 \\
\hline Caspase-3 & $\begin{array}{c}\text { P1 - }{ }^{5} \text { CGGGTGCGGTAGAGTAAG }^{3} \\
\text { P2 - }{ }^{\prime} \text { CTGGACTGCGGTATTGAGACA }{ }^{3}\end{array}$ \\
\hline Caspase-8 & $\begin{array}{l}\text { P1 - }{ }^{5} \text { ACCAAATGAAGAGCAAACCTCG }{ }^{3} \\
\text { P2 - }{ }^{5} \text { TTTTCTGTCCCGCATGTTGC }{ }^{3}\end{array}$ \\
\hline aMHC & $\begin{array}{l}\text { P1 - }{ }^{5} \text { CAAGAAGAACTTGGTGCGCGGC }{ }^{3} \\
\text { P2 - }{ }^{5} \text { ATCGTGCATTTTCTGCTTGGC }{ }^{\prime}\end{array}$ \\
\hline$\beta \mathrm{MHC}$ & $\begin{array}{c}\text { P1 - }{ }^{5} \text { AAGTCCTCCCTCAAGCTCCTAAGT }{ }^{3} \\
\text { P2 - }{ }^{5} \text { TTGCTTTGCCTTTGCCC }{ }^{3}\end{array}$ \\
\hline Col3A1 & $\begin{array}{l}\text { P1- }{ }^{5} \text { AGCATCCATCTTGCAGCCTT' } \\
\text { P2- }{ }^{3} \text { GCTCGGAATTGCAGAGACCT }{ }^{3}\end{array}$ \\
\hline
\end{tabular}

BNP, brain natriuretic peptide; Col3A1, Collagen type III alpha 1; CRHR2, corticotrophinreleasing hormone receptor type 2; ET-1, endothelin 1; GAPDH, glyceraldehyde 3phosphate dehydrogenase; HIF-1a, hypoxia inducible factor 1 alpha; UCN-2, urocortin-2; $\alpha \mathrm{MHC}$, alpha myosin heavy chain; $\beta \mathrm{MHC}$, beta myosin heavy chain. 
Table S3 Primary antibodies

\begin{tabular}{|c|c|}
\hline Protein & Antibody's Identification \\
\hline Akt & Akt (pan) (C67E7), Rabbit mAb, Cell Signaling Technology \\
\hline p-Akt & $\begin{array}{l}\text { Phospho-Akt (Ser473) (587F11), Mouse mAb, Cell Signaling } \\
\text { Technology }\end{array}$ \\
\hline & p44/42 MAPK (Erk1/2) (3A7), Mouse mAb, Cell Signaling \\
\hline ERK1/2 & Technology \\
\hline $\mathrm{p}-\mathrm{ERK} 1 / 2$ & $\begin{array}{l}\text { Phospho-p44/42 MAPK (Erk1/2) (Thr202/Tyr204), Rabbit pAb, } \\
\text { Cell Signaling Technology }\end{array}$ \\
\hline p38 & p38 $\alpha$ MAPK (L53F8), Mouse mAb, Cell Signaling Technology \\
\hline p-p38 & $\begin{array}{l}\text { Phospho-p38 MAPK (Thr180/Tyr182) (D3F9), Rabbit mAb, Cell } \\
\text { Signaling Technology }\end{array}$ \\
\hline STAT3 & Stat3 (124H6), Mouse mAb, Cell Signaling Technology \\
\hline p-STAT3 & $\begin{array}{l}\text { Phospho-Stat3 (Tyr705) (D3A7), Rabbit mAb, Cell Signaling } \\
\text { Technology }\end{array}$ \\
\hline 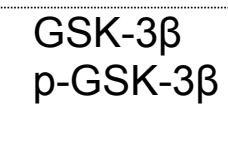 & 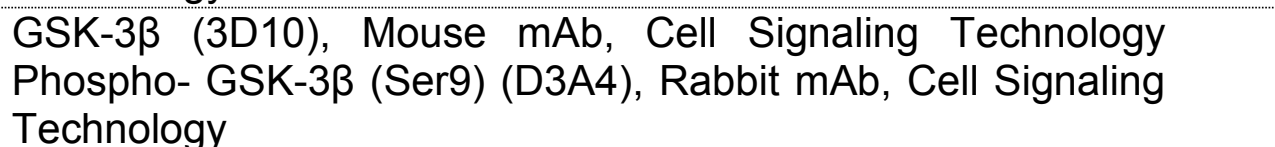 \\
\hline Bax & Bax (D2E11), Rabbit pAb, Cell Signaling Technology \\
\hline $\mathrm{Bcl}-2$ & Bcl-2 (124), Mouse mAb, Cell Signaling Technology \\
\hline CRHR2 & $\begin{array}{l}\text { Anti-Corticotropin Releasing Factor Receptor 2, Rabbit pAb, } \\
\text { Abcam }\end{array}$ \\
\hline GAPDH & GAPDH (0411), Mouse mAb, Santa Cruz Biotechnology, Inc. \\
\hline $\begin{array}{l}\text { CAMKII } \\
\text { p-CAMKII }\end{array}$ & $\begin{array}{l}\text { CaMKII (sc-5306), Mouse mAb, Santa Cruz Biotechnology, Inc. } \\
\text { Phospho-CaMKII (Thr286) (sc-32289), Mouse mAb, Santa Cruz } \\
\text { Biotechnology, Inc. }\end{array}$ \\
\hline $\begin{array}{l}\text { PKA } \\
\text { p-PKA }\end{array}$ & $\begin{array}{l}\text { PKAa (sc-28315), Mouse mAb, Santa Cruz Biotechnology, Inc. } \\
\text { p-PKAa (C-5) (sc-377575), Mouse mAb, Santa Cruz Biotechnology, } \\
\text { Inc. }\end{array}$ \\
\hline
\end{tabular}

Akt, protein kinase B; Bax, Bcl-2 Associated X Protein; Bcl-2, b-cell lymphoma 2; CAMKII, calmodulin-dependent protein kinase II; CRHR2, corticotropin-releasing hormone receptor type 2; ERK1/2, extracellular-signal regulated kinases 1 and 2; GAPDH, glyceraldehyde 3phosphate dehydrogenase; GSK-3 $\beta$, glycogen synthase kinase 3 beta; p38, p38 mitogenactivated protein kinase; PKA, protein kinase A ; PLB, phospholamban; Serca2A, sarcoplasmic reticulum Ca2+-ATPase; STAT3, signal transducer and activator of transcript 


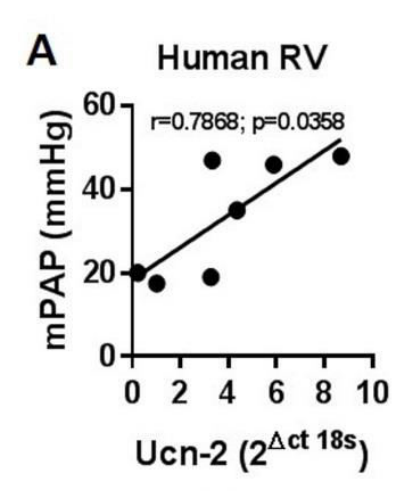

E

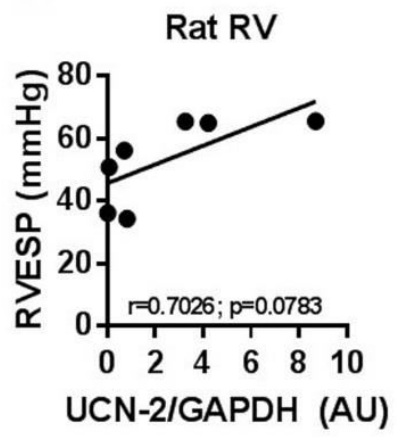

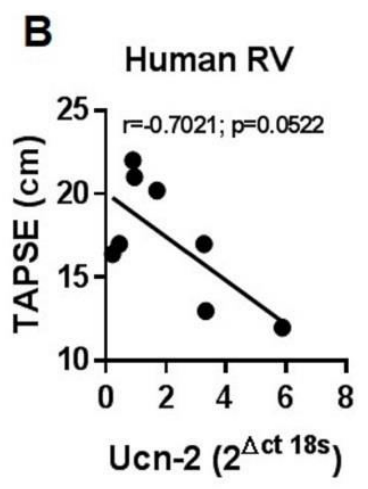

$\mathbf{F}$

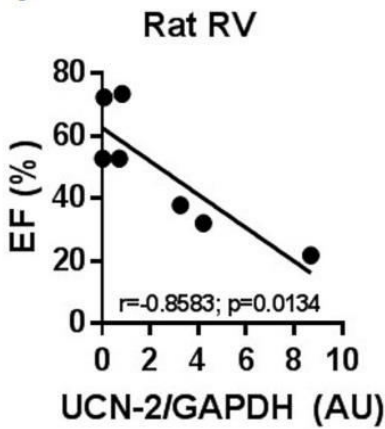

C

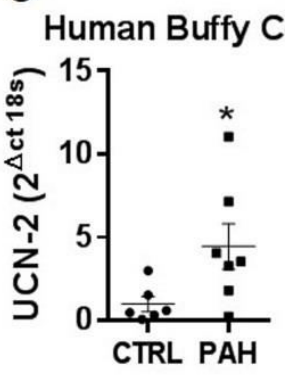

D

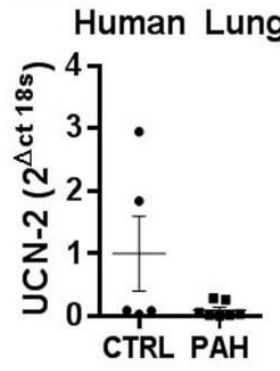

G
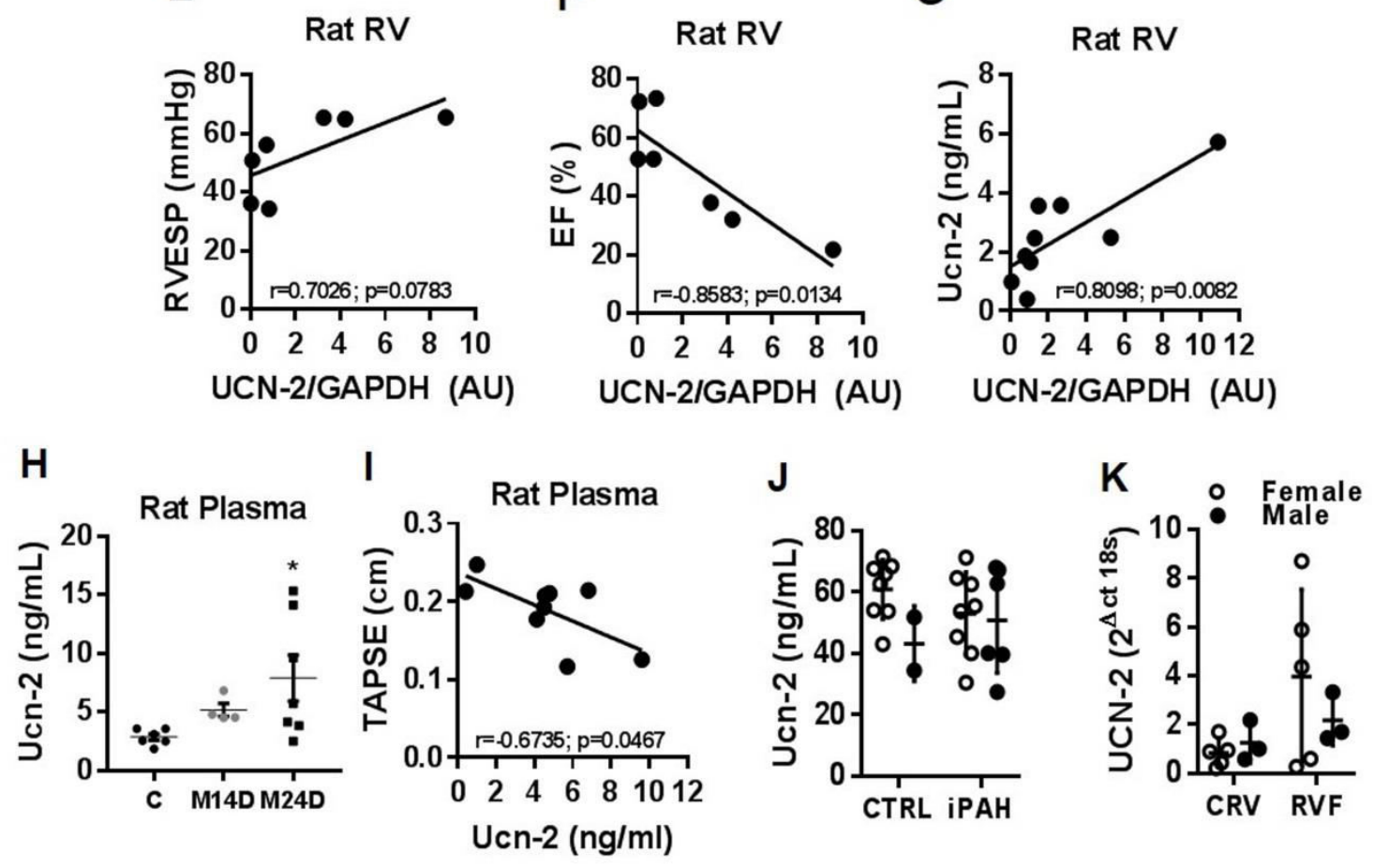

Figure S1. $(\boldsymbol{A}, \boldsymbol{B})$ Correlation between mRNA expression of urocortin-2 (Ucn-2) in the RV of PAH patients and mean pulmonary arterial pressure (mPAP) and tricuspid annular plane systolic excursion (TAPSE). (C) Buffy coat from patients with PAH shows increased expression of UCN-2 compared to control samples ( $n=6-7 / g r o u p$ ). (D) Ucn-2 expression in the lung of PAH patients is not significantly decreased when compared to non-PAH lung samples ( $n=5-8 /$ group). $(E, F)$ Correlation between mRNA expression of Ucn-2 in the RV of monocrotaline (MCT) rats and right ventricular end-systolic pressures (RVESP) and ejection fraction (EF). (G) Correlation between mRNA expression of Ucn-2 in the RV of all rats and Ucn-2 plasmatic levels. $(\boldsymbol{H})$ Plasmatic levels of Ucn-2 in MCT rats after 14 and 24 days of the MCT administration. (I) Correlation between Ucn-2 plasmatic levels and TAPSE in MCT animals. $(J, K)$ Plasmatic levels and mRNA expression of Ucn-2 in male and female patients. Results are presented as the mean \pm SEM. ${ }^{*} p<0.05$ vs $C T R L$ in panel $C$, and vs $C$ in panel $H$. Pearson correlation coefficient was used in panels $A, B, E$, $F, G$ and I. Student t-test were performed to compare groups in panels $C$ and $D$. One-way ANOVA was performed in panel $\mathrm{H}$. Two-way ANOVA was used in panel $\mathrm{J}$ and $\mathrm{K}$. 


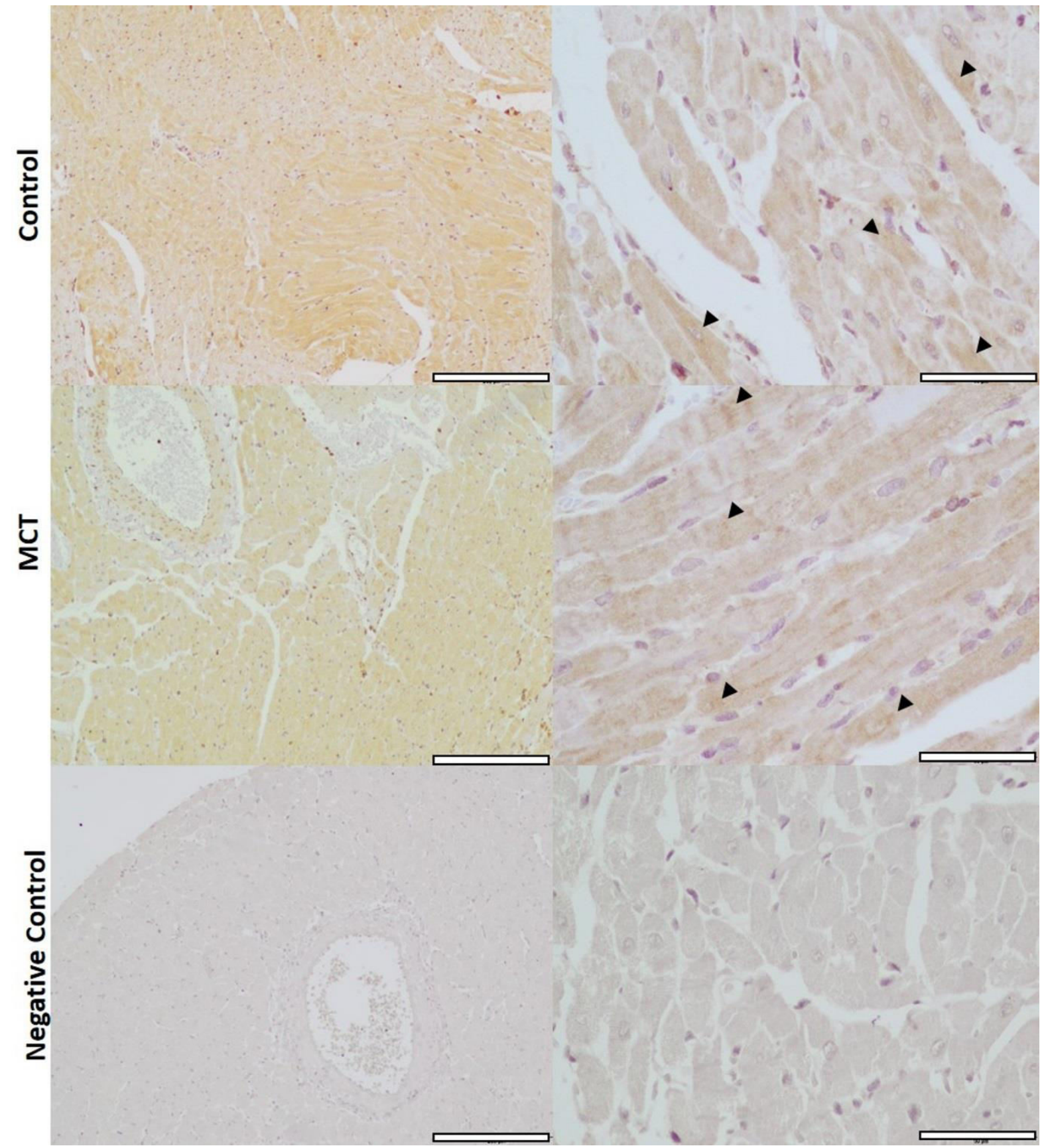

Figure S2. Immunohistochemistry for CRHR2 receptor protein in the right ventricular tissue of control and MCT-induced PH animals, confirming the presence of the receptor in heart tissue. Scale bars represent 200 $\mu \mathrm{m}$ (100X magnification) in the left

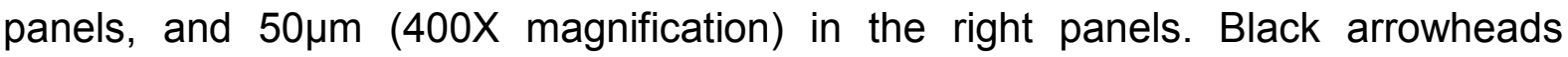
indicate zones of high intensity positive staining. 

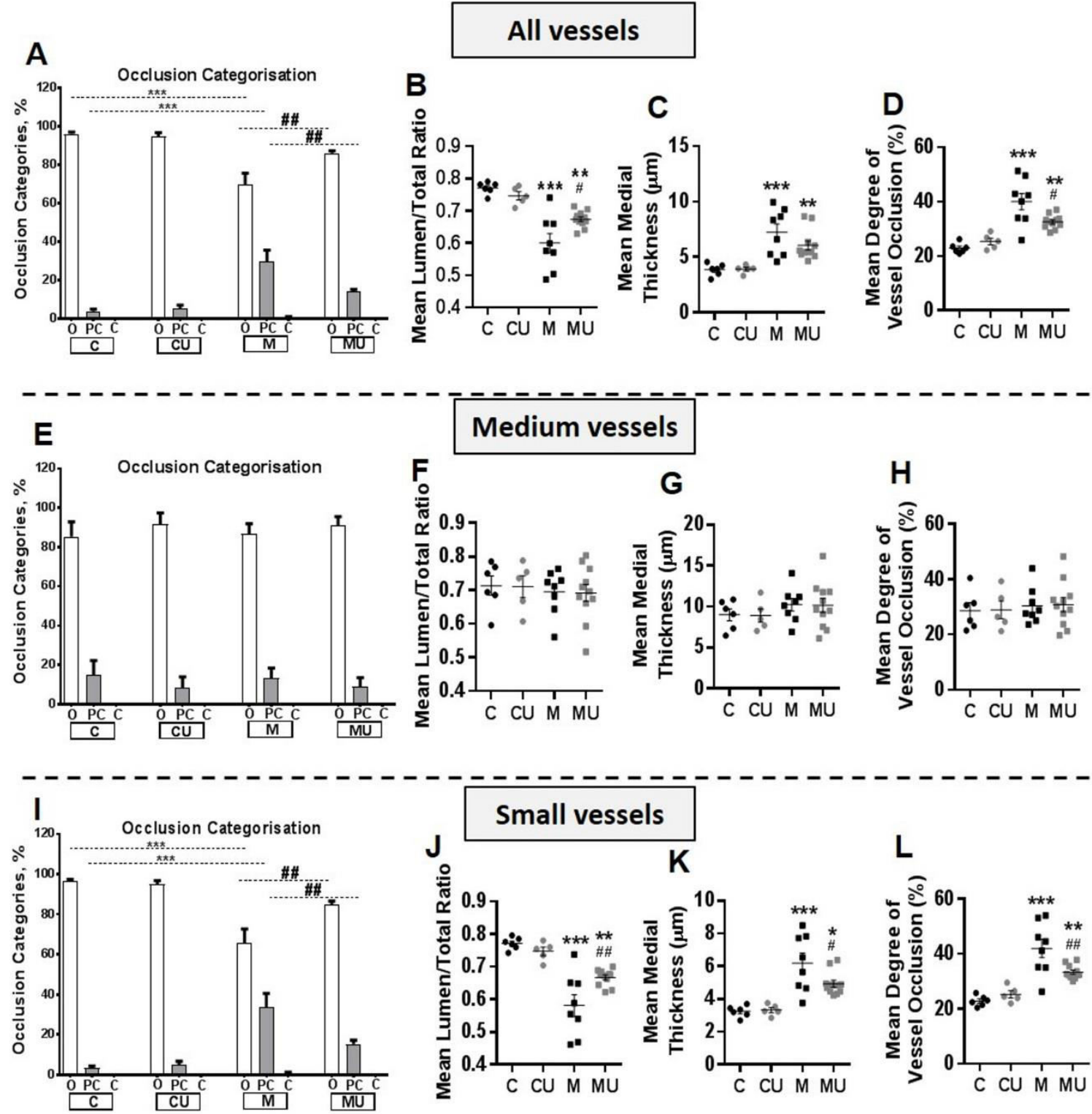

Figure S3. Morphometric analysis to evaluate vascular remodelling in all, small (15$50 \mu \mathrm{m})$ and medium $(50-100 \mu \mathrm{m})$ pulmonary arterioles. $(\boldsymbol{A}, \boldsymbol{E}, \boldsymbol{I})$ The degree of vessel occlusion of pulmonary arterioles was determined and vessels were categorised into Open $(\mathrm{O} ;<50 \%)$, Partially Closed (PC; $\geq 50 \%,<95 \%$ ) or Closed $(\mathrm{C} ; \geq 95 \%)$ vessels. In the all and small arterioles, the number of Open (O) and Partially Closed (PC) vessels in MCT-treated animals is significantly decreased relative to the CTRL group, whereas the number of Open (O) and Partially Closed (PC) vessels in MU animals is significantly increased relative to MCT animals. No differences were obtained in medium vessels. $(\boldsymbol{B}, \boldsymbol{F}, \boldsymbol{J}$ ) In all and small arterioles, the Lumen/Total Ratio in MCT animals is decreased compared to CTRL rats, whereas in MU animals the Lumen/Total Ratio is significantly increased from MCT animals. No differences were obtained in medium vessels. (C, $\mathbf{G}, \boldsymbol{K})$ In all and small arterioles, the mean medial thickness in MCT animals is increased compared to CTRL rats, whereas, in small arterioles, the medial thickness from MU animals is significantly decreased compared to MCT animals. No differences were obtained in medium vessels. $(\boldsymbol{D}, \boldsymbol{H}, \boldsymbol{L})$ In all and small arterioles, the mean degree of vessel 
occlusion in MCT animals is decreased compared to CTRL rats, whereas in MU animals is significantly increased compared to MCT animals. No differences were obtained in medium vessels ( $n=5-11 /$ group). Results are presented as the mean \pm SEM. ${ }^{*} p<0.05,{ }^{* *} p<0.01,{ }^{* * *} p<0.001$ versus line targeted groups (panels $A$ and $\mathrm{I}$ ) and versus $C$ in panels $B-D$ and $J-L ;{ }^{\#}<0.05 ;{ }^{*} p<0.01 ;{ }^{*} p<0.001$ versus line targeted groups (panels $A$ and $I$ ) and versus $M$ in panels $B-D$ and J-L. Two-way ANOVA was used for all comparisons. 
A

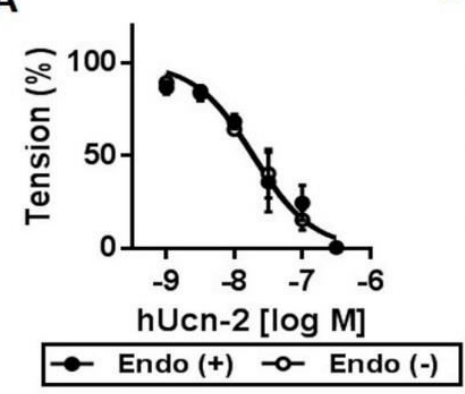

D

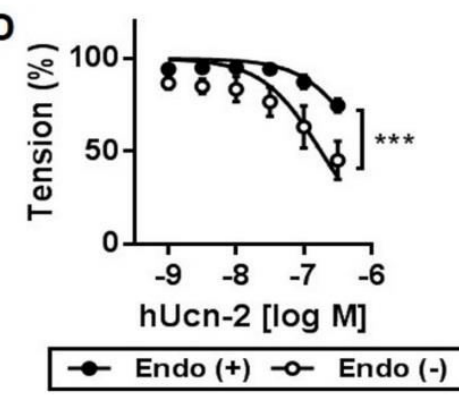

B
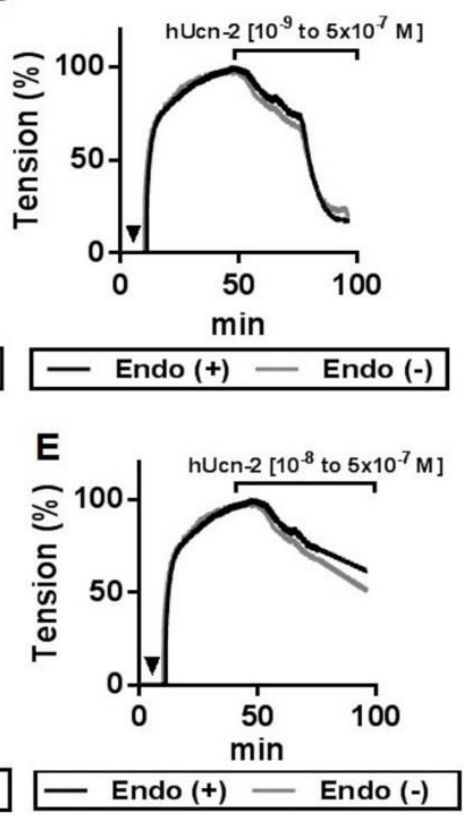

C
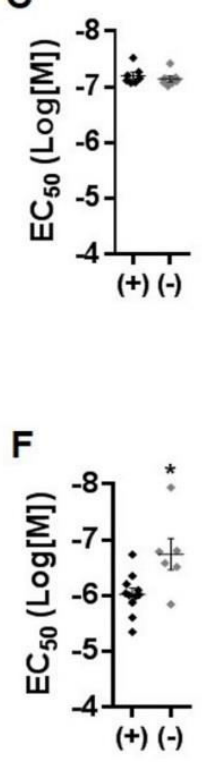

G

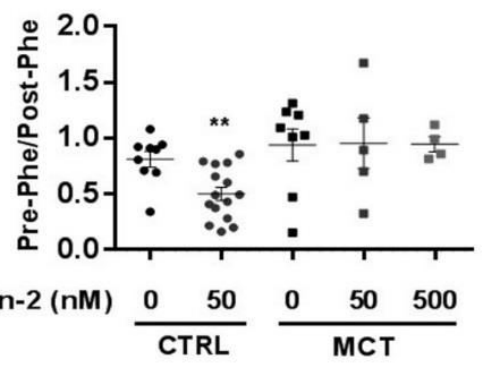

H

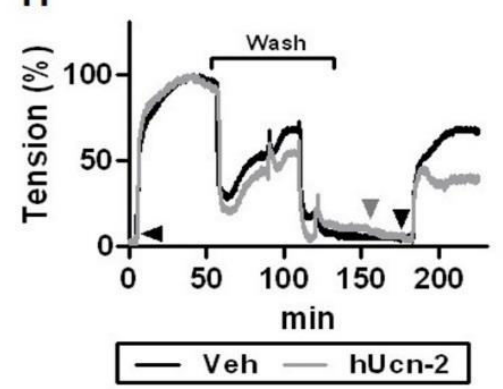

Figure S4. Vasodilation response to $\mathrm{hUcn}-2$ is independent from the endothelium and pre-treatment with hUcn-2 inhibits phenylephrine-induced vasoconstriction in control vessels. $(\boldsymbol{A}, \boldsymbol{B}, \boldsymbol{D}, \boldsymbol{E})$ In control ( $\mathrm{n}=6-8 /$ group) and MCT animals ( $\mathrm{n}=6$ $11 /$ group), vasodilation response to $\mathrm{hUcn}-2$ is independent from the endothelium, as both preserved and removed endothelium (Endo(+) and Endo(-), respectively) vessels pre-contracted with phenylephrine $\left(10^{-5} \mathrm{M}\right)$ respond to human urocortin-2 (hUcn-2; $10^{-9}$ to $5 \times 10^{-7} \mathrm{M}$, left panel). (C) In control animals, $\mathrm{EC}_{50}$ for hUcn-2 is not different in pulmonary arterial rings with $(+)$ and without $(-)$ endothelium $(n=6-$ 8/group). ( $\boldsymbol{F}$ ) In MCT rats, $\mathrm{EC}_{50}$ for hUcn-2 in pulmonary arterial rings without endothelium (-) is lower, compared to vessels with endothelium (+) ( $n=6-11 /$ group). $(\boldsymbol{G}, \boldsymbol{H})$ Pre-treatment with hUcn-2 $(50 \mathrm{nM})$ inhibits phenylephrine-induced vasoconstriction in pulmonary arterial rings isolated from control animals. In MCTinduced PH pulmonary arterial rings, neither $50 \mathrm{nM}$, nor $500 \mathrm{nM}$ exert an inhibitory effect on phenylephrine-induced vasoconstriction. Black arrowheads on the right panel represent incubation with $10^{-5} \mathrm{M}$ of phenylephrine, while grey arrowhead represents hUcn-2 treatment ( $n=6-8 /$ group). Results are presented as the mean \pm SEM. ${ }^{* *} p<0.01$, versus group $C$. Two-way ANOVA repeated measures was used for comparisons in panel $A$ and $D$. Student t-test was used for panels $C$ and $F$. 
Student t-test (CTRL group) and One-way ANOVA (MCT group) was used for panel G.
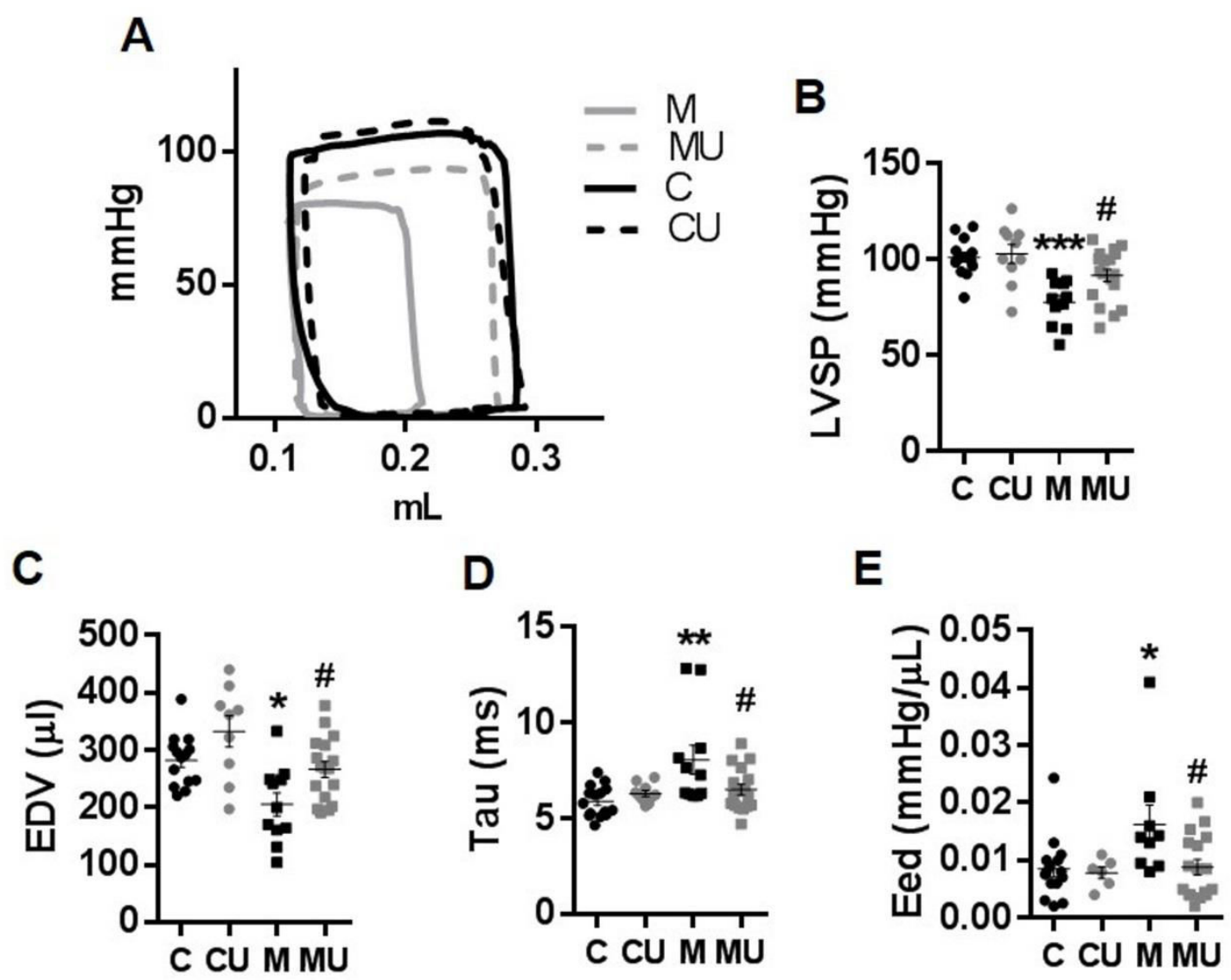

Figure S5. hUcn-2 therapy improves left ventricular (LV) function in MCT-induced $\mathrm{PH}$. (A) Representative pressure- volume loops of the different experimental groups. $(B)$ LV end-systolic pressures were decreased in MCT animals, and treatment with hUcn-2 attenuated this alteration. (C) End-diastolic volume was decreased in MCTinduced $\mathrm{PH}$ and normalized with hUcn-2 treatment. $(D)$ Isovolumic relaxation time constant (tau) was increased in MCT animals and normalized with hUcn-2 therapy. (E) Eed was increased in MCT-induced PH and normalized with treatment. $(n=10-$ 18/group). Results are presented as the mean \pm SEM. ${ }^{*} p<0.05,{ }^{* *} p<0.01,{ }^{* * *} p<0.001$ versus $C ;{ }^{*} p<0.05$ versus $M$. Two-way ANOVA was used for all the parameters presented. 

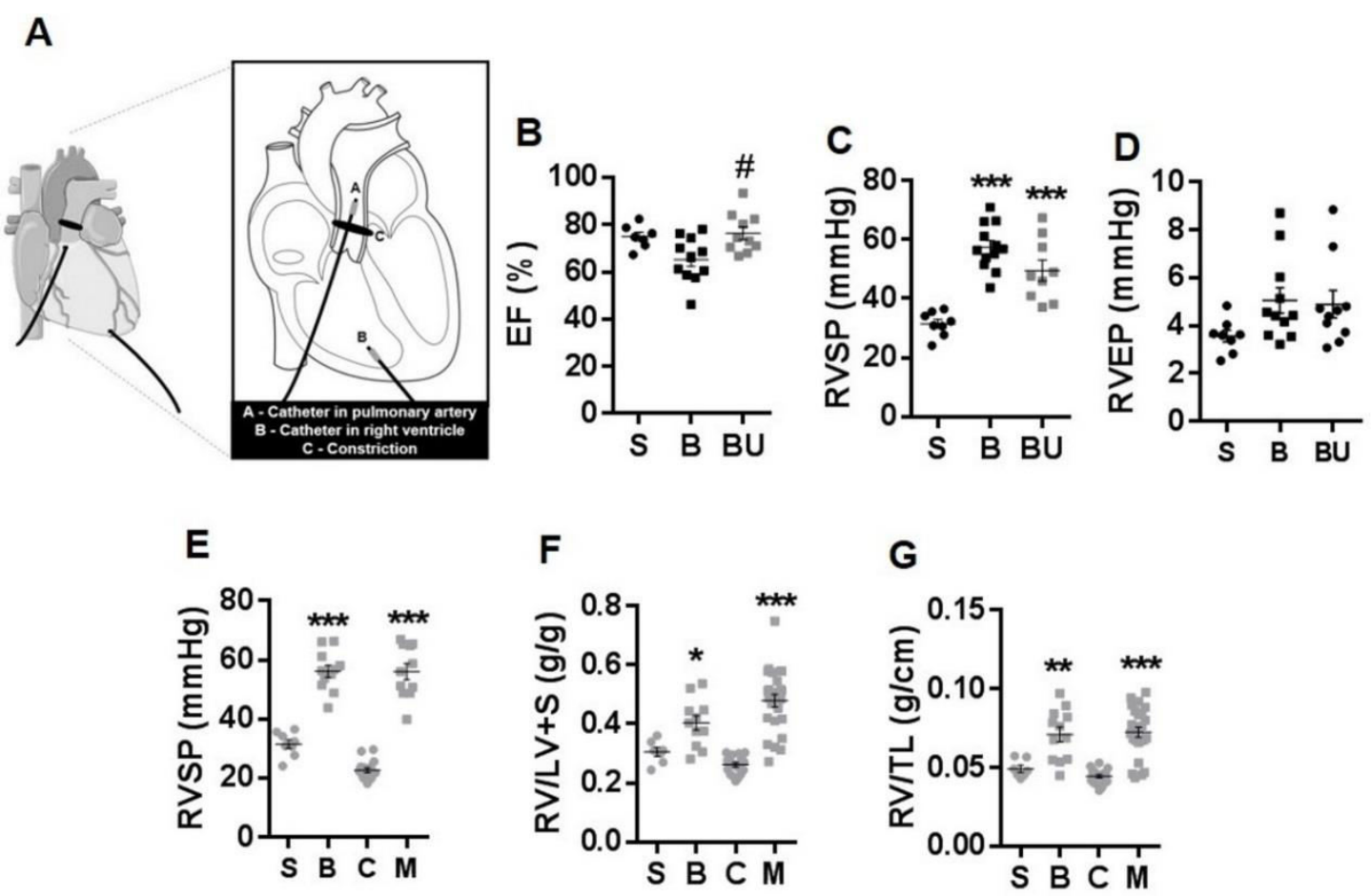

$\mathbf{F}$

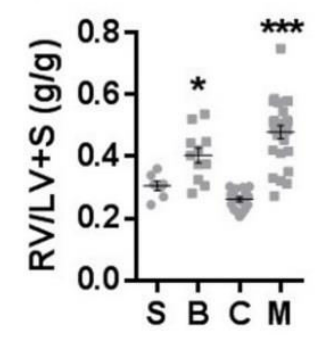

G

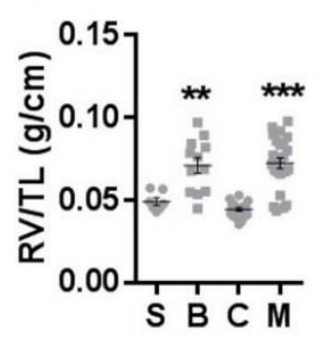

$\mathrm{H}$

I
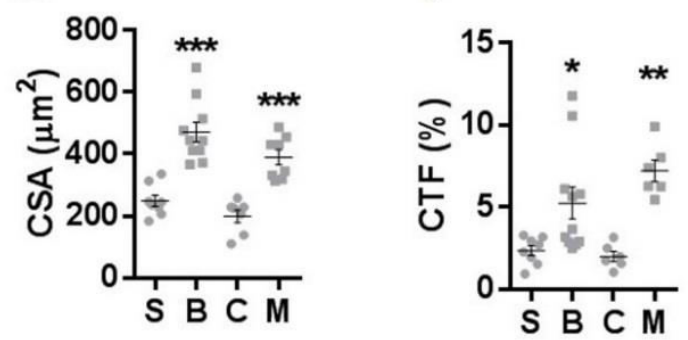

Figure S6. Pulmonary artery banding (PAB) results in similar degrees of RV hypertrophy and overload to the monocrotaline (MCT)-induced $\mathrm{PH}$ model. (A) Illustration of the placement of the catheters for the measurement of the pressure gradient (PAG) across the constriction. One of the catheters (PVR-1045) was introduced in the pulmonary artery and the other one in the RV. (B) PAB animals showed preserved ejection fraction, with an increase after hUcn-2 treatment. $(\boldsymbol{C}, \boldsymbol{D})$ $P A B$ resulted in an increased end-systolic pressure (RVSP) in both PAB groups, without changing end-diastolic pressures (RVEP). (E) PAB animals present similar values of RVSP, pointing to similar degrees of RV pressure overload in both animal models. $(F, G) P A B$ animals present values of $R V / L V+S$ and $R V / T L$ ratios identical to animals with MCT-induced $\mathrm{PH}$, pointing to the same degree of hypertrophy in both animal models. $(\boldsymbol{H}, \boldsymbol{I})$ Histological analysis of cardiomyocyte cross sectional area (CSA) and percentage of RV fibrosis indicated same degree of cardiomyocyte enlargement and collagen deposition in both models ( $n=7 / 29$ for MCT protocol; $\mathrm{n}=7 / 12$ for $\mathrm{PAB}$ protocol). Results are presented as the mean $\pm S E M$. ${ }^{*} p<0.05,{ }^{* *} p<0.01,{ }^{* * *} p<0.001$ vs respective control. One-way ANOVA was used for all parameters presented. 
A

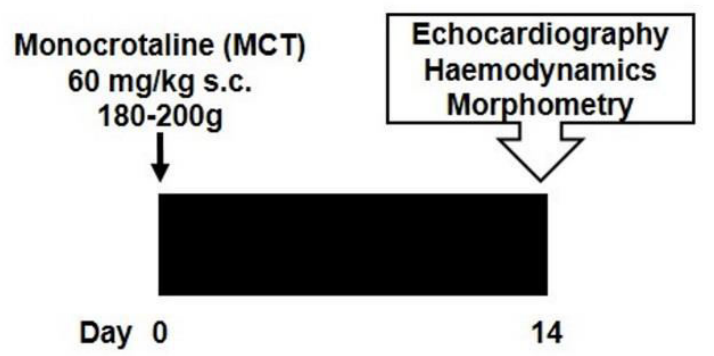

D
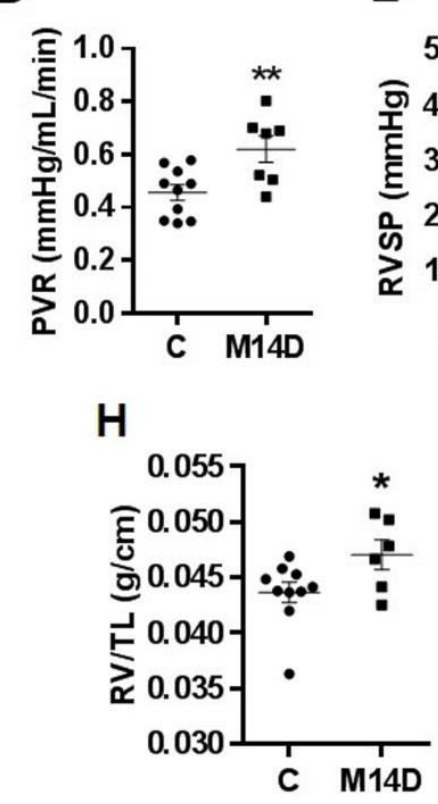

I
B

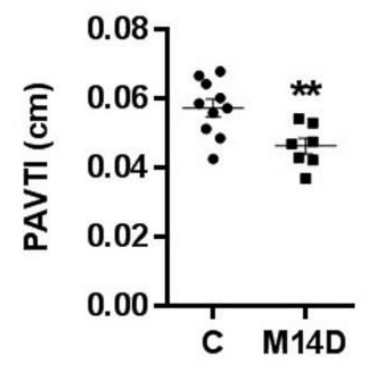

$\mathbf{F}$

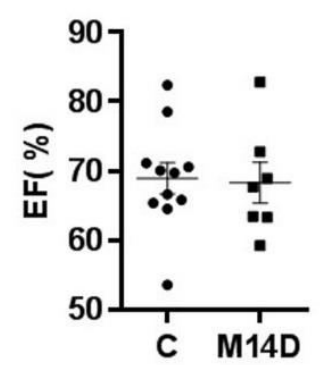

C

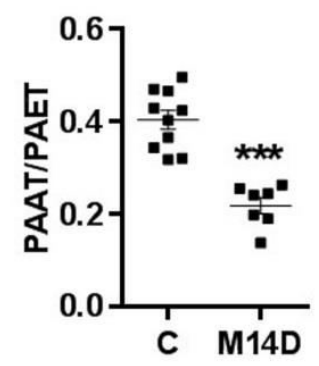

G

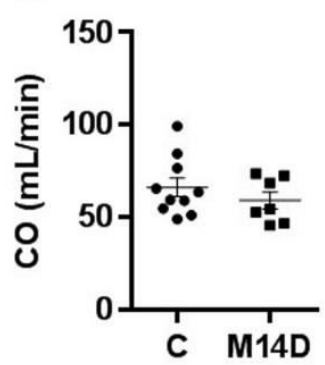

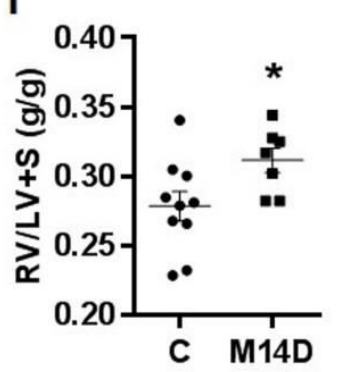

$\mathrm{J}$

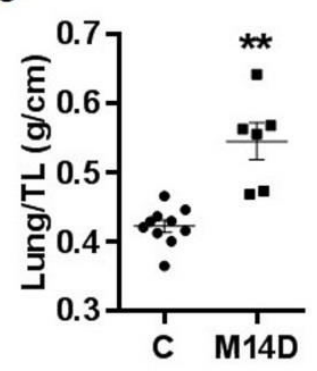

Figure S7. Signs of PAH 14 days after monocrotaline (MCT) injection. $(A)$ Diagram of rat experimental MCT protocol. $(B, C)$ Pulmonary flow is already compromised at this stage, with decreased pulmonary artery velocity-time integral (VTI) and the pulmonary acceleration/ejection time (PAAT/PAET) ratio. ( $D, E)$ RV increased afterload, as measured by pulmonary vascular resistance (PVR) is present, as well as RV end-systolic pressure (RVSP). $(\boldsymbol{F}, \boldsymbol{G}) \mathrm{RV}$ function is not compromised 14 days after MCT administration, without alterations in ejection fraction (EF) and cardiac output (CO). (H-J) Right ventricular hypertrophy is already present, as well as Lung oedema ( $n=6-10 /$ group). Results are presented as the mean $\pm S E M$. ${ }^{*} p<0.05,{ }^{* *} p<0.01,{ }^{* * *} p<0.001$ versus $C$. Student t-test was used for all the parameters presented. 


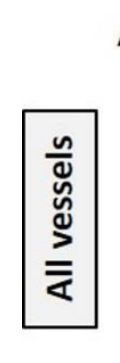

A
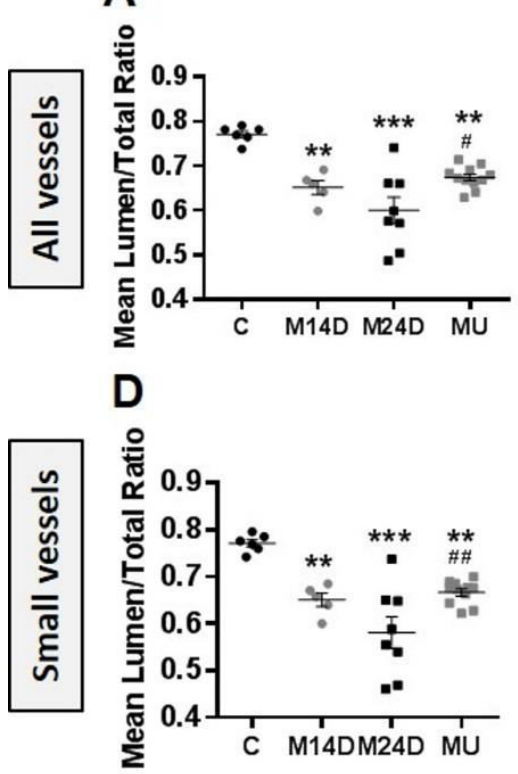

B

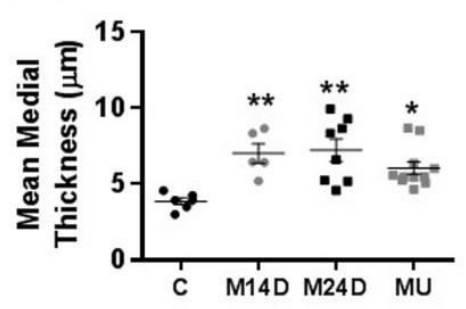

E

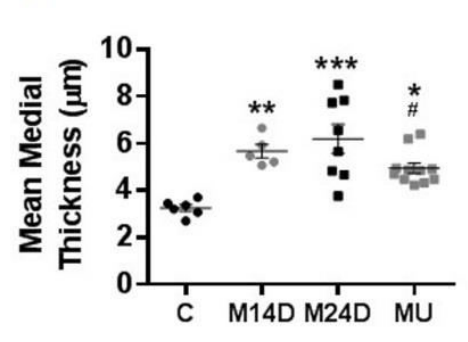

C

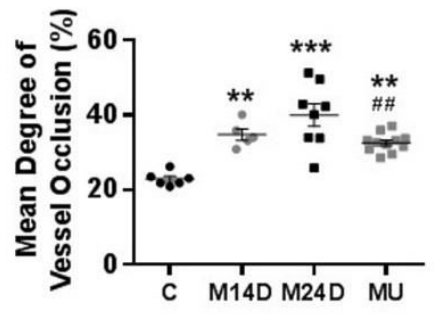

$\mathbf{F}$

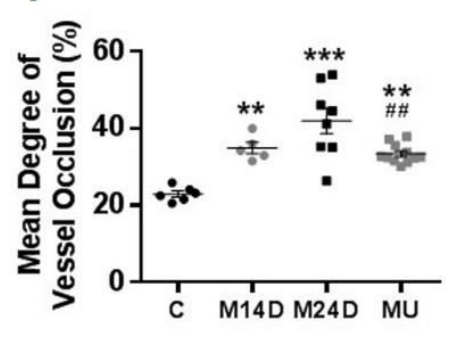

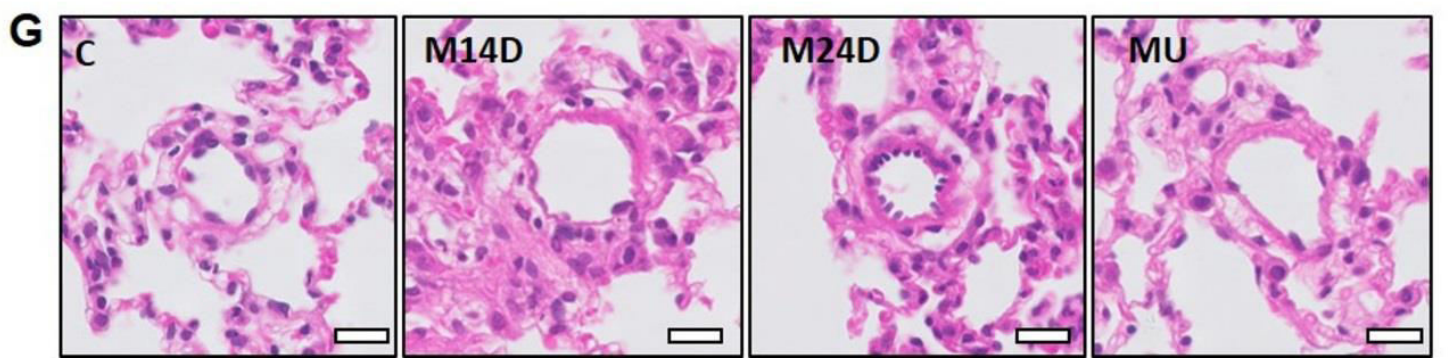

Figure S8. Starting chronic treatment with hUcn-2 at 14 days after MCT administration is able to stop the progression of already established pulmonary vascular remodeling. $(\boldsymbol{A}, \boldsymbol{D})$ In all and small arterioles, the mean Lumen/Total Ratio in MCT animals after 24 days of injection (M24D) and after 14 days (M14D) is decreased compared to CTRL rats, whereas in MU animals the Lumen/Total Ratio is significantly increased compared to M24D animals. $(B, E)$ In all and small arterioles, the mean medial thickness in M24D and M14D animals is increased compared to CTRL rats, whereas in small vessels of MU animals is significantly decreased compared to M24D animals. $(\boldsymbol{C}, \boldsymbol{F})$ In all and small arterioles, the mean degree of vessel occlusion in M24D and M14D animals is increased compared to CTRL rats, whereas in MU animals is significantly decreased compared to M24D animals. ( $G$ ) Representative H\&E staining of lung samples of all experimental groups. Scale bars

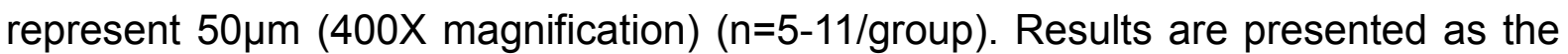
mean \pm SEM. ${ }^{*} p<0.05,{ }^{* *} p<0.01,{ }^{* * *} p<0.001$ versus $C ;{ }^{*} p<0.05$; ${ }^{* \#} p<0.01$ versus M24D. One-way ANOVA was used for all parameters presented. 


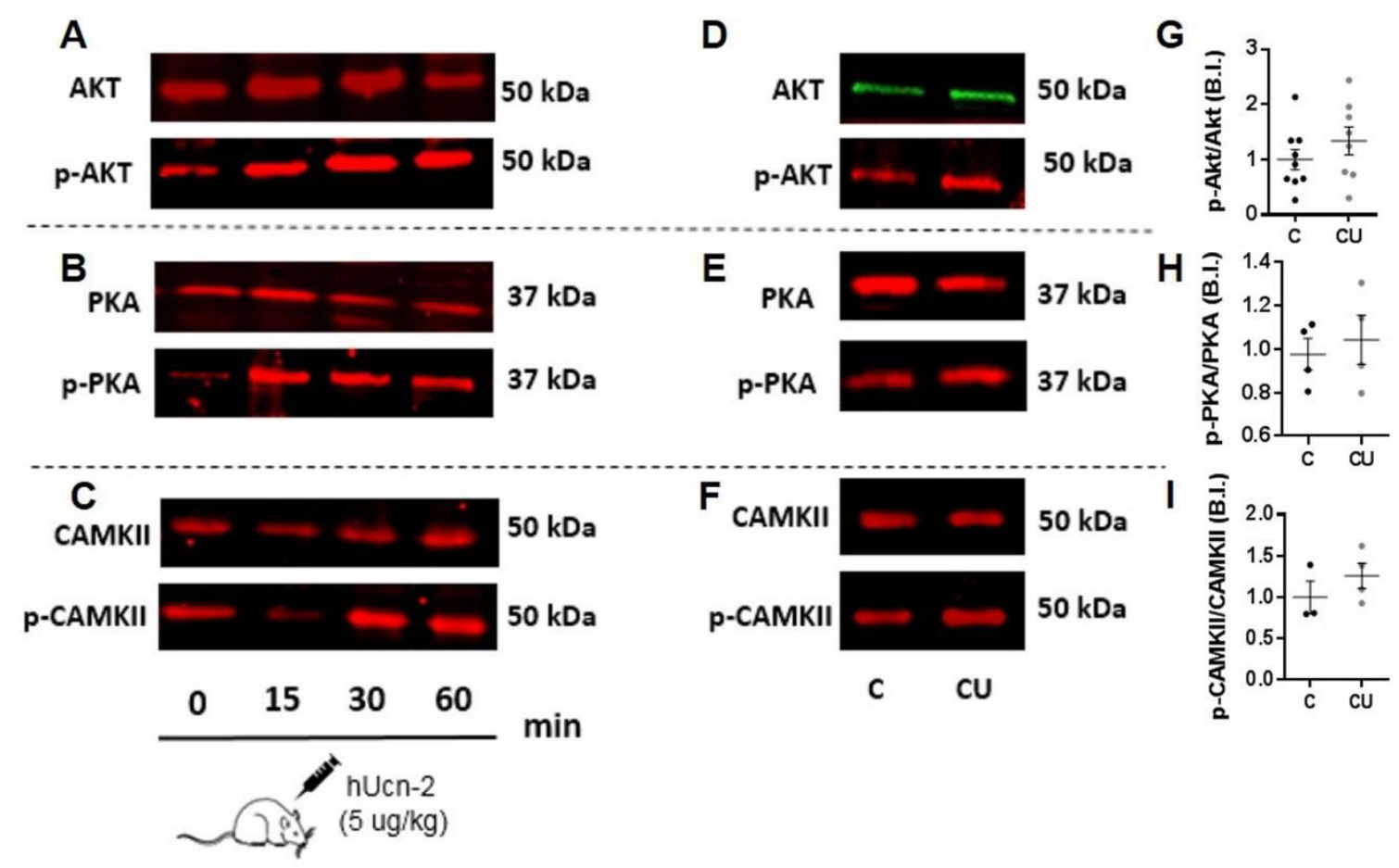

Figure 59. hUcn-2 administration acutely, but not chronically, stimulates the principal signalling pathways activated by $\mathrm{CRH}$ peptide family on the RV. $(\boldsymbol{A}, \boldsymbol{B}, \boldsymbol{C})$ Immunoblotting shows PKA, CaMKII, and AKT phosphorylation on the RV after 0 , 15,30 and 60 minutes of hUcn-2 stimulation (i.p. injection; $5 \mathrm{ug} / \mathrm{kg}$ ), proving that, the dose used in each injection acts specifically on the RV ( $n=2 /$ each time-point). ( $\boldsymbol{D}, \boldsymbol{G}$, $E, H, F, I)$ Protein phosphorylation of PKA, CaMKII, and AKT in the RV of control group non-treated (C) and treated chronically with hUcn-2 (CU; i.p. injection; 5ug/kg; bi-daily; 10 days) ( $n=3-9 / g r o u p)$. Results are presented as the mean $\pm S E M$. Student t-test was performed to compare groups in panels $\mathrm{G}, \mathrm{H}$ and $\mathrm{I}$. 


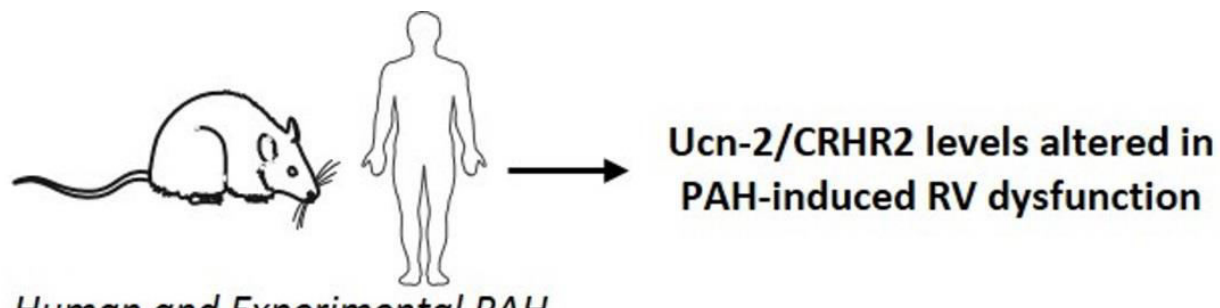

Human and Experimental PAH

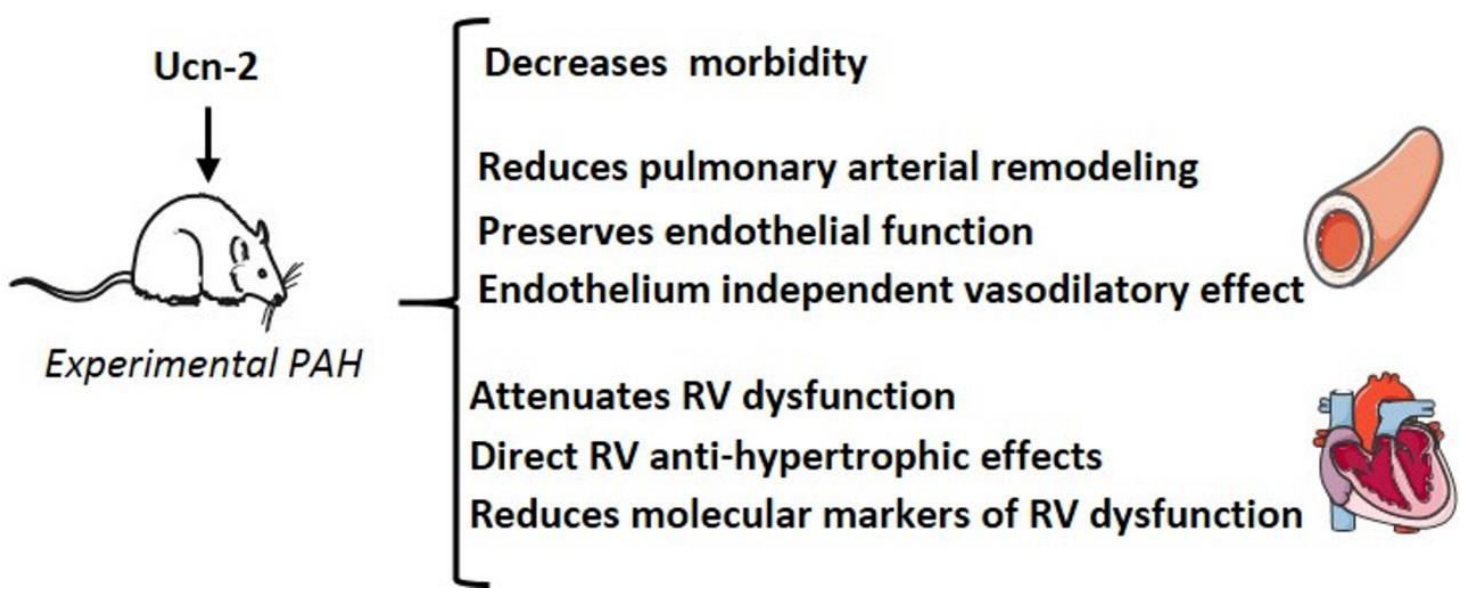

Figure S10. Major findings of the experimental study 


\section{Supplementary References}

1. Bonnet S, Provencher S, Guignabert C, Perros F, Boucherat O, Schermuly RT, Hassoun PM, Rabinovitch M, Nicolls MR, Humbert M. Translating Research into Improved Patient Care in Pulmonary Arterial Hypertension. Am J Respir Crit Care Med 2017; 195:583-595.

2. Potus F, Ruffenach G, Dahou A, Thebault C, Breuils-Bonnet S, Tremblay E, Nadeau V, Paradis R, Graydon C, Wong R, Johnson I, Paulin R, Lajoie AC, Perron J, Charbonneau E, Joubert P, Pibarot P, Michelakis ED, Provencher S, Bonnet S. Downregulation of MicroRNA-126 Contributes to the Failing Right Ventricle in Pulmonary Arterial Hypertension. Circulation 2015;132:932-943.

3. Ruffenach G, Chabot S, Tanguay VF, Courboulin A, Boucherat O, Potus F, Meloche J, Pflieger A, Breuils-Bonnet S, Nadeau V, Paradis R, Tremblay E, Girerd B, Hautefort A, Montani D, Fadel E, Dorfmuller P, Humbert M, Perros F, Paulin R, Provencher S, Bonnet S. Role for RUNX2 in Proliferative and Calcified Vascular Lesions in Pulmonary Arterial Hypertension. Am J Respir Crit Care Med 2016; 194:1273-1285.

4. Renard S, Paulin R, Breuils-Bonnet S, Simard S, Pibarot P, Bonnet S, Provencher S. Pim-1: A new biomarker in pulmonary arterial hypertension. Pulmonary circulation 2013;3:74-81.

5. Mendes-Ferreira P, Maia-Rocha C, Adao R, Mendes MJ, Santos-Ribeiro D, Alves BS, Cerqueira RJ, Castro-Chaves P, Lourenco AP, De Keulenaer GW, Leite-Moreira AF, Bras-Silva C. Neuregulin-1 improves right ventricular function and attenuates experimental pulmonary arterial hypertension. Cardiovasc Res 2016;109:44-54.

6. Mendes-Ferreira P, Santos-Ribeiro D, Adao R, Maia-Rocha C, Mendes-Ferreira M, SousaMendes C, Leite-Moreira AF, Bras-Silva C. Distinct right ventricle remodeling in response to pressure overload in the rat. Am J Physiol Heart Circ Physiol 2016;311:H85-95.

7. Dieterle T, Meili-Butz S, Buhler K, Morandi C, John D, Buser PT, Rivier J, Vale WW, Peterson $\mathrm{KL}$, Brink M. Immediate and sustained blood pressure lowering by urocortin 2: a novel approach to antihypertensive therapy? Hypertension 2009;53:739-744.

8. Leite $S$, Oliveira-Pinto J, Tavares-Silva M, Abdellatif M, Fontoura D, Falcao-Pires I, LeiteMoreira AF, Lourenco AP. Echocardiography and invasive hemodynamics during stress testing for diagnosis of heart failure with preserved ejection fraction: an experimental study. Am J Physiol Heart Circ Physiol 2015;308:H1556-1563.

9. Piao L, Fang YH, Parikh KS, Ryan JJ, D'Souza KM, Theccanat T, Toth PT, Pogoriler J, Paul J, Blaxall BC, Akhter SA, Archer SL. GRK2-mediated inhibition of adrenergic and dopaminergic signaling in right ventricular hypertrophy: therapeutic implications in pulmonary hypertension. Circulation 2012;126:2859-2869.

10. Bankhead P, Loughrey MB, Fernandez JA, Dombrowski Y, McArt DG, Dunne PD, McQuaid S, Gray RT, Murray LJ, Coleman HG, James JA, Salto-Tellez M, Hamilton PW. QuPath: Open source software for digital pathology image analysis. Sci Rep 2017;7:16878.

11. Lang M, Kojonazarov B, Tian X, Kalymbetov A, Weissmann N, Grimminger F, Kretschmer A, Stasch JP, Seeger W, Ghofrani HA, Schermuly RT. The soluble guanylate cyclase stimulator riociguat ameliorates pulmonary hypertension induced by hypoxia and SU5416 in rats. PLOS One 2012;7:e43433.

12. Oka M, Homma N, Taraseviciene-Stewart L, Morris KG, Kraskauskas D, Burns N, Voelkel NF, McMurtry IF. Rho kinase-mediated vasoconstriction is important in severe occlusive pulmonary arterial hypertension in rats. Circ Res 2007;100:923-929. 


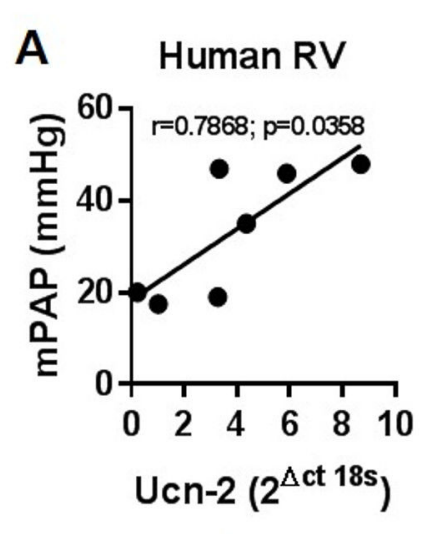

E

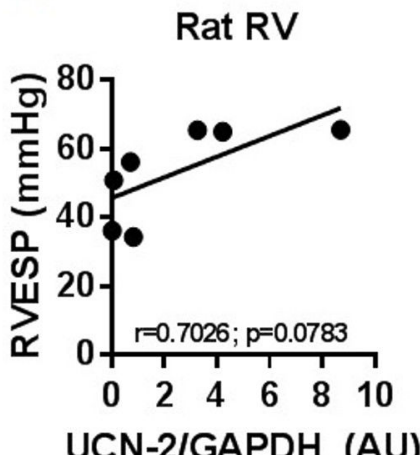

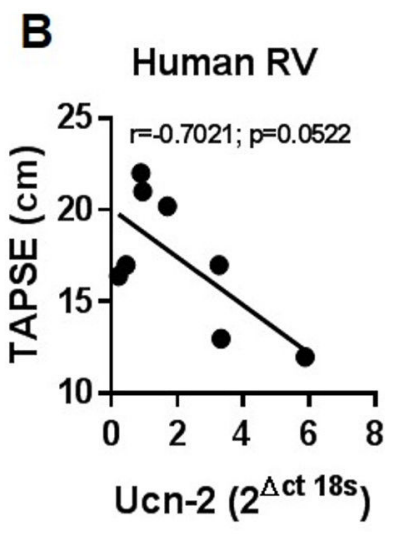

F

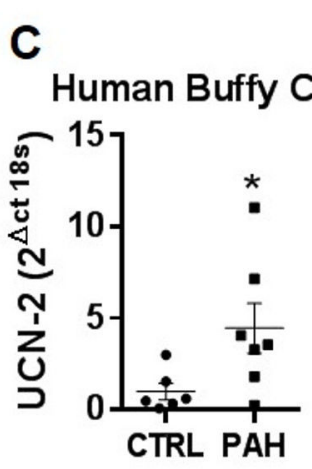

G
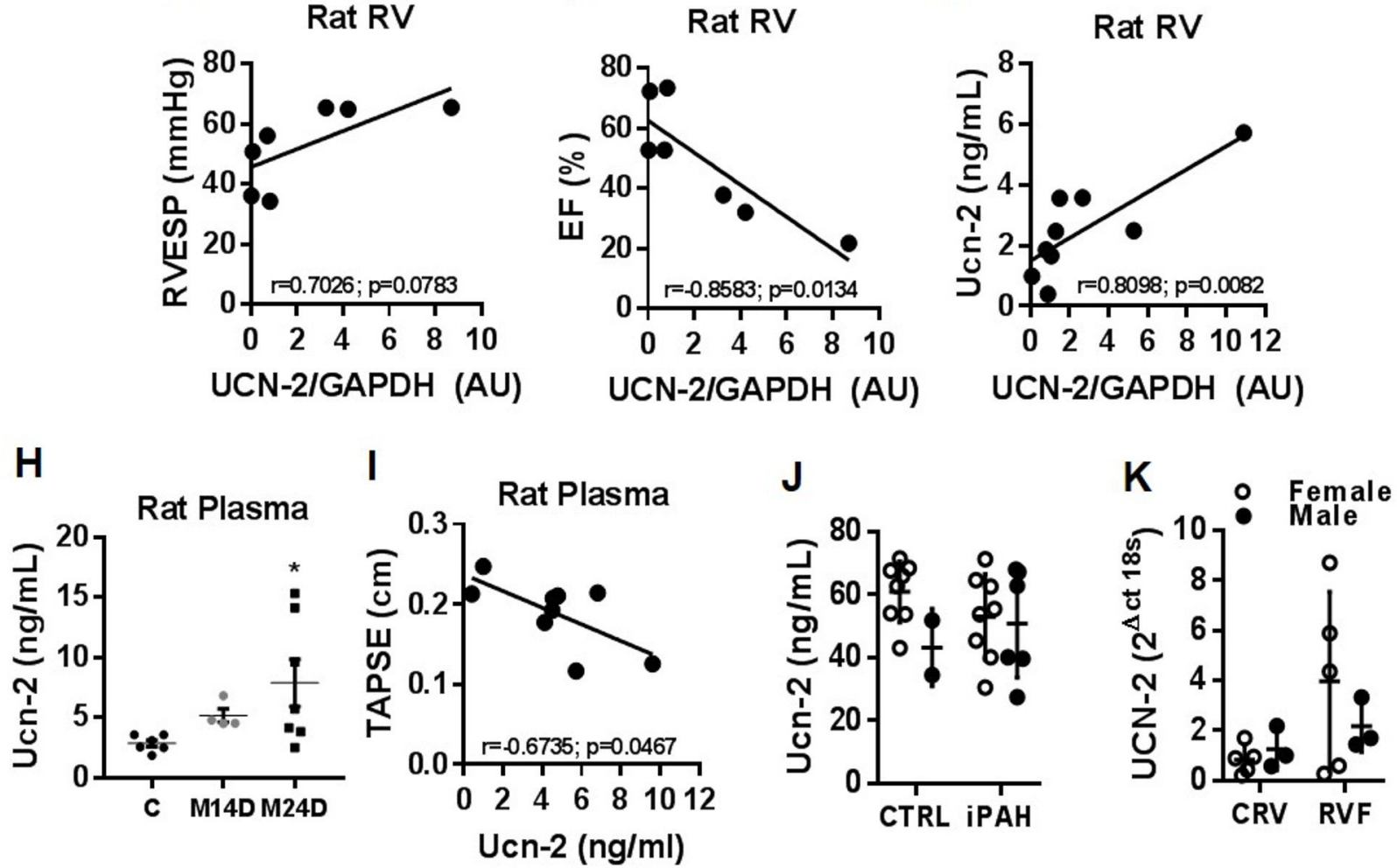


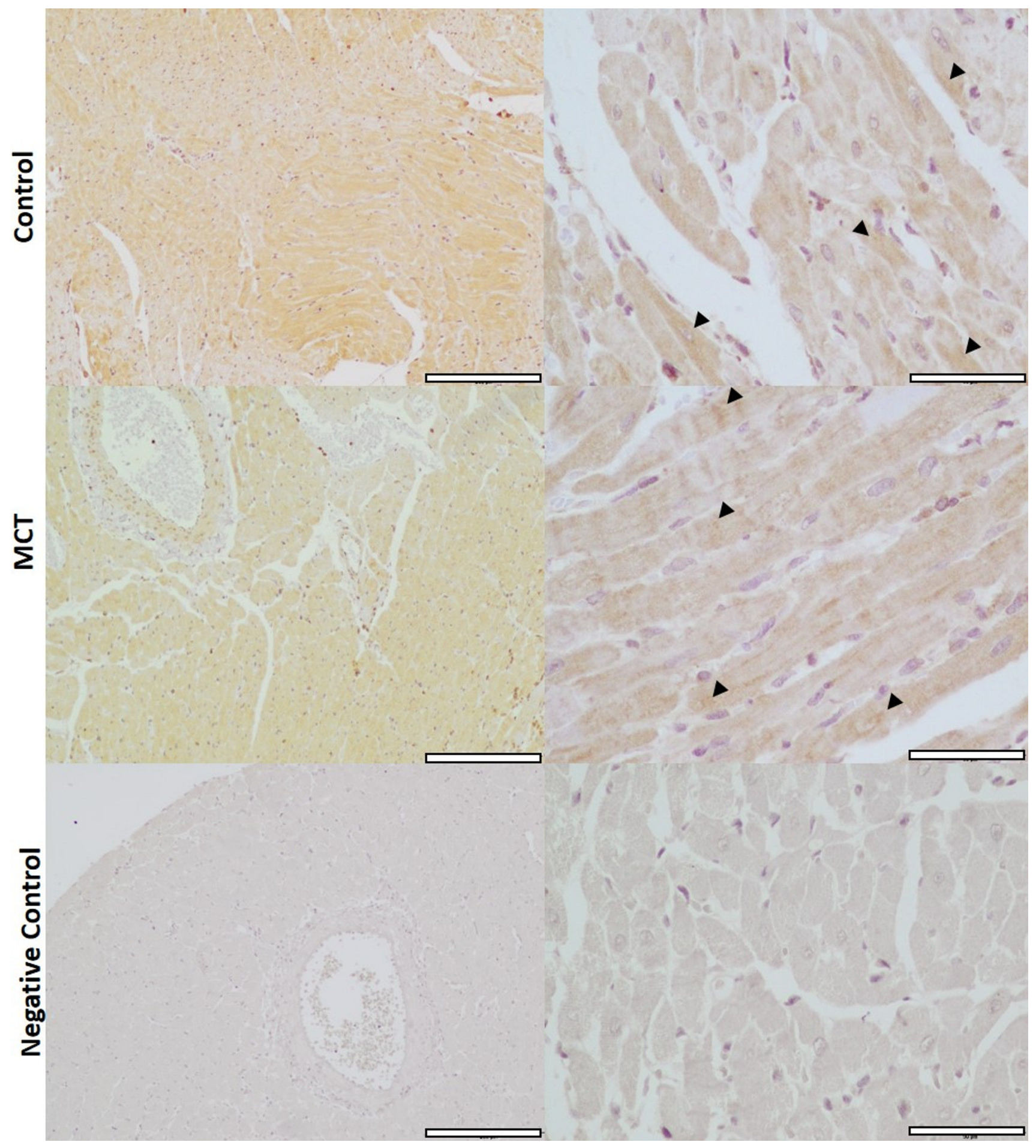



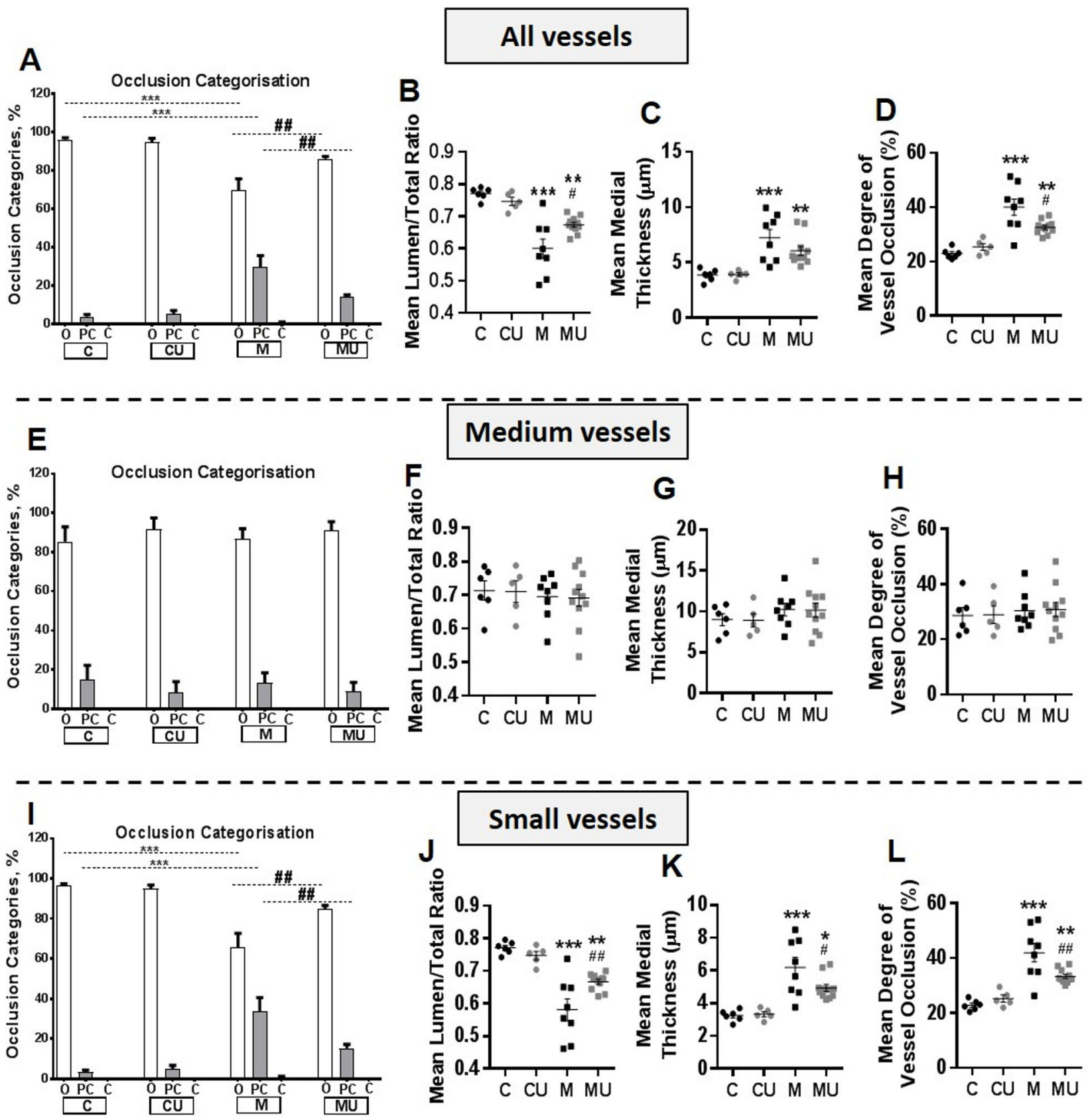
A

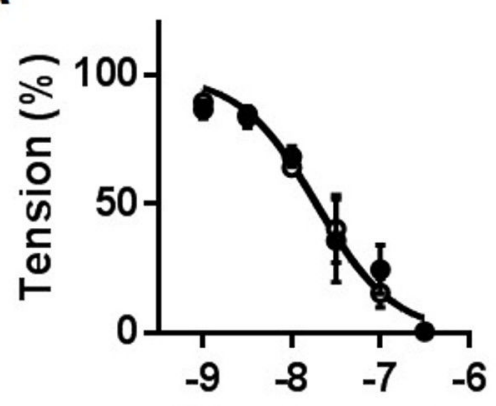

hUcn-2 [log M]

$\rightarrow-$ Endo (+) $\rightarrow-$ Endo (-)

D

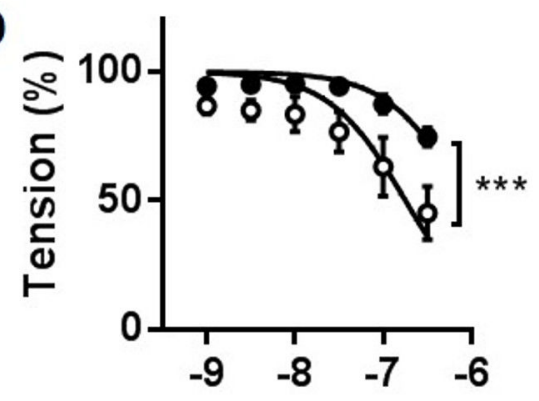

hUcn-2 [log M]

B

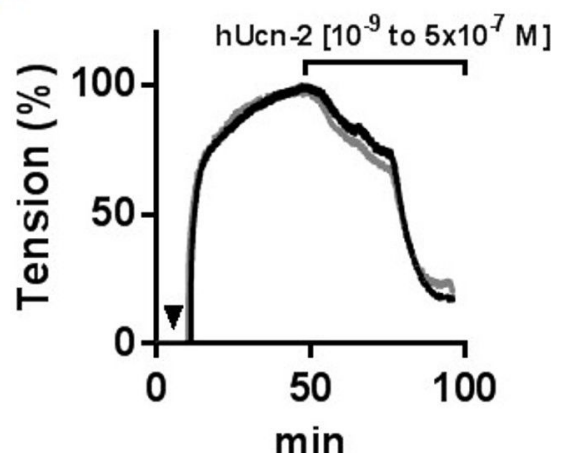

- Endo (+) - Endo (-)

E hUcn-2 $\left[10^{-8}\right.$ to $\left.5 \times 10^{-7} \mathrm{M}\right]$

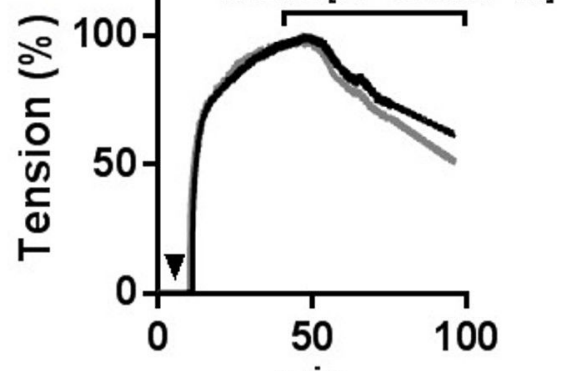

min

$\rightarrow-$ Endo (+) $-0-$ Endo (-)

- Endo (+) - Endo (-)

G

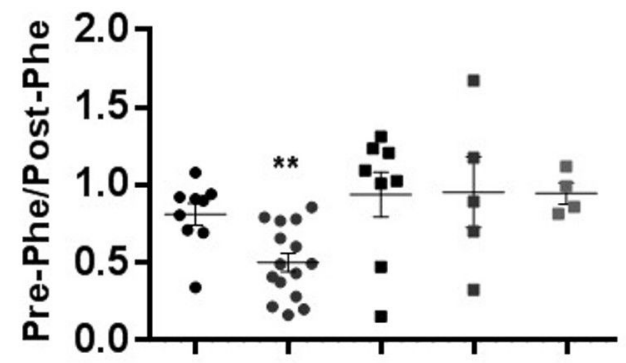

hUcn-2 (nM) $\frac{0 \quad 50}{\text { CTRL }} \frac{0}{\text { MCT }}$
H

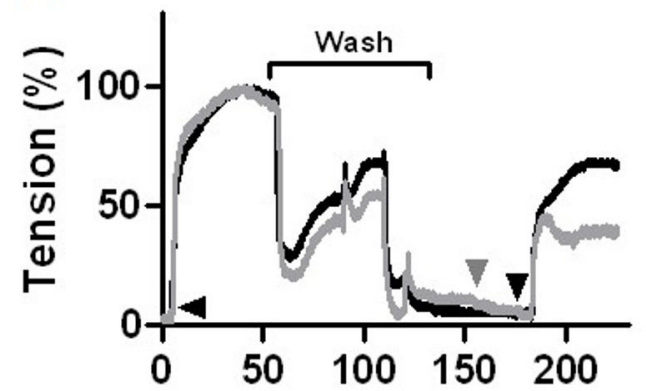

min
C

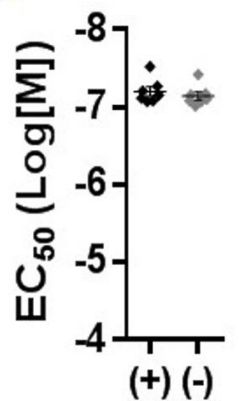

F

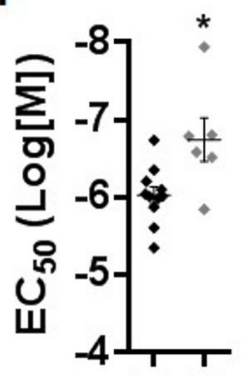

(+) (-) 

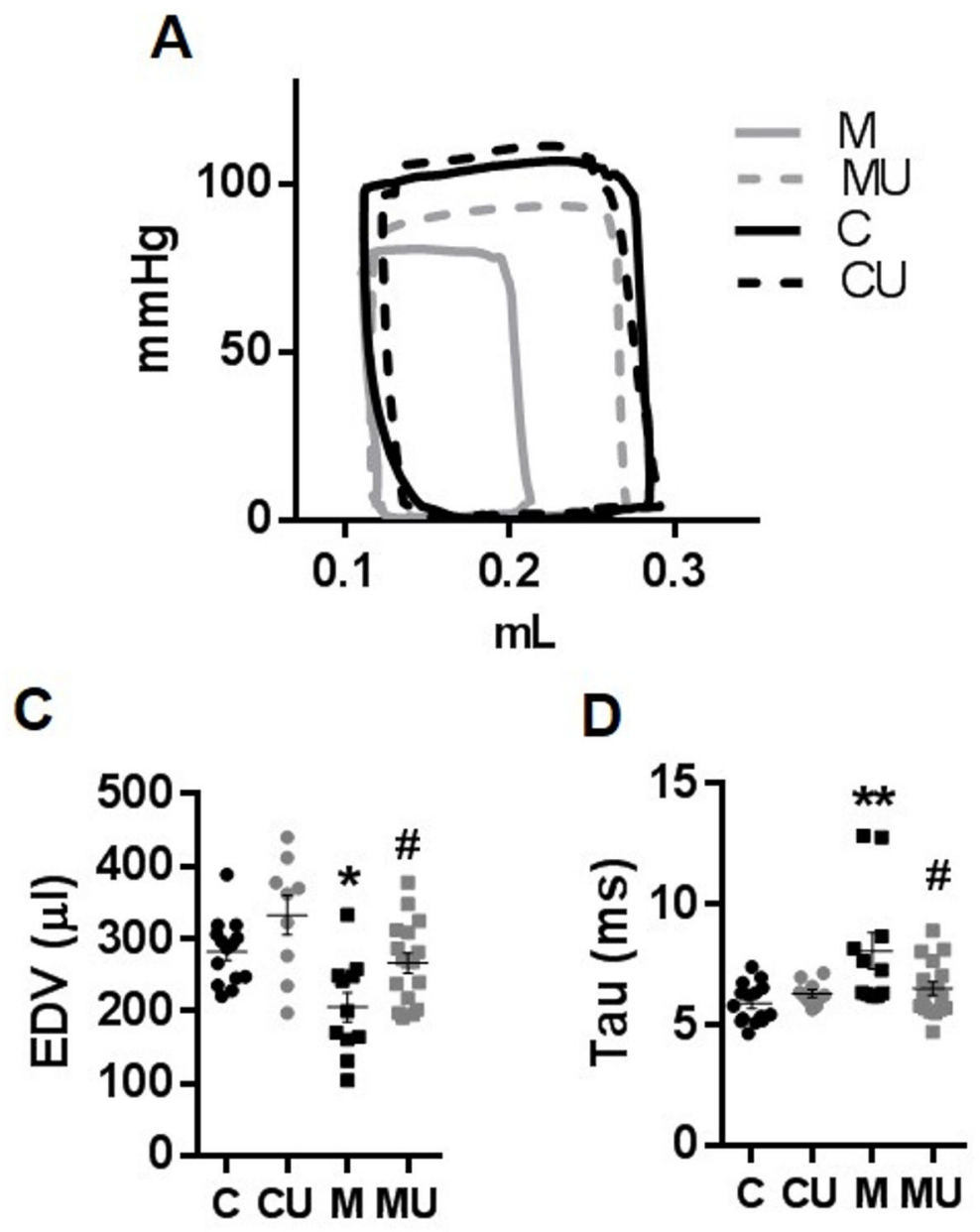

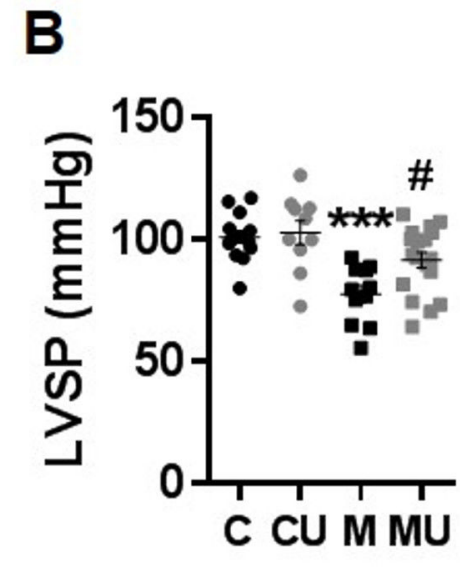

E

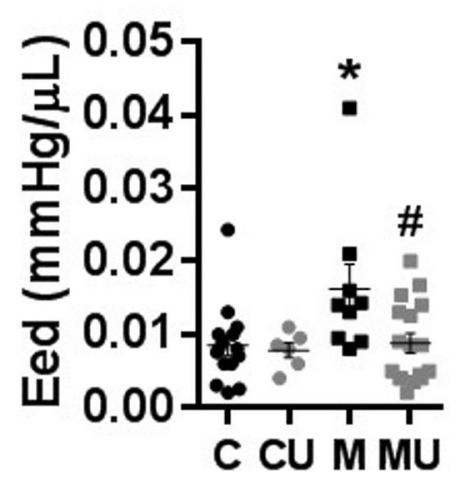



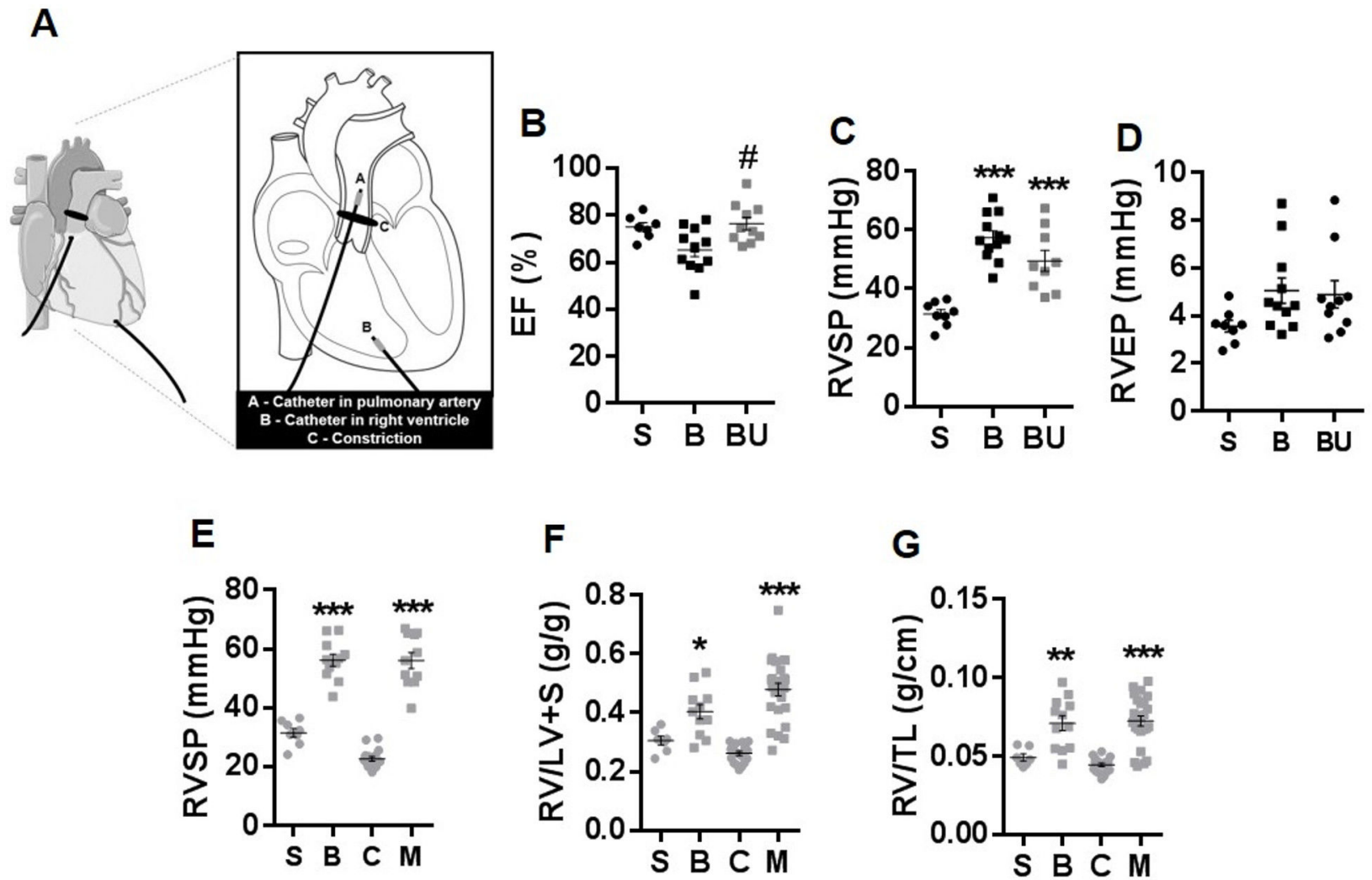

G

H

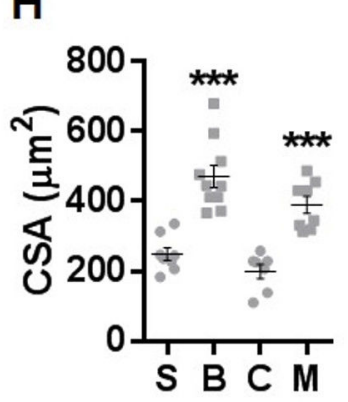

I
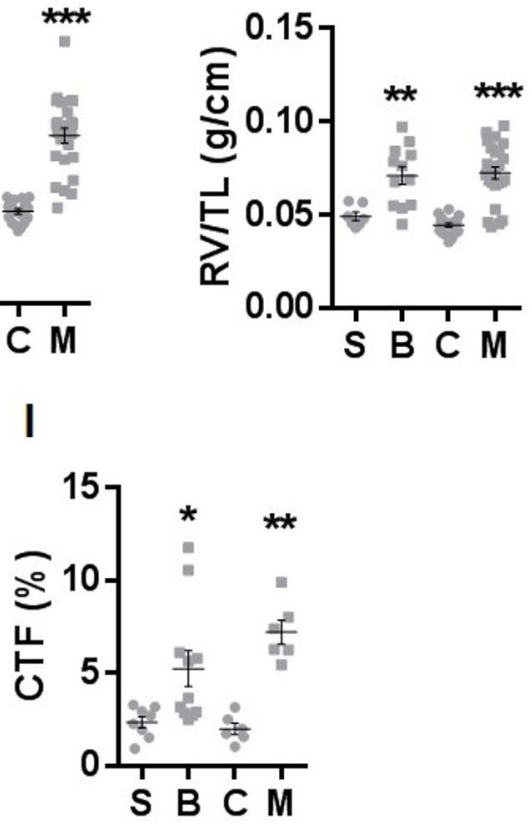
A

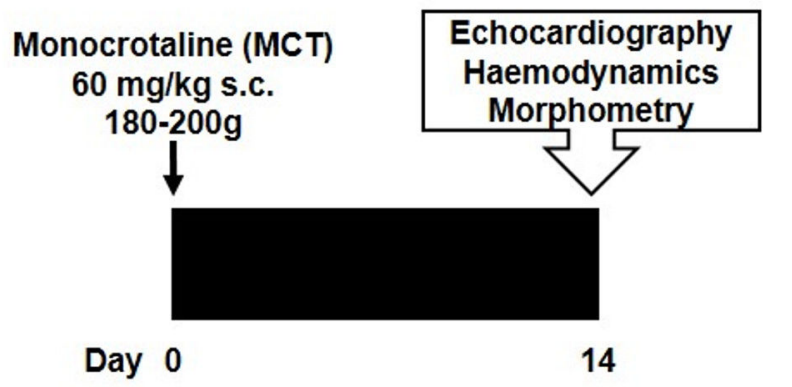

D

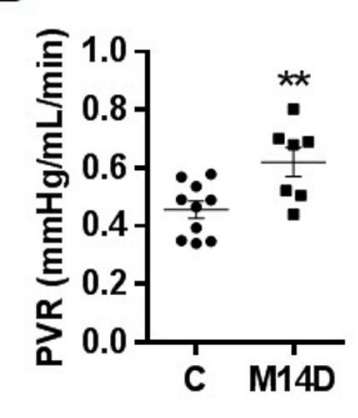

E

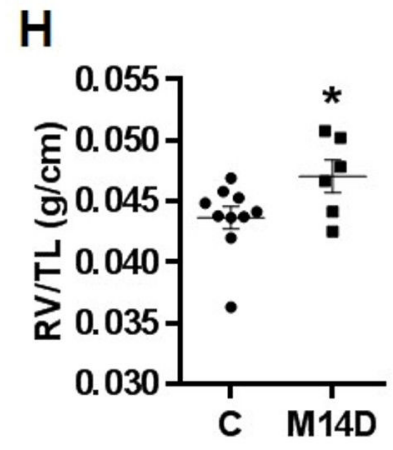

I
B

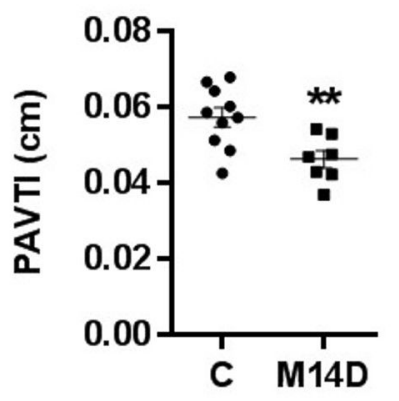

C
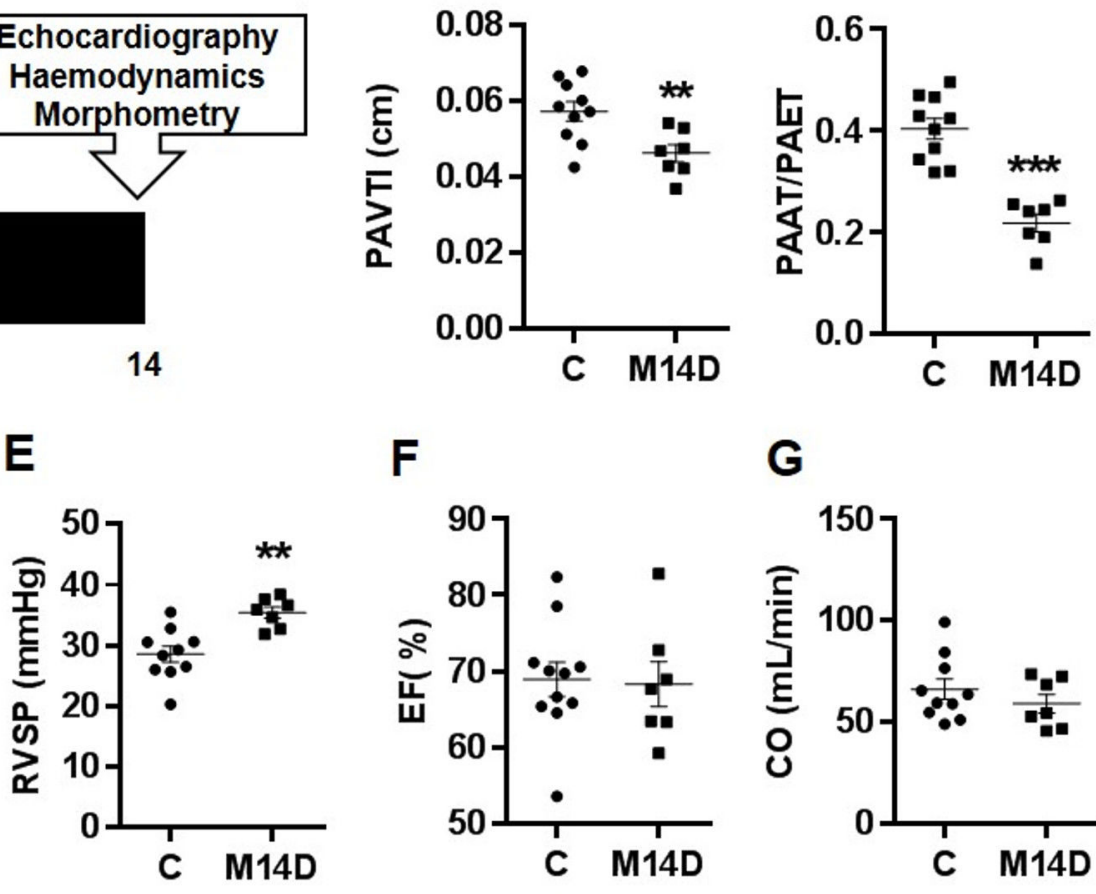

F

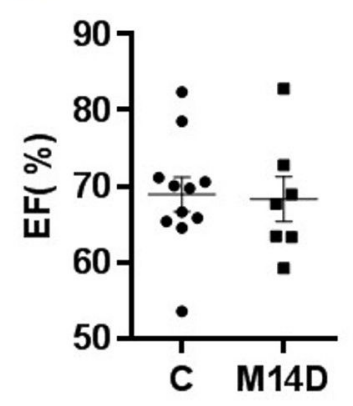

G

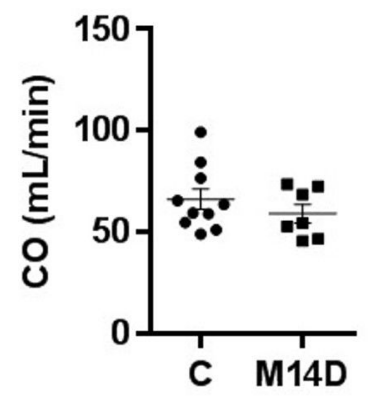

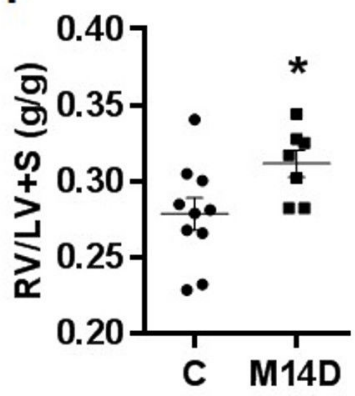

J

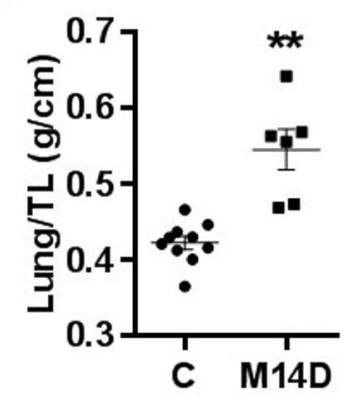




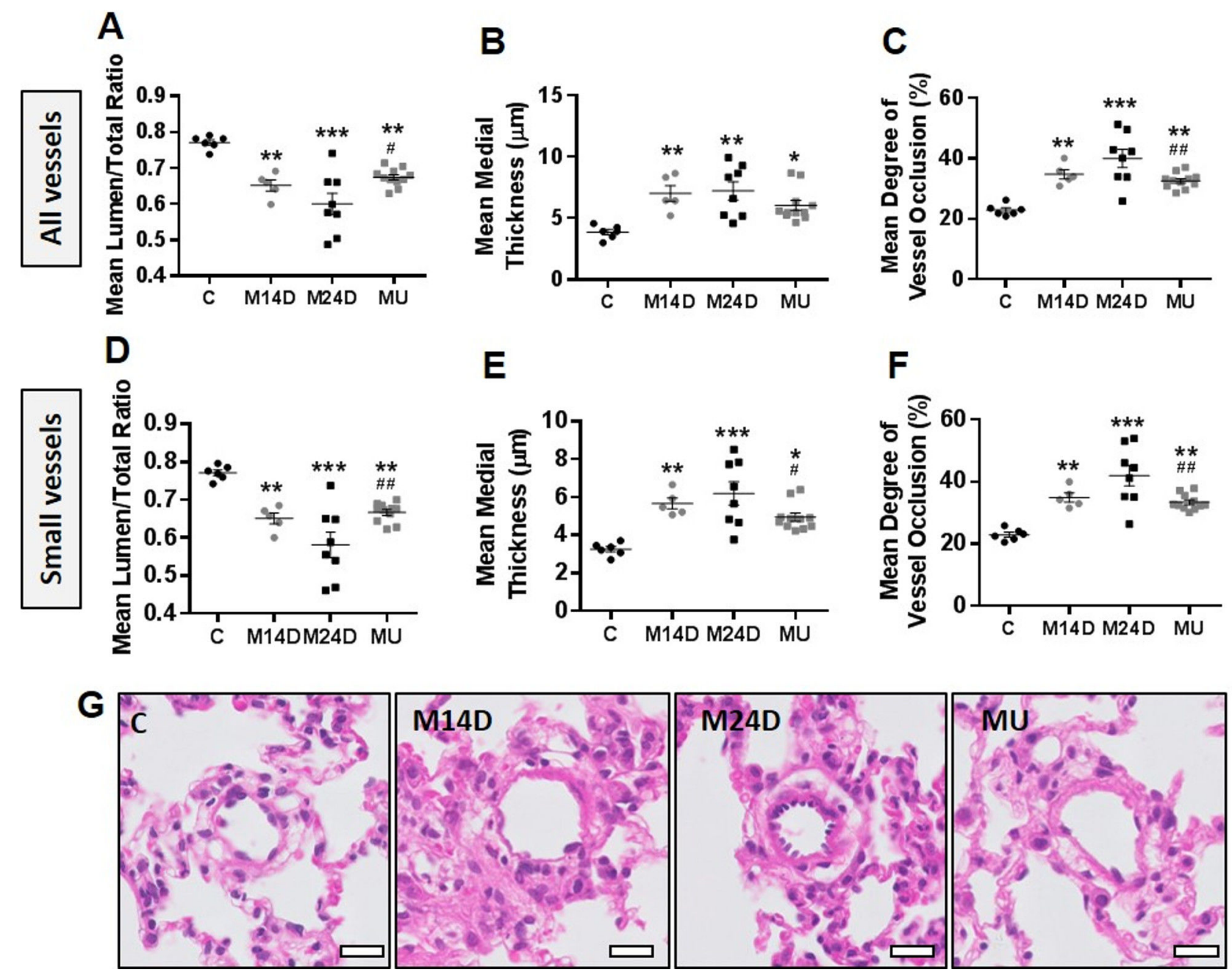




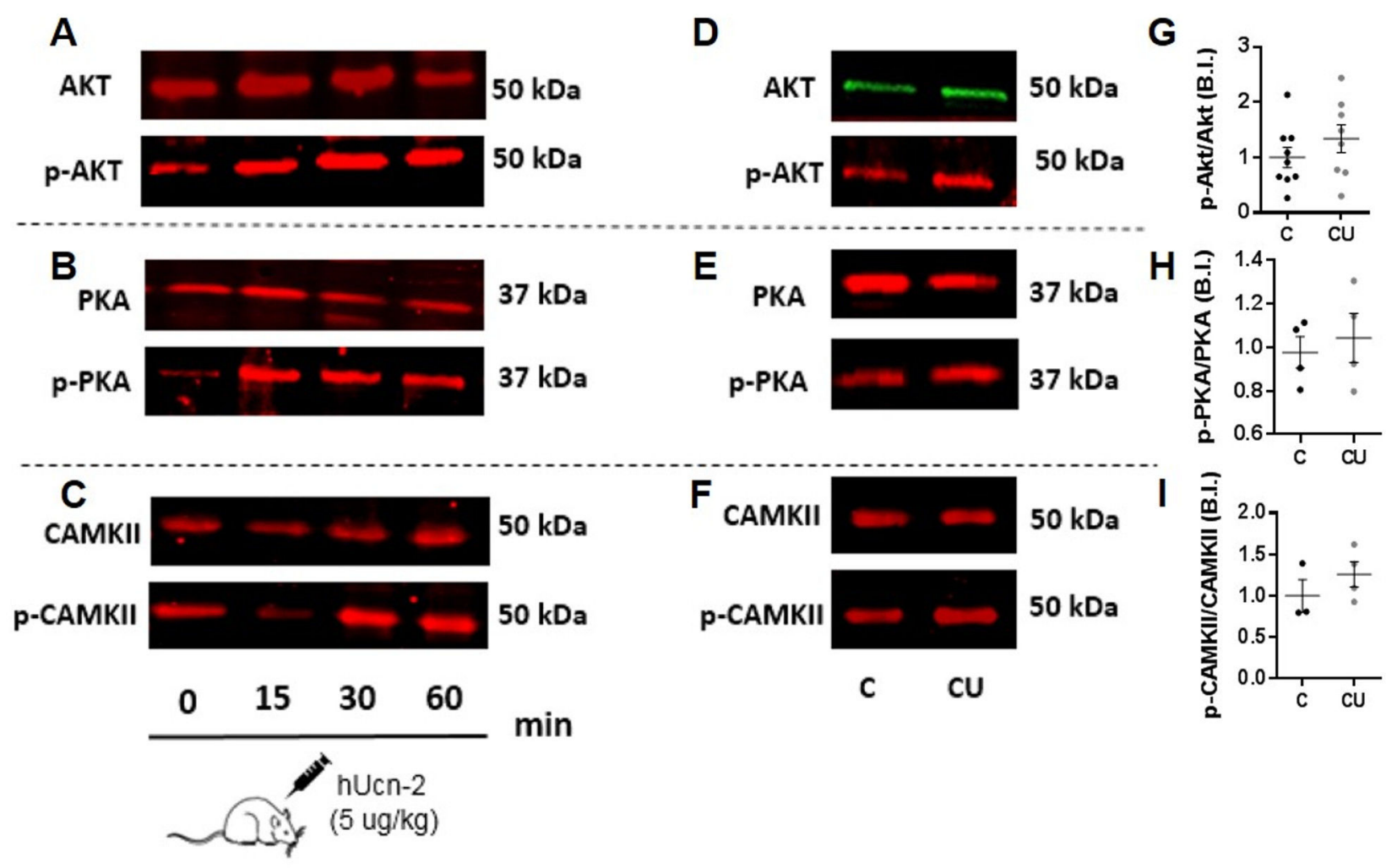




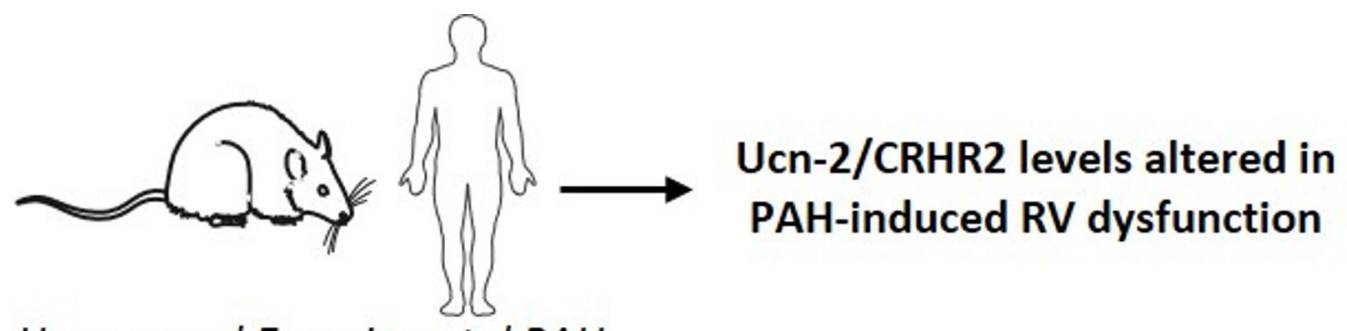

Human and Experimental PAH

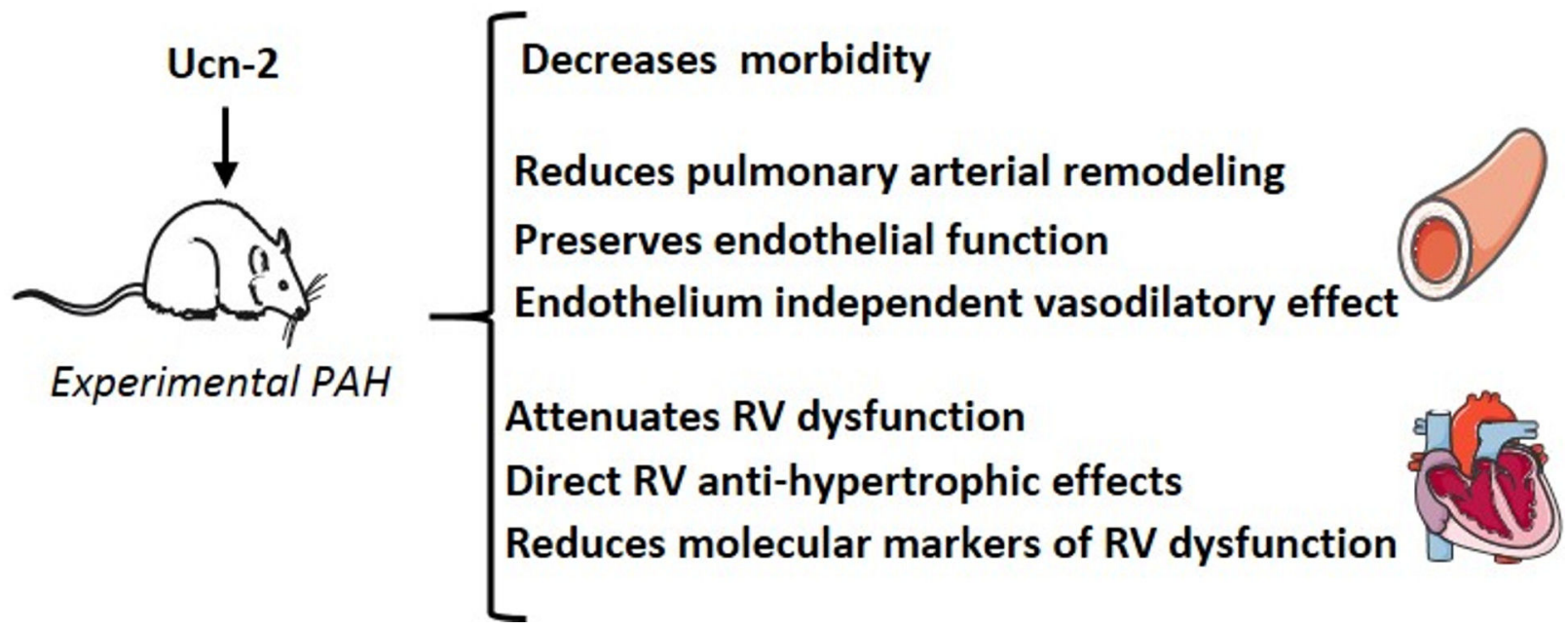

